\title{
Arterial wall abnormalities in chronic kidney disease
}

Citation for published version (APA):

Hermans, M. M. H. (2007). Arterial wall abnormalities in chronic kidney disease. [Doctoral Thesis, Maastricht University]. Datawyse / Universitaire Pers Maastricht. https://doi.org/10.26481/dis.20071116mh

Document status and date:

Published: 01/01/2007

DOI:

10.26481/dis.20071116mh

Document Version:

Publisher's PDF, also known as Version of record

\section{Please check the document version of this publication:}

- A submitted manuscript is the version of the article upon submission and before peer-review. There can be important differences between the submitted version and the official published version of record.

People interested in the research are advised to contact the author for the final version of the publication, or visit the DOI to the publisher's website.

- The final author version and the galley proof are versions of the publication after peer review.

- The final published version features the final layout of the paper including the volume, issue and page numbers.

Link to publication

\footnotetext{
General rights rights.

- You may freely distribute the URL identifying the publication in the public portal. please follow below link for the End User Agreement:

www.umlib.nl/taverne-license

Take down policy

If you believe that this document breaches copyright please contact us at:

repository@maastrichtuniversity.nl

providing details and we will investigate your claim.
}

Copyright and moral rights for the publications made accessible in the public portal are retained by the authors and/or other copyright owners and it is a condition of accessing publications that users recognise and abide by the legal requirements associated with these

- Users may download and print one copy of any publication from the public portal for the purpose of private study or research.

- You may not further distribute the material or use it for any profit-making activity or commercial gain

If the publication is distributed under the terms of Article $25 \mathrm{fa}$ of the Dutch Copyright Act, indicated by the "Taverne" license above, 
Arterial wall abnormalities in chronic kidney disease 
(C) Marc M.H. Hermans, Maastricht 2007

ISBN: 978-90-5278-667-4

Omslag: opname van de meanderende Geul en het kanaal van Korinthe Opmaak: Tiny Wouters

Production: Datawyse | Universitaire Pers Maastricht

Financial support by the Dutch Kidney Foundation for the publication of this thesis is gratefully acknowledged.

Additional financial support was granted by: Baxter B.V., Novartis Pharma B.V., Shering-Plough B.V., Novo Nordisk Farma B.V., Sanofi Aventis, Fresenius Medical Care Nederland B.V., Roche Nederland B.V., Servier Nederland Farma B.V., Genzyme Nederland, Pie Medical Benelux B.V., MSD B.V., Amgen B.V., Menarini Farma Nederland, Pfizer B.V., Shire Benelux, Daiichi-Sabkyo and Astellas. 


\title{
Arterial wall abnormalities in chronic kidney disease
}

\author{
Proefschrift
}

ter verkrijging van de graad van doctor

aan de Universiteit Maastricht, op gezag van de Rector Magnificus, Prof. mr. G.P.M.F. Mols, volgens het besluit van het College van Decanen,

in het openbaar te verdedigen

op vrijdag 16 november 2007 om 12.00 uur

door

Marcus Matheus Hendrik Hermans

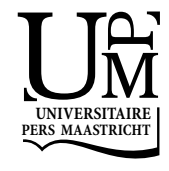




\section{Promotor}

Prof. dr. K.M.L. Leunissen

Prof. dr. C.D.A. Stehouwer

\section{Co-promotor}

Dr. J.P. Kooman

\section{Beoordelingscommissie}

Prof. dr. ir. A.P.G. Hoeks, voorzitter

Prof. dr. J.W. Cohen Tervaert

Prof. dr. J. Floege, University Hospital, RWTH, Aachen, Germany

Prof. dr. N.W. Levin, Albert Einstein College of Medicine, New York, USA

Dr. J.H. Tordoir 
“Der Mensch ist so alt wie seine Gefäße”

Rudolph Virchow, German pathologist (1821-1902)

Aan: mijn ouders

Voor: Jozet, Maurits, Reinout en Lennard 



\section{Contents}

Abbreviations

Chapter 1 General introduction

Chapter 2 Estimated glomerular filtration rate and urinary albumin excretion are independently associated with greater arterial stiffness - The Hoorn Study

Chapter 3 Spatial inhomogeneity of common carotid artery intima media 53 is increased in dialysis patients

Chapter 4 Study on the relationship of serum fetuin-A concentration with aortic stiffness in patients on dialysis

Chapter 5 Associations of serum fetuin-A concentrations with mortality in peritoneal and hemodialysis patients

Chapter 6 Undercarboxylated matrix-Gla protein levels are decreased in dialysis patients and related to parameters of calciumphosphate metabolism and aortic augmentation index

Chapter 7 Extra-osseous calcification in a dialysis patient with diabetes mellitus type 2

Chapter 8 General discussion

Chapter 9 Summary

Chapter 10 Samenvatting

Dankwoord

Curriculum vitae 

Abbreviations 
10 


\section{Abbreviations}

$\begin{array}{ll}\text { ADMA } & \text { asymmetric dimethylarginine } \\ \text { AGE } & \text { advanced glycation end product } \\ \text { AIx } & \text { aortic augmentation index } \\ \text { BMI } & \text { body mass index } \\ \text { CCA } & \text { common carotid artery } \\ \text { CFTT } & \text { carotid-femoral transit time } \\ \text { CKD } & \text { chronic kidney disease } \\ \text { CVD } & \text { cardiovascular disease } \\ \text { Einc } & \text { Young's Elastic modulus } \\ \text { ESRD } & \text { end-stage renal disease } \\ \text { (e)GFR } & \text { (estimated) glomerular filtration rate } \\ \text { GTS } & \text { glucose tolerance status } \\ \text { HDL } & \text { high density lipids } \\ \text { hSCRP } & \text { high-sensitivity C-reactive protein } \\ \text { IMT } & \text { intima media thickness } \\ \text { LDL } & \text { low density lipids } \\ \text { (Uc)MGP } & \text { (under carboxylated) Matrix gla protein } \\ \text { PTH } & \text { parathyroid hormone } \\ \text { PWV } & \text { pulse wave velocity } \\ \text { RAAS } & \text { renin angiotensin aldosteron system } \\ \text { SGA } & \text { subjective global assessment } \\ \text { TNF } & \text { tumor necrosis factor } \\ \text { UACR } & \text { urinary albumin creatinine ratio } \\ \text { VSMC } & \text { vascular smooth muscle cell }\end{array}$


12 


\section{Chapter 1}

General introduction 
Chapter 1 


\section{General introduction}

\section{Chronic kidney disease and cardiovascular disease}

In the Netherlands there has been a gradual rise in the prevalence of end-stage renal disease (ESRD) in the past decennia. In 2005 about 5200 patients were treated with renal replacement therapy, of which 3900 (75\%) were on hemodialysis and 1300 (25\%) were treated with peritoneal dialysis (www.renine.nl). This means about 307 dialysis patients per million inhabitants. Furthermore, almost 6300 people were living with a functioning donor kidney.

ESRD is the end of a spectrum of chronic kidney disease (CKD), which is defined as a lowering in glomerular filtration rate (GFR) and/or the presence of proteinuria. ${ }^{1}$ ESRD is just the top of the iceberg and it is estimated that about 60.000 people are unaware of having (mild) stage 1-2 CKD, whereas about 40.000 people are known with moderate to severe CKD (stage 3-4) (www.nierstichting.nl). However, because of the aging population and the obesity epidemic with a rise in the incidence of diabetes mellitus type 2, a major cause of CKD, the prognosis points to a further rise in the prevalence of CKD and ESRD.

Most patients regard renal replacement therapy as an inconvenient though adequate method to prolong their life after renal failure has been diagnosed. The truth for a 60-year old female patient starting dialysis however is, that her overall 5-years survival is worse than for a 60-year old patient diagnosed with breast cancer (Data renine/Integraal Kanker Centrum Limburg/Zuid). Both cardiovascular and non-cardiovascular mortality are greatly increased in dialysis patients. ${ }^{2-4}$ More recently it became clear that also stage 2 to 4 CKD was associated with increased cardiovascular morbidity and mortality. ${ }^{5-10}$ As already stated above, CKD is defined as a lowering in glomerular filtration rate and/or the presence of proteinuria. ${ }^{1}$ According to that definition also persons with albuminuria and a normal glomerular filtration rate are classified as having stage 1 CKD. Epidemiological data in a wide variety of populations have shown that albuminuria is associated with an increase in cardiovascular disease and mortality. ${ }^{11-13}$ Thus all stages of chronic kidney disease are clearly associated with an increase in cardiovascular disease (CVD).

The role of both traditional and non-traditional risk factors in the pathogenesis of this increase in mortality has been studied recently. It has become clear that although a clustering of the traditional "Framingham" risk factors, such as diabetes, dyslipidemia and hypertension, is seen in patients with CKD, this could not completely explain the excessive mortality risk in ESRD patients. ${ }^{14,15}$

Recently, vascular calcification and arterial stiffness have emerged as nontraditional risk factors that potentially play an important pathophysiological role in the association between CKD and CVD. ${ }^{16-19}$ 


\section{Atherosclerosis in chronic kidney disease}

Both in the general population and in CKD patients, atherosclerosis is a main cause of cardiovascular disease.3,20 It is characterized by the presence of plaques and occlusive lesions and primarily involves the intima. Its distribution may be focal and patchy, occurring preferentially in medium-sized conduit arteries and usually sparing muscular-type arteries. ${ }^{21}$ Clinical manifestations are due to ischemia or infarction of the downstream tissues. The mechanisms of atherogenesis are complex and involve traditional and non-traditional risk factors. Additional risk factors in CKD patients include anemia, homocysteinemia, oxidative stress and dyslipidemia with the forming of vasculotoxic lipids like oxidized low density lipids (LDL).22-24 Chronic inflammation characterized by elevated C-reactive protein (CRP) levels, Interleukin-6 (IL-6) or tumour necrosis factor alpha (TNF- $\alpha$ ) levels, contributes to accelerated atherosclerosis as well ${ }^{20}$ and this may be of special importance in dialysis patients with chronic malnutrition and inflammation. ${ }^{25,26}$ Notwithstanding the above, many vascular complications in CKD patients occur in the absence of clinically significant atherosclerosis. ${ }^{27,28}$ Furthermore, also intima media thickness (IMT) analysis of the common carotid artery, a surrogate marker of atherosclerosis ${ }^{29}$ showed some controversial results in dialysis patients. In nondialysis populations, values above $900 \mu \mathrm{m}$ are considered to represent atherosclerosis. ${ }^{30}$ Moreover, in dialysis patients only IMT values above $1.0 \mathrm{~mm}$ predicted cardiovascular mortality. ${ }^{31}$ Despite their greatly increased cardiovascular risk, several studies have shown that in most dialysis patients common carotid artery-IMT (CCA-IMT) values are well below $1.0 \mathrm{~mm} .{ }^{32-34}$ Among other, this may be due to the relative insensitivity of the commonly used measurement techniques, which either assess IMT at a single-point, or by averaging IMT thickness along an arterial segment. ${ }^{35}$ In addition, recent lesions, fatty streaks, more advanced lesions (atheroma) and fully developed plaques tend to be localised at specific sites ${ }^{36}$, which is obscured by averaging over relatively long arterial segments. Recently, a new technique has been developed which is able to detect local inhomogeneities in the IMT by assessing the spatial variance of IMT over an arterial segment. ${ }^{37}$ Application of this technique might increase the sensitivity of IMT measurements and enable the detection of focal atherosclerotic lesions at an earlier stage in the development.

At last, a striking phenomenon of atherosclerotic plaque lesions in dialysis patients is the large amount of calcification. ${ }^{38}$ This points to an important mechanism of vascular alterations in CKD patients, which will be discussed below.

\section{Vascular calcification in renal disease}

In dialysis patients vascular calcification is a complex process influenced by metabolic and physiological disturbances . Large studies have shown that vascular calcification is not a phenomenon exclusively restricted to older patients. In 
20-30-year-old subjects extensive coronary calcifications a few years after the start of dialysis were observed.16 Moreover in 92\% of dialysis patients aged 19 to 39 years with childhood onset CKD, coronary artery calcifications were present. ${ }^{39}$ In ESRD, calcification has been observed in two major forms. ${ }^{18,40}$ One form involves the intimal layer of the arteries and occurs within plaques, whereas the other form, also common in patients with diabetes mellitus, affects the medial layer and initially occurs within the elastic laminae. ${ }^{41}$ This process not only involves large elastic arteries but also smaller elastic arteries, and used to be described as Mönckeberg's calcification. ${ }^{42}$ Subjects with medial calcification are younger and have less traditional atherosclerotic risk factors than subjects with intimal calcification. ${ }^{18}$ Nonetheless, both forms are associated with increased cardiovascular mortality. ${ }^{18}$

\section{Calcification mechanism}

The vascular smooth muscle cell (VSMC) plays a pivotal role in intimal as well as medial calcification.43,44 In vitro, human VSMC's spontaneously convert to osteo/chondrocyte-like cells and express proteins that regulate mineralization, such as bone morphogenetic protein. ${ }^{45}$ In dialysis patients this osteogenic differentiation is also seen in vivo in calcified arteries. ${ }^{46}$

Elevated circulating levels of phosphate $(\mathrm{P})$, calcium $(\mathrm{Ca})$ and an elevated calcium phosphate product $(\mathrm{P} \times \mathrm{Ca}$ ) are frequently encountered in dialysis patients and associated with increased vascular calcifications. ${ }^{16,39,47}$ Media containing $P$ levels $>1.4 \mathrm{mmol} / \mathrm{l}$, which is even below the Kidney Disease Outcomes Quality Initiative (K/DOQI) guideline of $1.78 \mathrm{mmol} / \mathrm{I}^{48}$, enhances in vitro the osteogenic differentiation of VSMC. ${ }^{49}$ The effects are mediated via the sodium-dependent phosphate co-transporter (pit-1) and result in the production of core binding factor 1 (Cbfa-1), a central transcription factor in osteogenic differentiation, the expression of alkaline phosphatase and production of calcium- binding proteins such as osteocalcin and osteopontin. ${ }^{41,50}$ In this osteogenification process, calcium containing matrix vesicles are also formed which are finally released. In the end this obviously active process results in the formation of hydroxy-apatite. The calcification process is not exclusively influenced by $\mathrm{P}$ and $\mathrm{Ca}$. A large amount of traditional risk factors, such as hypertension and lipidemia and non-traditional atherosclerotic risk factors, including lipid oxidation ${ }^{52}$, the presence of advanced glycation end products (AGE's) ${ }^{53}$, calcitriol54 and inflammation ${ }^{55}$ may affect VSCM calcification. Although the role of parathyroid hormone (PTH) in bone formation is eminent, the importance of PTH for vascular calcification in dialysis patients is less clear. Some studies show an association between PTH levels and vascular calcification ${ }^{56,57}$ whereas others don't. ${ }^{16}$ Furthermore, the associations may even differ between groups using calcium containing or calcium-free phosphate binding therapy. 58 
From the foregoing it may be clear that vascular calcification is a frequently encountered phenomenon in dialysis patients. However, some subjects will, even in the presence of comparable risk factors, never develop vascular calcifications. Furthermore, studies have shown that patients who do not have calcifications, rarely develop calcifications on follow-up. ${ }^{59}$ Recently, research has been done on the presence of so called calcification-inhibitors as an explanation for the latter observations.

\section{Calcification inhibitors}

Recently, an increasing number of potential calcification inhibitory molecules have been identified. Below, the calcification inhibitors that seem to play a pivotal role in the calcification process in dialysis patients will be addressed.

\section{Fetuin-A ( $\alpha 2$-Schmid Heremans glycoprotein)}

Fetuin-A is a serum glycoprotein, produced in the liver and present in high serum concentrations $(0.4-1.0 \mathrm{~g} / \mathrm{l}) .{ }^{60}$ With a molecular weight of $56 \mathrm{kDa}$ it is nondialyzable. It acts as a negative acute phase protein 61 and is a powerfull calcification inhibitor. ${ }^{60,62}$ Together with matrix gla protein (MGP, see below), fetuin$A$ is able to make up a complex with calcium and phosphate that is far more soluble than calcium and phosphate alone, preventing its extra skeletal deposition. ${ }^{63}$ In transgenic fetuin-A deficient mice (DBA2), extra skeletal calcification, including soft tissue and peri-vertebral arterial calcification develops. ${ }^{62}$ Other arterial calcifications are lacking, probably because up-regulation of other potent calcification inhibitors such as MGP and osteopontin. ${ }^{64}$ In dialysis patients serum fetuin-A levels negatively correlated with coronary artery calcification. ${ }^{65}$ In some studies low fetuin-A levels were associated with higher allcause and cardiovascular mortality. ${ }^{66-68}$ This effect was partially mediated by inflammation, according to the correlation with higher levels of CRP.

\section{Matrix Gla protein}

MGP, an extracellular matrix protein, belongs to the $\gamma$-carboxyglutamic acid (Gla) residue containing protein family, which have a high affinity for calcium and phosphate ions. ${ }^{69} \mathrm{MGP}$ is a vitamin $\mathrm{K}$-dependent protein synthesized by chondrocytes and vascular smooth muscle cells. ${ }^{70}$ MGP knockout mice develop severe calcifications of the arterial media. ${ }^{71,72}$ MGP polymorphisms were found to be related to mortality in dialysis patients ${ }^{72}$, but very limited data exist on serum MGP levels in dialysis patients, nor on its relation with fetuin-A. In non-uremic patients with coronary artery disease, serum MGP levels were decreased compared to control subjects. ${ }^{70}$ Furthermore, not only the quantity of MGP, but also its carboxylation status appears to be of great importance in the inhibition of calcification. Inactivation of MGP $\gamma$-carboxylation by warfarin resulted in extensive 
calcification of arteries in vitro ${ }^{41}$ and in vivo. ${ }^{73-75}$ Using immunohistochemistry, Schurgers et al. found a strong association between vascular calcification and local deposition of undercarboxylated MGP (UCMGP) in arteries of non-uremic patients with atherosclerosis and Mönckeberg's sclerosis. ${ }^{70}$

With current MGP assays, no distinction between carboxylated and undercarboxylated MGP in serum can be made. However, recently an assay has been developed, enabling the measurement of ucMGP in serum. It was shown that ucMGP levels were lower in a patient population prone to vascular calcification as compared to non-age and sex-matched controls. ${ }^{76}$

Until now, no data exist on ucMGP levels in dialysis patients compared to controls.

\section{Other factors}

Osteoprotegerin (OPG) is a member of the TNF receptor family. OPG is a potential explanation for the epidemiological association between osteoporosis on one side and atherosclerosis and vascular calcification on the other. ${ }^{79,80}$ OPG-deficient mice namely develop severe osteoporosis and medial artery calcification, which is prevented by restoration of the gene. ${ }^{81}$ OPG functions as a soluble decoy receptor for the receptor activator of nuclear factor $\mathrm{KB}$ ligand (RANKL). ${ }^{82}$ By blocking RANK activation, osteoclastogenesis is diminished. In dialysis patients OPG levels are higher compared to controls 83 and coronary calcification scores were shown to correlate positively with OPG. ${ }^{65}$ Whether this means that the OPG up regulation is just insufficient to prevent calcification or that $O P G$ is not really a calcification inhibitor remains to be proven. Osteopontin (OPN) is another bone matrix protein and calcification inhibitor in vivo. Compared to MGP knockout mice, mice deficient in both MGP and OPN had accelerated aortic calcification. ${ }^{84}$ In dialysis patients however the concentration of soluble serum OPN was higher than in controls and correlated positively with aortic calcification. ${ }^{85}$ This resembles the situation of OPG in dialysis patients and questions whether OPN up regulation is just insufficient or plays a different role in uremia.

\section{Clinical implications of vascular calcification}

As mentioned earlier, vascular calcification in CKD can be divided in intimal and medial sclerosis which are both associated with greater cardiovascular mortality. ${ }^{18}$ In dialysis patients, calcification scores in general are associated with greater cardiac morbidity. ${ }^{86}$ Arterial intima calcification represents an advanced stage of atherosclerosis. As a consequence, plaques tend to be more calcified in dialysis patients than in controls. ${ }^{33}$ These plaques may obstruct the arterial lumen and cause occlusive symptoms. ${ }^{87}$ However, intravascular ultrasound has recently shown that atherosclerosis also may be circumferential, without causing a stenotic lesion. 88 It has been suggested that calcification under uremic conditions may act as a natural "stent" by "stabilizing" plaques. ${ }^{89,90}$ Arterial disease would lead to less 
acute ischemic events, but more toward chronic ischemia and fibrosis through progressive luminal obliteration. 89

Arterial media calcification is mostly localized in muscle-type conduit arteries such as femoral and tibial arteries. These lesions in their most pure form do not obstruct the arterial lumen. This form of calcification has been associated with increased arterial stiffness and mortality. ${ }^{91,92}$

\section{Arterial stiffness}

Increased arterial stiffness is a typical feature of the aging process and encountered in many diseases as diabetes, atherosclerosis and CKD. Vascular stiffening develops from a complex interaction between stable and dynamic changes involving structural and cellular elements of the vessel wall. ${ }^{93}$ Two proteins, collagen and elastin largely determine the compliance of the vascular wall and are normally held stable by a slow, dynamic process of production and degeneration. ${ }^{93}$ Deregulation of this system, by stimulation of an inflammatory process may lead to overproduction of abnormal collagen and diminished quantities of normal elastin, which contribute to vascular stiffness. ${ }^{94}$ In CKD several mechanisms are involved in arterial stiffness. Hypertension for example causes increased luminal pressure and stimulates excessive collagen production. ${ }^{95}$ Increased extracellular matrix collagen content and VSMC proliferation are promoted by activated systemic and local renin-angiotensin-aldosteron system (RAAS). Moreover, volume overload and subsequently RAAS activation has been shown to be related to a greater arterial stiffness in ESRD patients. ${ }^{96}$ Also, elasticity and digestibility of collagen and other extracellular cell matrix proteins may be reduced because of advanced glycation end products (AGE's). ${ }^{97}$ Generalized endothelial dysfunction is another contributor to the arterial alterations in CKD patients 98.99 and markers of endothelial dysfunction are related to renal dysfunction and cardiovascular mortality in CKD.8 Apart from the above mentioned causes of increased arterial stiffness, arterial calcification, more precisely media calcification is a driving force for arterial stiffness in CKD. In patients with ESRD, coronary calcification and large artery calcification has been associated with greater arterial stiffness and greater cardiovascular mortality. ${ }^{18,91,100}$ Although calcification inhibitors such as fetuin-A and MGP seem to play an important role in the prevention of vascular calcification, it is not known whether these proteins are also related with arterial stiffness.

Arterial stiffening compromises normal arterial function. Apart from their blood supplying role, arteries also have to dampen the pressure and flow oscillations resulting from intermittent ventricular ejection. The pulsatile flow has to be transformed to a continuous flow required in peripheral tissues and organs. ${ }^{101}$ Arterial stiffening results in a loss of this so called cushioning function which leads to an isolated increase in systolic blood pressure and an increased pulse 
pressure ${ }^{102}$, which is closely related to left ventricular hypertrophy in dialysis patients. ${ }^{103}$ Pulse pressure is an independent cardiovascular risk factor in the general population 104 and associated with mortality in dialysis patients. ${ }^{105}$ Furthermore, pulse wave velocity (PWV), the time a pressure wave travels from the heart to the tissue, increases. Increase of PWV has a strong impact on survival in dialysis patients, with a $14 \%$ increase of cardiovascular mortality for each $\mathrm{m} / \mathrm{s}$ increase in aortic PWV.106 Controversy exists whether a greater PWV is also seen in mild renal insufficiency. ${ }^{107,108}$ The combination of a lower diastolic and higher systolic blood pressure will eventually result in a decrease in coronary perfusion in a hypertrophied heart with an elevated myocardial consumption.

\section{Arterial stiffness measurement}

In the past years a host of indices have been introduced to measure arterial stiffness. Peripheral arterial stiffness can be measured as carotid, brachial and femoral artery distensibility and compliance coefficients. The distensibility coefficient reflects the arterial elastic properties whereas the compliance coefficient reflects the arterial buffering capacity. ${ }^{109}$ From intima media thickness (IMT), diameter and carotid distensibility, calculated Young's elastic modulus (Einc), an indicator of the intrinsic wall properties can be measured. The most used measure of central arterial stiffness is the already above mentioned aortic pulse wave velocity (PWV). ${ }^{109}$ In this thesis the PWV was measured non-invasively with the use of the SphygmoCor (AtCor Medical Ltd., Moreton-in-Marsh, UK). In one study, however, we measured the carotid-femoral transit time, which is the travel time of a pressure wave from the common carotid to the femoral artery and it is closely related to the PWV. The PWV is calculated by dividing the non-invasively measured carotid-femoral distance by carotid-femoral transit time. Especially in elderly, obese patients this length measurement might introduce error. We therefore obtained the carotid-femoral transit time and adjusted for height in statistical analyses. We also measured augmentation index (Alx), which represents the additional load to which the left ventricle is subjected as a result of the timing of wave reflection. ${ }^{110}$ Both PWV and Alx have been shown to be independently related to cardiovascular mortality in ESRD. ${ }^{106,111}$

At last, systemic arterial stiffness can be determined according to the ratio of stroke volume to aortic pulse pressure. 


\section{Introduction and outline of the thesis}

From the above it is clear that cardiovascular morbidity and mortality are largely increased in CKD. Atherosclerosis and arteriosclerosis combined with arterial calcification seem to be pathophysiological key players. In CKD, next to traditional cardiovascular risk factors also non-traditional risk factors are associated with the greatly increased cardiovascular burden. This thesis describes several, mostly cross-sectional, studies in patients with CKD stage 2-4 and dialysis patients (CKD stage 5). The thesis emphasizes on the associations of potential risk factors with arterial stiffness and atherosclerosis. Furthermore, the association of the calcification inhibitor fetuin-A with mortality in dialysis patients is studied. The hypotheses of the studies resulted from recently supposed pathophysiological mechanisms involved in arterial calcification, atherosclerosis and arterial stiffness in CKD.

\section{Chapter 2.}

Although increased arterial stiffness is a well-known phenomenon in ESRD, data on arterial stiffness in CKD 2-4 are scarce. CKD is often accompanied by albuminuria. Albuminuria, at least partly, may represent endothelial dysfunction, which has been associated with arterial stiffness. It is not known whether a lower estimated GFR (eGFR) is an albuminuria independent factor related to greater arterial stiffness in CKD 2-3. The central hypothesis of the presented study in chapter 2 is that estimated glomerular filtration and urinary albumin excretion are related to arterial stiffness in patients with mild to moderate CKD. This chapter describes the study on the association between estimated glomerular filtration and urinary albumin excretion with arterial stiffness in the HOORN study population. The Hoorn Study is a cohort study of glucose tolerance and cardiovascular disease in the general population.

\section{Chapter 3}

IMT is a somewhat disappointing surrogate marker of atherosclerosis in CKD. With a recently developed technique it is possible to detect local inhomogeneities in the IMT by assessing the spatial variance of IMT over an arterial segment. Application of this technique might increase the sensitivity of IMT measurements and enable the detection of focal atherosclerotic lesions at an earlier stage in the development. The aim of the presented study in this chapter was to study the difference in CCA-IMT and inhomogeneities in CCA-IMT between dialysis patients and controls with the use of the above mentioned ultrasound technique. Secondly, the associations between the IMT and inhomogeneity measurements and several 
traditional risk factors, as well as the non-traditional risk factors anti-oxLDL antibodies, serum fetuin-A levels and hsCRP were studied.

\section{Chapter 4}

Arterial calcification and in particular media-calcification is a hallmark of ESRD. It has been associated with increased cardiovascular mortality. A possible mechanism responsible for this increase in mortality is greater arterial stiffness, which also has been associated with media-calcification. It is not known whether the level of calcification inhibitors is associated with arterial stiffness in ESRD patients. The circulating calcification inhibitor Fetuin-A plays a central role in this chapter. The hypothesis of the presented study was that fetuin-A serum levels in dialysis patients were associated with arterial stiffness.

\section{Chapter 5}

Recently it has been shown that fetuin-A was associated with all-cause and cardiovascular mortality in dialysis patients. Fetuin-A reacts as a negative acute phase protein and thus, although clearly involved in calcification processes, hypothetically may be related with non-cardiovascular mortality as well. This chapter shows the result of a study on the association of fetuin-A serum levels with mortality in dialysis patients from The Netherlands Cooperative Study on the Adequacy of Dialysis (NECOSAD). Although fetuin-A is mostly regarded as a potential cardiovascular risk marker in dialysis patients, we tested the hypothesis that fetuin-A was both related with cardiovascular and non-cardiovascular mortality.

\section{Chapter 6}

MGP is a calcification inhibitor known to play an important role in the active calcification process. UcMGP, the non-active form of MGP is abundantly seen in calcified aortic lesions. In this chapter we used a recently developed ucMGP assay to study the difference in ucMGP levels between dialysis patients and healthy controls. Furthermore, the relation between clinical parameters of mineral metabolism and ucMGP levels and the relation between ucMGP and arterial stiffness indices were studied in dialysis patients.

\section{Chapter 7}

This chapter comprises an illustrative case report presenting a dialysis patient with mediasclerosis and calcification of the vasa deferentia as representatives of extraosseous calcification. 


\section{Chapter 8}

A summary of the main findings of the thesis is given in this final chapter. Moreover the findings will be incorporated in the context of recent literature. 


\section{References}

1. K/DOQI clinical practice guidelines for chronic kidney disease: evaluation, classification, and stratification. Am J Kidney Dis 2002;39(2 Suppl 1):S1-266.

2. Foley RN, Parfrey PS, Sarnak MJ. Epidemiology of cardiovascular disease in chronic renal disease. J Am Soc Nephrol 1998;9(12 Suppl):S16-23.

3. Lindner A, Charra B, Sherrard DJ, Scribner BH. Accelerated atherosclerosis in prolonged maintenance hemodialysis. N Engl J Med 1974;290:697-701.

4. Wheeler DC. Cardiovascular disease in patients with chronic renal failure. Lancet 1996; 348:1673-1674.

5. Go AS, Chertow GM, Fan D, McCulloch CE, Hsu CY. Chronic kidney disease and the risks of death, cardiovascular events, and hospitalization. N Engl J Med 2004;351:1296-1305.

6. De Leeuw PW, Thijs L, Birkenhager WH, Voyaki SM, Efstratopoulos AD, Fagard RH, Leonetti G, Nachev C, Petrie JC, Rodicio JL, Rosenfeld JJ, Sarti C, Staessen JA. Systolic Hypertension in Europe (Syst-Eur) Trial Investigators. Prognostic significance of renal function in elderly patients with isolated systolic hypertension: results from the Syst-Eur trial. J Am Soc Nephrol 2002;13: 2213-2222.

7. Henry RM, Kostense PJ, Bos G, Dekker JM, Nijpels G, Heine RJ, Bouter LM, Stehouwer CD. Mild renal insufficiency is associated with increased cardiovascular mortality: The Hoorn Study. Kidney Int 2002;62:1402-1407.

8. Stam F, van Guldener C, Becker A, Dekker JM, Heine RJ, Bouter LM, Stehouwer CD. Endothelial dysfunction contributes to renal function-associated cardiovascular mortality in a population with mild renal insufficiency: the Hoorn study. J Am Soc Nephrol 2006;17:537-545.

9. Leoncini G, Viazzi F, Parodi D, Ratto E, Vettoretti S, Vaccaro V, Ravera M, Deferrari G, Pontremoli R. Mild renal dysfunction and cardiovascular risk in hypertensive patients. J Am Soc Nephrol 2004;15 Suppl 1:S88-90.

10. Manjunath G, Tighiouart H, Coresh J, Macleod B, Salem DN, Griffith JL, Levey AS, Sarnak MJ. Level of kidney function as a risk factor for cardiovascular outcomes in the elderly. Kidney Int 2003;63:1121-1129.

11. Gerstein HC, Mann JF, Yi Q, Zinman B, Dinneen SF, Hoogwerf B, Halle JP, Young J, Rashkow A, Joyce C, Nawaz S, Yusuf S; HOPE Study Investigators. Albuminuria and risk of cardiovascular events, death, and heart failure in diabetic and nondiabetic individuals. JAMA 2001;286: 421-426.

12. Kramer H, Jacobs DR, Jr., Bild D, Post W, Saad MF, Detrano R, Tracy R, Cooper R, Liu K. Urine albumin excretion and subclinical cardiovascular disease. The Multi-Ethnic Study of Atherosclerosis. Hypertension 2005;46:38-43.

13. Stehouwer CD, Nauta JJ, Zeldenrust GC, Hackeng WH, Donker AJ, den Ottolander GJ. Urinary albumin excretion, cardiovascular disease, and endothelial dysfunction in non-insulin-dependent diabetes mellitus. Lancet 1992;340:319-323.

14. Longenecker JC, Coresh J, Powe NR, Levey AS, Fink NE, Martin A, Klag MJ. Traditional cardiovascular disease risk factors in dialysis patients compared with the general population: the CHOICE Study. J Am Soc Nephrol 2002;13:1918-1927.

15. Sarnak MJ, Coronado BE, Greene T, Wang SR, Kusek JW, Beck GJ, Levey AS. Cardiovascular disease risk factors in chronic renal insufficiency. Clin Nephrol 2002;57:327-335.

16. Goodman WG, Goldin J, Kuizon BD, Yoon C, Gales B, Sider D, Wang Y, Chung J, Emerick A, Greaser L, Elashoff RM, Salusky IB. Coronary-artery calcification in young adults with end-stage renal disease who are undergoing dialysis. N Engl J Med 2000;342:1478-1483.

17. Guerin AP, Blacher J, Pannier B, Marchais SJ, Safar ME, London GM. Impact of aortic stiffness attenuation on survival of patients in end-stage renal failure. Circulation 2001;103:987-992.

18. London GM, Guerin AP, Marchais SJ, Metivier F, Pannier B, Adda H. Arterial media calcification in end-stage renal disease: impact on all-cause and cardiovascular mortality. Nephrol Dial Transplant 2003;18:1731-1740.

19. London GM, Marchais SJ, Metivier F, Guerin AP. Cardiovascular risk in end-stage renal disease: vascular aspects. Nephrol Dial Transplant 2000;15 Suppl 5:97-104. 
20. Ross R. Atherosclerosis--an inflammatory disease. N Engl J Med 1999;340:115-126.

21. Zarins CK, Zatina MA, Giddens DP, Ku DN, Glagov S. Shear stress regulation of artery lumen diameter in experimental atherogenesis. J Vasc Surg 1987;5:413-420.

22. Wanner C, Krane V, Metzger T, Quaschning T. Lipid changes and statins in chronic renal insufficiency and dialysis. J Nephrol 2001;14 Suppl 4:S76-80.

23. Yla-Herttuala S, Palinski W, Butler SW, Picard S, Steinberg D, Witztum JL. Rabbit and human atherosclerotic lesions contain IgG that recognizes epitopes of oxidized LDL. Arterioscler Thromb 1994;14:32-40.

24. Drueke TB, Nguyen Khoa T, Massy ZA, Witko-Sarsat V, Lacour B, Descamps-Latscha B. Role of oxidized low-density lipoprotein in the atherosclerosis of uremia. Kidney Int Suppl 2001;78: S114-119.

25. Pecoits-Filho R, Lindholm B, Stenvinkel P. The malnutrition, inflammation, and atherosclerosis (MIA) syndrome -- the heart of the matter. Nephrol Dial Transplant 2002;17 Suppl 11:28-31.

26. Stenvinkel P. Inflammatory and atherosclerotic interactions in the depleted uremic patient. Blood Purif 2001;19:53-61.

27. Roig E, Betriu A, Castaner A, Magrina J, Sanz G, Navarro-Lopez F. Disabling angina pectoris with normal coronary arteries in patients undergoing long-term hemodialysis. Am J Med 1981;71: 431-434.

28. Rostand SG, Kirk KA, Rutsky EA. Dialysis-associated ischemic heart disease: insights from coronary angiography. Kidney Int 1984;25:653-659.

29. Grobbee DE, Bots ML. Carotid artery intima-media thickness as an indicator of generalized atherosclerosis. J Intern Med 1994;236:567-573.

30. 2003 European Society of Hypertension-European Society of Cardiology guidelines for the management of arterial hypertension. J Hypertens 2003;21:1011-1053.

31. Benedetto FA, Mallamaci F, Tripepi G, Zoccali C. Prognostic value of ultrasonographic measurement of carotid intima media thickness in dialysis patients. J Am Soc Nephrol 2001;12:2458-2464.

32. Konings CJ, Dammers R, Rensma PL, Kooman JP, Hoeks AP, Kornet L, Gladziwa U, van der Sande FM, Leunissen KM. Arterial wall properties in patients with renal failure. Am J Kidney Dis 2002;39:1206-1212.

33. Savage T, Clarke AL, Giles M, Tomson CR, Raine AE. Calcified plaque is common in the carotid and femoral arteries of dialysis patients without clinical vascular disease. Nephrol Dial Transplant 1998;13:2004-2012.

34. London GM, Guerin AP, Marchais SJ, Pannier B, Safar ME, Day M, Metivier F. Cardiac and arterial interactions in end-stage renal disease. Kidney Int 1996;50:600-608.

35. Reneman RS, Hoeks AP. Noninvasive vascular ultrasound: an asset in vascular medicine. Cardiovasc Res 2000;45:27-35.

36. Badimon JJ, Fuster V, Chesebro JH, Badimon L. Coronary atherosclerosis. A multifactorial disease. Circulation 1993;87(3 Suppl):II3-16.

37. Meinders JM, Kornet L, Hoeks AP. Assessment of spatial inhomogeneities in intima media thickness along an arterial segment using its dynamic behavior. Am J Physiol Heart Circ Physiol 2003;285:H384-391.

38. Leskinen Y, Lehtimaki T, Loimaala A, Lautamatti V, Kallio T, Huhtala H, Salenius JP, Saha H. Carotid atherosclerosis in chronic renal failure-the central role of increased plaque burden. Atherosclerosis 2003;171:295-302.

39. Oh J, Wunsch R, Turzer M, Bahner M, Raggi P, Querfeld U, Mehls O, Schaefer F. Advanced coronary and carotid arteriopathy in young adults with childhood-onset chronic renal failure. Circulation 2002;106:100-105.

40. Goodman WG, London G, Amann K, Block GA, Giachelli C, Hruska KA, Ketteler M, Levin A, Massy Z, McCarron DA, Raggi P, Shanahan CM, Yorioka N; Vascular Calcification Work Group. Vascular calcification in chronic kidney disease. Am J Kidney Dis 2004;43:572-579.

41. Price PA, Chan WS, Jolson DM, Williamson MK. The elastic lamellae of devitalized arteries calcify when incubated in serum: evidence for a serum calcification factor. Arterioscler Thromb Vasc Biol 2006;26:1079-1085. 
42. Proudfoot D, Shanahan CM, Weissberg PL. Vascular calcification: new insights into an old problem. J Pathol 1998;185:1-3.

43. Trion A, van der Laarse A. Vascular smooth muscle cells and calcification in atherosclerosis. Am Heart J 2004;147:808-814.

44. Proudfoot D, Shanahan CM. Biology of calcification in vascular cells: intima versus media. Herz 2001;26:245-251.

45. Bostrom K, Watson KE, Horn S, Wortham C, Herman IM, Demer LL. Bone morphogenetic protein expression in human atherosclerotic lesions. J Clin Invest 1993;91:1800-1809.

46. Moe SM, O'Neill KD, Duan D, Ahmed S, Chen NX, Leapman SB, Fineberg N, Kopecky K. Medial artery calcification in ESRD patients is associated with deposition of bone matrix proteins. Kidney Int 2002;61: 638-647.

47. Block GA, Hulbert-Shearon TE, Levin NW, Port FK. Association of serum phosphorus and calcium $x$ phosphate product with mortality risk in chronic hemodialysis patients: a national study. Am J Kidney Dis 1998;31:607-617.

48. National Kidney Foundation K/DOQI Clinical Practice Guidelines for Bone Metabolism and Disease in Chronic Kidney Disease. Am J Kidney Dis 2003;42((suppl 3)):s1-202.

49. Jono S, McKee MD, Murry CE, Shioi A, Nishizawa Y, Mori K, Morii H, Giachelli CM. Phosphate regulation of vascular smooth muscle cell calcification. Circ Res 2000;87:E10-17.

50. Floege J, Ketteler M. Vascular calcification in patients with end-stage renal disease. Nephrol Dial Transplant 2004;19 Suppl 5:V59-66.

51. Giachelli CM, Jono S, Shioi A, Nishizawa Y, Mori K, Morii H. Vascular calcification and inorganic phosphate. Am J Kidney Dis 2001;38(4 Suppl 1):S34-37.

52. Parhami F, Morrow AD, Balucan J, Leitinger N, Watson AD, Tintut Y, Berliner JA, Demer LL. Lipid oxidation products have opposite effects on calcifying vascular cell and bone cell differentiation. $A$ possible explanation for the paradox of arterial calcification in osteoporotic patients. Arterioscler Thromb Vasc Biol 1997;17:680-687.

53. Yamagishi S, Fujimori H, Yonekura H, Tanaka N, Yamamoto H. Advanced glycation endproducts accelerate calcification in microvascular pericytes. Biochem Biophys Res Commun 1999;258: 353-357.

54. Jono S, Nishizawa Y, Shioi A, Morii H. 1,25-Dihydroxyvitamin D3 increases in vitro vascular calcification by modulating secretion of endogenous parathyroid hormone-related peptide. Circulation 1998;98:1302-1306.

55. Moe SM, Chen NX. Inflammation and vascular calcification. Blood Purif 2005;23(1):64-71.

56. Ahmed S, O'Neill KD, Hood AF, Evan AP, Moe SM. Calciphylaxis is associated with hyperphosphatemia and increased osteopontin expression by vascular smooth muscle cells. Am J Kidney Dis 2001;37:1267-1276.

57. Wang AY, Wang M, Woo J, Lam CW, Li PK, Lui SF, Sanderson JE. Cardiac valve calcification as an important predictor for all-cause mortality and cardiovascular mortality in long-term peritoneal dialysis patients: a prospective study. J Am Soc Nephrol 2003;14:159-168.

58. Chertow GM, Raggi P, Chasan-Taber S, Bommer J, Holzer H, Burke SK. Determinants of progressive vascular calcification in haemodialysis patients. Nephrol Dial Transplant 2004;19:1489-1496.

59. Moe SM, O'Neill KD, Reslerova M, Fineberg N, Persohn S, Meyer CA. Natural history of vascular calcification in dialysis and transplant patients. Nephrol Dial Transplant 2004;19:2387-2393.

60. Ketteler M, Wanner C, Metzger T, Bongartz P, Westenfeld R, Gladziwa U, Schurgers LJ, Vermeer C, Jahnen-Dechent W, Floege J. Deficiencies of calcium-regulatory proteins in dialysis patients: a novel concept of cardiovascular calcification in uremia. Kidney Int Suppl 2003:S84-87.

61. Lebreton JP, Joisel F, Raoult JP, Lannuzel B, Rogez JP, Humbert G. Serum concentration of human alpha $2 \mathrm{HS}$ glycoprotein during the inflammatory process: evidence that alpha $2 \mathrm{HS}$ glycoprotein is a negative acute-phase reactant. J Clin Invest 1979;64:1118-1129.

62. Schafer C, Heiss A, Schwarz A, Westenfeld R, Ketteler M, Floege J, Muller-Esterl W, Schinke T, Jahnen-Dechent $W$. The serum protein alpha 2 -Heremans-Schmid glycoprotein/fetuin-A is a systemically acting inhibitor of ectopic calcification. J Clin Invest 2003;112:357-366. 
63. Coen G, Ballanti P, Balducci A, Grandi F, Manni M, Mantella D, Pierantozzi A, Ruggeri M, Sardella D, Sorbo G, Bonucci E. Renal osteodystrophy: alpha-Heremans Schmid glycoprotein/fetuin-A, matrix GLA protein serum levels, and bone histomorphometry. Am J Kidney Dis 2006;48:106-113.

64. Ketteler M, Westenfeld R, Schlieper G, Brandenburg V. Pathogenesis of vascular calcification in dialysis patients. Clin Exp Nephrol 2005;9:265-270.

65. Moe SM, Reslerova M, Ketteler M, O'neill K, Duan D, Koczman J, Westenfeld R, Jahnen-Dechent W, Chen NX. Role of calcification inhibitors in the pathogenesis of vascular calcification in chronic kidney disease (CKD). Kidney Int 2005;67:2295-2304.

66. Ketteler M, Bongartz P, Westenfeld R, Wildberger JE, Mahnken AH, Böhm R, Metzger T, Wanner C, Jahnen-Dechent W, Floege J. Association of low fetuin-A (AHSG) concentrations in serum with cardiovascular mortality in patients on dialysis: a cross-sectional study. Lancet 2003;361: 827-833.

67. Stenvinkel P, Wang K, Qureshi AR, Axelsson J, Pecoits-Filho R, Gao P, Barany P, Lindholm B, Jogestrand T, Heimbürger O, Holmes C, Schalling M, Nordfors L. Low fetuin-A levels are associated with cardiovascular death: Impact of variations in the gene encoding fetuin. Kidney Int 2005;67:2383-2392.

68. Wang AY, Woo J, Lam CW, Wang M, Chan IH, Gao P, Lui SF, Li PK, Sanderson JE. Associations of serum fetuin-A with malnutrition, inflammation, atherosclerosis and valvular calcification syndrome and outcome in peritoneal dialysis patients. Nephrol Dial Transplant 2005;20:16761685.

69. Price PA, Williamson MK. Primary structure of bovine matrix Gla protein, a new vitamin Kdependent bone protein. J Biol Chem 1985;260:14971-14975.

70. Schurgers LJ, Teunissen KJ, Knapen MH, Kwaijtaal M, van Diest R, Appels A, Reutelingsperger CP, Cleutjens JP, Vermeer C. Novel conformation-specific antibodies against matrix gammacarboxyglutamic acid (Gla) protein: undercarboxylated matrix Gla protein as marker for vascular calcification. Arterioscler Thromb Vasc Biol 2005;25:1629-1633.

71. Luo G, Ducy P, McKee MD, Pinero GJ, Loyer E, Behringer RR, Karsenty G. Spontaneous calcification of arteries and cartilage in mice lacking matrix GLA protein. Nature 1997;386:78-81.

72. Brancaccio D, Biondi ML, Gallieni M, Turri O, Galassi A, Cecchini F, Russo D, Andreucci V, Cozzolino M. Matrix GLA protein gene polymorphisms: clinical correlates and cardiovascular mortality in chronic kidney disease patients. Am J Nephrol 2005;25:548-552.

73. Spronk HM, Soute BA, Schurgers L, Thijssen HH, De Mey JG, Vermeer C. Tissue-specific utilization of menaquinone- 4 results in the prevention of arterial calcification in warfarin-treated rats. J Vasc Res 2003;40:531-537.

74. Koos R, Mahnken AH, Mühlenbruch G, Brandenburg V, Pflueger B, Wildberger JE, Kühl HP. Relation of oral anticoagulation to cardiac valvular and coronary calcium assessed by multislice spiral computed tomography. Am J Cardiol 2005;96:747-749.

75. Schurgers $\sqcup$, Aebert H, Vermeer C, Bultmann B, Janzen J. Oral anticoagulant treatment: friend or foe in cardiovascular disease? Blood 2004;104:3231-3132.

76. Ellen Cranenburg CV, Ralf Koos, Marie-Louise Bouwmans, Martijn Kwaijtaal, Vincent Bandenburg, Markus Ketteler, Leon J. Schurgers. The circulating inactive form of Matrix Gla Protein (ucMGP) as a biomarker for cardiovascular disease. 2006.

77. Wilmer WA, Magro CM. Calciphylaxis: emerging concepts in prevention, diagnosis, and treatment. Semin Dial 2002;15:172-186.

78. Schurgers LJ, Teunissen KJ, Knapen MH, Geusens P, van der Heijde D, Kwaijtaal M, van Diest R, Ketteler M, Vermeer C. Characteristics and performance of an immunosorbent assay for human matrix Gla-protein. Clin Chim Acta 2005;351:131-138.

79. Kiel DP, Kauppila LI, Cupples LA, Hannan MT, O'Donnell CJ, Wilson PW. Bone loss and the progression of abdominal aortic calcification over a 25 year period: the Framingham Heart Study. Calcif Tissue Int 2001;68:271-276.

80. Hak AE, Pols HA, van Hemert AM, Hofman A, Witteman JC. Progression of aortic calcification is associated with metacarpal bone loss during menopause: a population-based longitudinal study. Arterioscler Thromb Vasc Biol 2000;20:1926-1931. 
81. Bucay N, Sarosi I, Dunstan CR, Morony S, Tarpley J, Capparelli C, Scully S, Tan HL, Xu W, Lacey DL, Boyle WJ, Simonet WS. osteoprotegerin-deficient mice develop early onset osteoporosis and arterial calcification. Genes Dev 1998;12:1260-1268.

82. Collin-Osdoby P. Regulation of vascular calcification by osteoclast regulatory factors RANKL and osteoprotegerin. Circ Res 2004;95:1046-1057.

83. Nitta K, Akiba T, Uchida K, Kawashima A, Yumura W, Kabaya T, Nihei H. The progression of vascular calcification and serum osteoprotegerin levels in patients on long-term hemodialysis. Am J Kidney Dis 2003;42:303-309.

84. Speer MY, McKee MD, Guldberg RE, Liaw L, Yang HY, Tung E, Karsenty G, Giachelli CM. Inactivation of the osteopontin gene enhances vascular calcification of matrix Gla protein-deficient mice: evidence for osteopontin as an inducible inhibitor of vascular calcification in vivo. J Exp Med 2002;196:1047-1055.

85. Nitta K, Ishizuka T, Horita S, Hayashi T, Ajiro A, Uchida K, Honda K, Oba T, Kawashima A, Yumura W, Kabaya T, Akiba T, Nihei H. Soluble osteopontin and vascular calcification in hemodialysis patients. Nephron 2001;89:455-458.

86. Raggi P, Boulay A, Chasan-Taber S, Amin N, Dillon M, Burke SK, Chertow GM.. Cardiac calcification in adult hemodialysis patients. A link between end-stage renal disease and cardiovascular disease? J Am Coll Cardiol 2002;39:695-701.

87. Shanahan CM, Cary NR, Salisbury JR, Proudfoot D, Weissberg PL, Edmonds ME. Medial localization of mineralization-regulating proteins in association with Monckeberg's sclerosis: evidence for smooth muscle cell-mediated vascular calcification. Circulation 1999;100: 2168-2176.

88. Virmani R, Kolodgie FD, Burke AP, Farb A, Schwartz SM. Lessons from sudden coronary death: a comprehensive morphological classification scheme for atherosclerotic lesions. Arterioscler Thromb Vasc Biol 2000;20:1262-1275.

89. Goldsmith D, Ritz E, Covic A. Vascular calcification: a stiff challenge for the nephrologist: does preventing bone disease cause arterial disease? Kidney Int 2004;66:1315-1333.

90. Abedin M, Tintut Y, Demer LL. Vascular calcification: mechanisms and clinical ramifications. Arterioscler Thromb Vasc Biol 2004;24:1161-1170.

91. Blacher J, Guerin AP, Pannier B, Marchais SJ, London GM. Arterial calcifications, arterial stiffness, and cardiovascular risk in end-stage renal disease. Hypertension 2001;38:938-942.

92. Guerin AP, London GM, Marchais SJ, Metivier F. Arterial stiffening and vascular calcifications in end-stage renal disease. Nephrol Dial Transplant 2000;15:1014-1021.

93. Zieman SJ, Melenovsky V, Kass DA. Mechanisms, pathophysiology, and therapy of arterial stiffness. Arterioscler Thromb Vasc Biol 2005;25:932-943.

94. Johnson CP, Baugh R, Wilson CA, Burns J. Age related changes in the tunica media of the vertebral artery: implications for the assessment of vessels injured by trauma. J Clin Pathol 2001;54: 139-145.

95. Xu C, Zarins CK, Pannaraj PS, Bassiouny HS, Glagov S. Hypercholesterolemia superimposed by experimental hypertension induces differential distribution of collagen and elastin. Arterioscler Thromb Vasc Biol 2000;20:2566-2572.

96. Tycho Vuurmans JL, Boer WH, Bos WJ, Blankestijn PJ, Koomans HA. Contribution of volume overload and angiotensin II to the increased pulse wave velocity of hemodialysis patients. J Am Soc Nephrol 2002;13:177-183.

97. Makita Z, Bucala R, Rayfield EJ, Fuh H, Manogue KR, Cerami A, Viassara H, Friedman EA, Kaufman $\mathrm{AM}$, Korbet SM, Barth RH, Winston JA. Reactive glycosylation endproducts in diabetic uraemia and treatment of renal failure. Lancet 1994; 343:1519-1522.

98. van Guldener C, Lambert J, Janssen MJ, Donker AJ, Stehouwer CD. Endothelium-dependent vasodilatation and distensibility of large arteries in chronic haemodialysis patients. Nephrol Dial Transplant 1997;12 Suppl 2:14-18.

99. van Guldener C, Janssen MJ, Lambert J, Steyn M, Donker AJ, Stehouwer CD. Endotheliumdependent vasodilatation is impaired in peritoneal dialysis patients. Nephrol Dial Transplant 1998;13:1782-1786.

100. Haydar AA, Covic A, Colhoun H, Rubens M, Goldsmith DJ. Coronary artery calcification and aortic pulse wave velocity in chronic kidney disease patients. Kidney Int 2004;65:1790-1794. 
101. O'Rourke M. Mechanical principles in arterial disease. Hypertension 1995;26:2-9.

102. London G, Guerin A, Pannier B, Marchais S, Benetos A, Safar M. Increased systolic pressure in chronic uremia. Role of arterial wave reflections. Hypertension 1992;20:10-19.

103. Parfrey PS, Foley RN, Harnett JD, Kent GM, Murray DC, Barre PE. Outcome and risk factors for left ventricular disorders in chronic uraemia. Nephrol Dial Transplant 1996;11:1277-1285.

104. Madhavan S, Ooi WL, Cohen H, Alderman MH. Relation of pulse pressure and blood pressure reduction to the incidence of myocardial infarction. Hypertension 1994;23:395-401.

105. Klassen PS, Lowrie EG, Reddan DN, DeLong ER, Coladonato JA, Szczech LA, Lazarus JM, Owen WF Jr. Association between pulse pressure and mortality in patients undergoing maintenance hemodialysis. JAMA 2002;287:1548-1555.

106. Blacher J, Safar ME, Guerin AP, Pannier B, Marchais SJ, London GM. Aortic pulse wave velocity index and mortality in end-stage renal disease. Kidney Int 2003;63:1852-1860.

107. Mourad JJ, Pannier B, Blacher J, Rudnichi A, Benetos A, London GM, Safar ME. Creatinine clearance, pulse wave velocity, carotid compliance and essential hypertension. Kidney Int 2001;59: 1834-1841.

108. Briet M, Bozec E, Laurent S, Fassot C, London GM, Jacquot C, Froissart M, Houillier P, Boutouyrie P. Arterial stiffness and enlargement in mild-to-moderate chronic kidney disease. Kidney Int 2006;69:350-357.

109. O'Rourke MF, Staessen JA, Vlachopoulos C, Duprez D, Plante GE. Clinical applications of arterial stiffness; definitions and reference values. Am J Hypertens 2002;15:426-444.

110. Davies JI, Struthers AD. Pulse wave analysis and pulse wave velocity: a critical review of their strengths and weaknesses. J Hypertens 2003;21:463-472.

111. London GM, Blacher J, Pannier B, Guerin AP, Marchais SJ, Safar ME. Arterial wave reflections and survival in end-stage renal failure. Hypertension 2001;38:434-438. 


\section{Chapter 2}

Estimated glomerular filtration rate and urinary

albumin excretion are independently associated with greater arterial stiffness - The Hoorn Study

MMH Hermans, RMA Henry, JM Dekker, JP Kooman, PJ Kostense, G Nijpels, RJ Heine, CDA Stehouwer

Journal of American Society of Nephrology, 2007;18:1942-1952 


\section{Abstract}

\section{Background}

Mild renal insufficiency is a risk factor for cardiovascular disease (CVD). Both a decline in glomerular filtration rate (GFR) and (micro)albuminuria are associated with greater cardiovascular mortality. In endstage renal disease (ESRD), arterial stiffness, an important cause of CVD, is known to be greater, but few data exist in individuals with mild renal insufficiency or microalbuminuria. We investigated the association of impaired renal function expressed as lower GFR or greater urinary albumin excretion with arterial stiffness.

\section{Methods}

In a population-based study in 806 individuals (402 men), mean age 68 years (range 50-87), we ultrasonically measured peripheral arterial stiffness (by compliance and distensibility of the carotid, brachial and femoral artery, and by the carotid elastic modulus $\left(E_{\text {inc }}\right)$ ) and central arterial stiffness (by total systemic arterial compliance, carotid-femoral transit time (CFTT) and aortic augmentation index (Alx)). GFR was estimated (eGFR) by the Modification of Diet in Renal Disease (MDRD) formula. Urinary albumin excretion was expressed as urinary albumin-creatinine ratio (UACR).

\section{Results}

eGFR was $60.6( \pm 11.1) \mathrm{ml} / \mathrm{min} / 1.73 \mathrm{~m}^{2}$. Median UACR was 0.57 (range 0.1 to 26.6) mg/mmol. After adjustment for age, mean arterial pressure (MAP), sex and glucose tolerance status (GTS), each $5 \mathrm{ml} / \mathrm{min} / 1.73 \mathrm{~m}^{2}$ lower eGFR was associated with a lower distensibility coefficient (DC) of the carotid (regression coefficient $\beta$ with 95\% confidence intervals, $-0.20(-0.34$ to -0.07$) 10^{-3} \mathrm{kPa}^{-1}$ ) and brachial artery $\left(-0.15(-0.28\right.$ to -0.03$\left.) 10^{-3} \mathrm{kPa}^{-1}\right)$, and a greater carotid $\mathrm{E}_{\text {inc }}(0.02$ (0.0004 to 0.04$\left.) \mathrm{kPa}\right)$. No statistically significant association was found of eGFR with other arterial stiffness indices. After adjustment for age, MAP, sex, and GTS, a greater UACR (per quartile) was associated with a greater $\mathrm{E}_{\text {inc }}$ (0.03 $(0.001$ to 0.07$) \mathrm{kPa})$ and a trend to a lower DC $\left(-0.24(-0.49\right.$ to 0.02$\left.) 10^{-3} \mathrm{kPa}^{-1}\right)$ of the carotid artery. After adjustment for age, MAP, sex, and GTS, a greater UACR (per quartile) was in addition associated with a shorter CFTT (-1.67 (-3.24 to -0.10) ms). These associations were not substantially changed by mutual adjustment for eGFR and UACR.

\section{Conclusion}

In individuals with mild to moderate renal insufficiency, both a lower eGFR and a greater albumin excretion, even below levels considered to reflect microalbuminuria, are independently associated with greater arterial stiffness. Moreover, these associations were mutually independent. These findings may explain, in part, why eGFR and microalbuminuria are associated with greater risk of CVD and suggest that amelioration of arterial stiffness could be a target of intervention. 


\section{Introduction}

Chronic kidney disease (CKD) is defined as a lowering of the glomerular filtration rate (GFR) and/or the presence of (micro)albuminuria. ${ }^{1}$ In severe CKD (end-stage renal disease), cardiovascular mortality is greatly increased. ${ }^{2}$ Mild renal insufficiency has also been associated with a greater cardiovascular mortality.,3 In addition, (micro)albuminuria has been associated with an increase in cardiovascular disease (CVD) and mortality in a wide variety of populations. . $^{5-7}$ The underlying mechanisms are incompletely understood. Increased arterial stiffness is a well-known process in severe $\mathrm{CKD}^{8-10}$ and has been associated with a greater cardiovascular mortality. ${ }^{11,12}$

We hypothesized that arterial stiffness may be increased in mild to moderate renal insufficiency (stage 2-3 CKD ${ }^{1}$ ) and in individuals with (micro)albuminuria, and that this may be one of the mechanisms linking these conditions to CVD. To test this hypothesis, we investigated, in a population-based study of 806 individuals, the association between GFR (estimated by the Modification of Diet in Renal Disease (MDRD) formula ${ }^{13}$ ) and arterial stiffness. In addition, we investigated the association between urinary albumin excretion and arterial stiffness, and whether these associations were mutually independent.

\section{Methods}

\section{Study population}

For the present cross-sectional investigation, we used data from the 2000 Hoorn Study follow-up examination and the Hoorn Screening Study. Details have been described elsewhere. ${ }^{14,15}$ Briefly, the Hoorn Study is a cohort study of glucose tolerance and CVD in the general population. The Hoorn Screening Study is a population-based targeted type 2 diabetes (DM-2) screening study. The local ethics committee approved the studies and written informed consent was obtained from all participants. Each participant underwent an oral glucose tolerance test, except those with previously diagnosed diabetes, and glucose tolerance status (GTS) was classified according to the 1999 WHO criteria. ${ }^{16}$ The final study population consisted of 806 individuals (299 with NGM, 181 with impaired glucose metabolism (IGM), and 326 with DM-2).

\section{Estimates of renal function}

Renal function was estimated by the MDRD formula in $\mathrm{ml} / \mathrm{min} / 1.73 \mathrm{~m}^{2}$ $\left(170 *(\text { creatinine })^{-0.999 *}(\text { age })^{-0.176 *} \text { (urea) }-0.170 * \text { (albumin }\right)^{+0.318 * 0.762}$ if female; all 
participants where Caucasian). Because of missing laboratory values, eGFR could not be determined in 31 cases. Urinary albumin-creatinine ratio (UACR) in $\mathrm{mg} / \mathrm{mmol}$ was determined in an overnight first-voided urine sample. Microalbuminuria was defined as a UACR between 2 and $30 \mathrm{mg} / \mathrm{mmol}$. Urinary albumin was measured by rate nephelometry (Array Protein system, Beckman) with an assay treshold of $2 \mathrm{mg} / \mathrm{l}$. Urinary and serum creatinine was measured by a modified Jaffé's test. Subjects with macroalbuminuria $(>30 \mathrm{mg} / \mathrm{mmol} ; \mathrm{n}=8)$ were excluded from further analysis. To include patients $(n=86)$ with an albuminuria level below the assay threshold, a UACR was calculated with albumin concentration set at $1.9 \mathrm{mg} / \mathrm{I}$ divided by the urinary creatinine concentration. Formulas are given in traditional units. To convert to International System units multiply creatinine in $\mathrm{mg} / \mathrm{dl}$ by 88.4 , urea in $\mathrm{mg} / \mathrm{dl}$ by 0.357 and albumin in $\mathrm{g} / \mathrm{dl}$ by 10 .

\section{Blood pressure measurement}

Brachial artery (BA) systolic and diastolic pressures were assessed in the left upper arm at 5-minute intervals with an oscillometric device (Collin, Press Mate, BP-8800), as previously described. ${ }^{17}$ Brachial pulse pressure (PP) was calculated as systolic minus diastolic pressure and brachial mean arterial pressure (MAP) as $(2$ * diastolic pressure + systolic pressure)/3. PP at the carotid (CCA) and femoral artery (FA) was calculated according to the calibration method described by Kelly and Fitchett ${ }^{18}$, with use of distension waveforms as adapted from Van Bortel et al. ${ }^{19}$ This method assumes a constant difference between MAP and diastolic pressure (DP) along the arterial tree. PP can be calculated at a target artery (PPtar) from the PP at a reference artery (PPref) and a calibration factor (K) at target and reference arteries (Ktar and Kref) by the formula: PPtar=PPref * Ktar/Kref, in which $\mathrm{K}$ is defined as (MAP-DP)/PP, and (MAP-DP) can be calculated from the area under the pressure curve divided by time. ${ }^{18,19}$

\section{Arterial properties}

\section{Diameter, Distension, and Intima-Media Thickness)}

Details have been described elsewhere. ${ }^{17}$ Briefly, a single observer unaware of the participants' clinical or glucose tolerance status obtained properties of the right CCA, FA and BA, with the use of an ultrasound scanner (350 Series, Pie Medical, 7.5-MHz probe). The scanner was connected to a PC equipped with vessel wall movement detection software (Wall Track System, Pie Medical). Data were obtained from three consecutive measurements. Diastolic diameter was calculated as the difference between the anterior and posterior wall markers. The change of diameter as a function of time (distension) was estimated and presented on the computer screen (distension waveform). Additionally the carotid posterior wall 
thickness was calculated. The mean diameter, distension and intima-media thickness (IMT) were used in analysis.

\section{Peripheral Arterial Stiffness: Distensibility, Compliance and Young’s Elastic Modulus}

We calculated carotid, brachial and femoral artery distensibility and compliance coefficients as follows. ${ }^{20}$

Distensibility coefficient $=\left(2 \Delta D * D+\Delta D^{2}\right) /\left(\Delta P * D^{2}\right)$ in $10^{-3} * k^{-1}$

Compliance coefficient $=\pi\left(2 \mathrm{D} * \Delta \mathrm{D}+\Delta \mathrm{D}^{2}\right) /(4 * \Delta \mathrm{P})$ in $\mathrm{mm}^{2} * \mathrm{kPa}^{-1}$

where $\Delta D$ is distension, $D$ is diameter and $\Delta P$ is $P P$.

The distensibility coefficient reflects the elastic properties whereas the compliance coefficient reflects the buffering capacity. From IMT, diameter and carotid distensibility, we calculated Young's elastic modulus (Einc), an indicator of the intrinsic wall properties:

$\mathrm{E}_{\mathrm{inc}}=$ diameter $/(\mathrm{IMT} *$ distensibility coefficient $)$ in $\mathrm{kPa}$.

Central Arterial Stiffness: Carotid-Femoral Transit Time, Aortic Augmentation Index (Alx), and Total Systemic Arterial Compliance

CFTT, which is a measure of aortic (thoracic-abdominal) distensibility, was measured as described elsewhere. ${ }^{17,21}$ Briefly, CFTT is the travel time of a pressure wave from the CCA to the FA and it is an approximation of the PWV. ${ }^{22}$ We determined the CFTT by continuous measurement of the diameter (distension curves) of the right CCA and FA. We then determined the average time delay (mean of three recordings) from the electrocardiograph trigger to $10 \%$ of the ascending slope of the distension curve of both arteries and subtracted the carotid value from the femoral value to obtain the CFTT. We did not measure the carotid-femoral distance non-invasively, because this might induce error in obese and older patients (tortuous aorta). Instead of measuring the carotid-femoral distance we adjusted for height in statistical analysis. Reproducibility of the CFTT has been reported. 23

The Alx represents the additional load to which the left ventricle is subjected as a result of the timing of wave reflection. In addition, the Alx depends on the heart rate amplitude and location of the reflection sites, and is a less pure estimate of arterial stiffness. ${ }^{24}$ We used radial applanation tonometry performed with a Millar piezoresistive pressure transducer connected to an arterial wave form analysis 
device (Sphygmocor) 25 to obtain the Alx and aortic PP. The Alx was calculated as augmented pressure divided by (tonometrically derived) central PP.

Total systemic arterial compliance $(\mathrm{ml} / \mathrm{mmHg})$ was determined according to the ratio of stroke volume to aortic PP. ${ }^{26}$ This method used the ratio of stroke volume to aortic PP ( $\mathrm{ml} / \mathrm{mmHg}$ ) to determine total systemic arterial compliance, for which stroke volume was calculated as cardiac output divided by heart rate, and aortic PP was calculated by use of a calibration method (vide supra). This method multiplies the difficulty in accurately determining stroke volume and PP at the ascending aorta non-invasively 27 , which means that these data should be interpreted with caution.

\section{Reproducibility}

Reproducibilities of the above mentioned methods have been reported. ${ }^{17,25}$

\section{Statistical analyses}

All analyses were carried out with SPSS. Multiple linear regression analysis was used to investigate the associations between renal function estimates and arterial properties. All associations were first analysed without adjustments and then with adjustments for potential confounders. Because the population was stratified according to age, sex and GTS, and arterial stiffness is affected by age, sex, GTS and MAP20,28, these variables were considered first in the adjusted models. We used brachial MAP for all adjustments because MAP is constant throughout the arterial tree. ${ }^{19}$ Diabetes is often accompanied with impaired renal function and arterial stiffness. Interaction terms were used to investigate whether the association between eGFR and urinary albumin excretion with arterial stiffness differed according to the presence of diabetes. Two sided $p$-values $<0.05$ were considered statistically significant.

\section{Results}

Of the 806 participants, eGFR was missing in 31 cases and UACR in 5 cases. Seven subjects were excluded because of macroalbuminuria (albuminuria $>30 \mathrm{mg} / \mathrm{mmol}$ ). The associations between eGFR and arterial stiffness were studied in the remaining 767 individuals and the association between UACR and arterial stiffness in 794 subjects. Qualitatively satisfactory examinations were obtained of 756 carotid, 689 brachial and 656 femoral arteries. The main reason for missing data was poor definition of the arterial wall attributable to obesity. Except for BMI the non-participants were comparable with the study population. 


\section{Baseline characteristics}

Tables 2.1 and 2.2 show the characteristics of the study population according to tertiles of eGFR and according to quartiles of UACR, respectively. Estimated GFR ranged from 24 to $114 \mathrm{ml} / \mathrm{min}$ per $1.73 \mathrm{~m}^{2}$. Most individuals $(\mathrm{n}=755)$ had mild to moderate CKD (stage 2 to $3 \mathrm{CKD}$ ). Three participants had severe (stage 4) CKD, and nine stage $1 \mathrm{CKD}$ (eGFR $\geq 90 \mathrm{ml} / \mathrm{min} / 1.73 \mathrm{~m}^{2}$ with (micro)albuminuria). Median UACR was $0.57 \mathrm{mg} / \mathrm{mmol}$ (range, 0.1 to $26.6 \mathrm{mg} / \mathrm{mmol}$ ).

Table 2.1 Baseline characteristics of the study population according to tertiles of eGFR.

\begin{tabular}{lcccc}
\hline $\begin{array}{l}\text { eGFR }(\text { per 1.73m²) } \\
(\mathrm{n}=767)\end{array}$ & $\begin{array}{c}264 \mathrm{ml} / \mathrm{min} \\
(\mathrm{n}=255)\end{array}$ & $\begin{array}{c}56-64 \mathrm{ml} / \mathrm{min} \\
(\mathrm{n}=256)\end{array}$ & $\begin{array}{c}<56 \mathrm{ml} / \mathrm{min} \\
(\mathrm{n}=256)\end{array}$ & $\begin{array}{c}p \\
(\text { trend })\end{array}$ \\
\hline Age, years & $67.7 \pm 7.0$ & $67.8 \pm 7.1$ & $70.0 \pm 7.0$ & $<0.001$ \\
Sex, M/F, $\mathrm{n} / \mathrm{n}$ & $124 / 131$ & $126 / 130$ & $133 / 123$ & 0.72 \\
Serum creatinine, $\mu \mathrm{mol} / \mathrm{I}$ & $84 \pm 10$ & $93 \pm 9$ & $108 \pm 20$ & $<0.001$ \\
eGFR, ml/min/1.73m² & $73 \pm 8$ & $60 \pm 2$ & $49 \pm 5$ & $<0.001$ \\
Microalbuminuria, \% & 14 & 14 & 19 & 0.16 \\
UACR, mg/mmol & $1.5 \pm 2.9$ & $1.4 \pm 2.8$ & $1.7 \pm 3.1$ & 0.48 \\
HbA1c, \% & $6.1 \pm 0.8$ & $6.0 \pm 0.7$ & $6.2 \pm 0.8$ & 0.08 \\
DM-2, \% & 38 & 41 & 40 & 0.53 \\
Impaired Glucose Metabolism, \% & 23 & 19 & 28 & 0.07 \\
Normal Glucose Metabolism, \% & 39 & 40 & 32 & 0.08 \\
BMI, kg/m & $26.0 \pm 3.4$ & $27.8 \pm 4.1$ & $29.2 \pm 4.4$ & $<0.001$ \\
Waist-to-hip ratio & $0.92 \pm 0.09$ & $0.94 \pm 0.10$ & $0.94 \pm 0.09$ & 0.01 \\
Brachial Blood Pressure, mmHg & & & & \\
$\quad$ Systolic & $140 \pm 20$ & $143 \pm 19$ & $146 \pm 20$ & 0.01 \\
Diastolic & $77 \pm 9$ & $78 \pm 9$ & $78 \pm 9$ & 0.09 \\
Mean & $98 \pm 12$ & $100 \pm 11$ & $101 \pm 11$ & 0.01 \\
$\quad$ Pulse & $64 \pm 15$ & $66 \pm 14$ & $68 \pm 16$ & 0.01 \\
Hypertension, \% & 62 & 72 & 76 & $<0.001$ \\
Anti-hypertensive medication, \% & 26 & 38 & 50 & $<0.001$ \\
Total serum cholesterol, mmol/I & $5.7 \pm 1.0$ & $5.7 \pm 1.1$ & $5.7 \pm 1.0$ & 0.81 \\
Total serum LDL, mmol/I & $3.6 \pm 0.9$ & $3.6 \pm 0.9$ & $3.6 \pm 0.9$ & 0.72 \\
Total serum HDL, mmol/l & $1.5 \pm 0.4$ & $1.4 \pm 0.4$ & $1.3 \pm 0.4$ & $<0.001$ \\
Total serum triglycerides, mmol/I & $1.4 \pm 0.8$ & $1.5 \pm 0.7$ & $1.7 \pm 1.0$ & $<0.001$ \\
Lipid-lowering medication, \% & 17 & 14 & 19 & 0.59 \\
Prior Cardiovascular Disease, \% & 47 & 45 & 51 & 0.51 \\
Current smoking, \% & 19 & 15 & 11 & 0.01 \\
\hline
\end{tabular}

Results are expressed as total numbers, mean \pm standard deviation or percentage. UACR, urinary albumin-creatinine ratio. Microalbuminuria was defined as UACR between 2 and $30 \mathrm{mg} / \mathrm{mmol}$.

\section{Arterial properties according to eGFR}

For the carotid, brachial and femoral arteries, a lower eGFR was associated with greater arterial diameter, PP and carotid IMT, whereas associations with distension were not significant. As a result, a lower eGFR was associated with lower distensibility coefficients and a greater carotid Young's elastic modulus, while associations with the compliance coefficients were not significant (Table 2.3). Lower eGFR was not associated with central arterial stiffness . 
Table 2.2 Baseline characteristics of the study population according to quartiles of urinary albumincreatinine ratio.

\begin{tabular}{lccccc}
\hline $\begin{array}{l}\text { urinary albumin-creatinine ratio } \\
\mathrm{mg} / \mathrm{mmol}(\mathrm{n}=794)\end{array}$ & $\begin{array}{c}<0.4 \\
(\mathrm{n}=202)\end{array}$ & $\begin{array}{c}0.4-0.6 \\
(\mathrm{n}=195)\end{array}$ & $\begin{array}{c}0.6-1.1 \\
(\mathrm{n}=199)\end{array}$ & $\begin{array}{c}1.1-30 \\
(\mathrm{n}=198)\end{array}$ & $\begin{array}{c}p \\
\text { (trend) }\end{array}$ \\
\hline Age, years & $66 \pm 6$ & $68 \pm 7$ & $69 \pm 7$ & $70 \pm 8$ & $<0.001$ \\
Sex, M/F, $\mathrm{n} / \mathrm{n}$ & $108 / 94$ & $82 / 113$ & $95 / 104$ & $109 / 89$ & 0.52 \\
Serum creatinine, $\mu \mathrm{mol} / \mathrm{I}$ & $98 \pm 14$ & $93 \pm 13$ & $91 \pm 13$ & $97 \pm 20$ & 0.29 \\
eGFR, ml/min/1.73m² & $58 \pm 9$ & $60 \pm 10$ & $64 \pm 12$ & $61 \pm 11$ & 0.04 \\
Microalbuminuria, \% & 0 & 0 & 0 & 60 & \\
UACR, mg/mmol & $0.3 \pm 0.1$ & $0.5 \pm 0.1$ & $0.8 \pm 0.2$ & $4.5 \pm 4.7$ & $<0.001$ \\
HbA1c, \% & $5.9 \pm 0.6$ & $6.1 \pm 0.7$ & $6.1 \pm 0.8$ & $6.2 \pm 0.8$ & $<0.001$ \\
DM-2,\% & 31 & 39 & 42 & 51 & 0.004 \\
Impaired Glucose Metabolism, \% & 23 & 22 & 23 & 23 & 0.82 \\
Normal Glucose Metabolism, \% & 46 & 39 & 35 & 26 & 0.01 \\
BMI, kg/m2 & $27.9 \pm 4.3$ & $27.6 \pm 3.8$ & $27.4 \pm 4.1$ & $28.0 \pm 4.4$ & 0.72 \\
Waist-to-hip ratio & $0.93 \pm 0.11$ & $0.92 \pm 0.10$ & $0.93 \pm 0.09$ & $0.95 \pm 0.09$ & 0.09 \\
Brachial Blood Pressure, mmHg & & & & & \\
$\quad$ Systolic & $137 \pm 18$ & $141 \pm 20$ & $145 \pm 21$ & $150 \pm 18$ & $<0.001$ \\
Diastolic & $76 \pm 9$ & $76 \pm 9$ & $78 \pm 10$ & $80 \pm 9$ & $<0.001$ \\
$\quad$ Mean & $96 \pm 10$ & $98 \pm 12$ & $100 \pm 12$ & $103 \pm 11$ & $<0.001$ \\
Pulse & $61 \pm 14$ & $65 \pm 15$ & $67 \pm 16$ & $70 \pm 15$ & $<0.001$ \\
Hypertension, \% & 61 & 66 & 71 & 80 & $<0.001$ \\
Antihypertensive medication, \% & 32 & 33 & 41 & 48 & $<0.001$ \\
Total serum cholesterol, mmol/l & $5.7 \pm 1.0$ & $5.9 \pm 1.1$ & $5.6 \pm 1.1$ & $5.6 \pm 1.0$ & 0.32 \\
Serum LDL, mmol/l & $3.6 \pm 0.9$ & $3.8 \pm 1.0$ & $3.5 \pm 0.9$ & $3.5 \pm 0.8$ & 0.02 \\
Serum HDL, mmol/l & $1.4 \pm 0.4$ & $1.4 \pm 0.4$ & $1.4 \pm 0.4$ & $1.4 \pm 0.4$ & 0.76 \\
Serum triglycerides, mmol// & $1.6 \pm 0.9$ & $1.6 \pm 0.7$ & $1.5 \pm 0.9$ & $1.6 \pm 1.0$ & 0.60 \\
Lipid lowering medication, \% & 15 & 12 & 19 & 19 & 0.41 \\
Prior Cardiovascular Disease, \% & 42 & 41 & 49 & 60 & $<0.001$ \\
Current smoking, \% & 11 & 17 & 13 & 17 & 0.58 \\
\hline
\end{tabular}

Results are expressed as total numbers, mean \pm standard deviation or percentage. UACR, urinary albumin-creatinine ratio. Microalbuminuria was defined as UACR between 2 and $30 \mathrm{mg} / \mathrm{mmol}$.

After adjustment for age, MAP, sex and GTS, a lower eGFR was inversely associated with carotid, brachial and femoral distensibility $(p=0.002, p=0.03$ and $p=0.07)$ and carotid compliance $(p=0.09)$, and directly with carotid Young's elastic modulus $(p=0.04)$. These associations were not affected by further adjustment for UACR. The association with carotid Young's elastic was not significant after additional adjustment for BMI (Table 2.4). 
Table 2.3 Arterial wall properties according to tertiles of eGFR.

\begin{tabular}{|c|c|c|c|c|}
\hline $\begin{array}{l}\text { eGFR/1.73m² } \\
(n=767)\end{array}$ & $\begin{array}{c}\geq 64 \mathrm{ml} / \mathrm{min} \\
(\mathrm{n}=255)\end{array}$ & $\begin{array}{c}56-64 \mathrm{ml} / \mathrm{min} \\
(\mathrm{n}=256)\end{array}$ & $\begin{array}{c}<56 \mathrm{ml} / \mathrm{min} \\
(\mathrm{n}=256)\end{array}$ & $\begin{array}{c}p \\
\text { (trend) }\end{array}$ \\
\hline \multicolumn{5}{|l|}{ Carotid artery } \\
\hline Diameter, mm & $7.9 \pm 1.1$ & $7.9 \pm 1.1$ & $8.1 \pm 1.0$ & 0.01 \\
\hline Distension, $\mu \mathrm{m}$ & $355 \pm 112$ & $350 \pm 114$ & $338 \pm 102$ & 0.10 \\
\hline Pulse pressure, $\mathrm{mmHg}$ & $61 \pm 15$ & $62 \pm 15$ & $65 \pm 19$ & 0.005 \\
\hline Intima-media thickness, mm & $0.85 \pm 0.17$ & $0.84 \pm 0.16$ & $0.89 \pm 0.17$ & 0.01 \\
\hline Distensibility coefficient, $10^{-3} \mathrm{kPa}^{-1}$ & $12.4 \pm 4.7$ & $11.7 \pm 4.2$ & $10.7 \pm 4.3$ & $<0.001$ \\
\hline Compliance coefficient, $\mathrm{mm}^{2} \mathrm{kPa}^{-1}$ & $0.58 \pm 0.24$ & $0.56 \pm 0.24$ & $0.54 \pm 0.21$ & 0.06 \\
\hline Young's Elastic Modulus, kPa & $0.91 \pm 0.47$ & $0.97 \pm 0.56$ & $1.02 \pm 0.47$ & 0.02 \\
\hline \multicolumn{5}{|l|}{ Brachial artery } \\
\hline Diameter, mm & $4.5 \pm 0.7$ & $4.6 \pm 0.8$ & $4.8 \pm 0.7$ & $<0.001$ \\
\hline Distension, $\mu \mathrm{m}$ & $144 \pm 66$ & $136 \pm 61$ & $151 \pm 71$ & 0.42 \\
\hline Pulse pressure, $\mathrm{mmHg}$ & $64 \pm 15$ & $65 \pm 14$ & $68 \pm 16$ & 0.01 \\
\hline Distensibility coefficient, $10^{-3} \mathrm{kPa}^{-1}$ & $8.2 \pm 4.6$ & $7.1 \pm 3.4$ & $7.4 \pm 3.8$ & 0.04 \\
\hline Compliance coefficient, $\mathrm{mm}^{2} \mathrm{kPa}^{-1}$ & $0.13 \pm 0.07$ & $0.12 \pm 0.07$ & $0.13 \pm 0.07$ & 0.70 \\
\hline Flow-mediated dilatation, \% & $3.62 \pm 3.99$ & $4.18 \pm 4.17$ & $3.66 \pm 3.36$ & 0.86 \\
\hline \multicolumn{5}{|l|}{ Femoral artery } \\
\hline Diameter, mm & $9.9 \pm 1.7$ & $10.0 \pm 1.6$ & $10.3 \pm 1.7$ & 0.004 \\
\hline Distension, $\mu \mathrm{m}$ & $200 \pm 74$ & $205 \pm 72$ & $210 \pm 77$ & 0.19 \\
\hline Pulse pressure, $\mathrm{mmHg}$ & $68 \pm 17$ & $71 \pm 17$ & $74 \pm 19$ & 0.001 \\
\hline Distensibility coefficient, $10^{-3} \mathrm{kPa}^{-1}$ & $5.0 \pm 2.5$ & $4.6 \pm 1.8$ & $4.5 \pm 2.1$ & 0.03 \\
\hline Compliance coefficient, $\mathrm{mm}^{2} \mathrm{kPa}^{-1}$ & $0.37 \pm 0.21$ & $0.35 \pm 0.16$ & $0.37 \pm 0.19$ & 0.95 \\
\hline \multicolumn{5}{|l|}{ Central artery stiffness } \\
\hline Carotid-femoral transit time, ms & $53 \pm 15$ & $55 \pm 15$ & $55 \pm 20$ & 0.35 \\
\hline Augmentation index, \% & $33 \pm 9$ & $33 \pm 9$ & $32 \pm 8$ & 0.15 \\
\hline $\begin{array}{l}\text { Total systemic arterial compliance } \\
\text { (SV/aortic PP), } \mathrm{ml} / \mathrm{mmHg}\end{array}$ & $1.03 \pm 0.36$ & $1.04 \pm 0.32$ & $1.01 \pm 0.34$ & 0.59 \\
\hline
\end{tabular}

Results are expressed as total numbers, mean \pm standard deviation or percentage. SV/aortic PP indicates stroke volume/aortic pulse pressure. Carotid-femoral transit time is shown unadjusted for height.

Table 2.5 shows that the association between a lower eGFR and greater arterial stiffness of BA and FA was driven by associations with greater arterial diameter. The association with greater carotid Einc was driven by a smaller distension of the CCA.

\section{Arterial properties according to urinary albumin excretion expressed as UACR}

For the carotid, brachial and femoral arteries, a greater UACR was associated with a greater carotid and brachial, and a smaller femoral diameter; with less carotid and femoral, and more brachial distension; with greater PP in all three arteries; and with greater carotid IMT. As a result, a greater UACR was associated with less carotid and femoral distensibility and compliance, and with a greater carotid Young's elastic modulus (Table 2.6). 


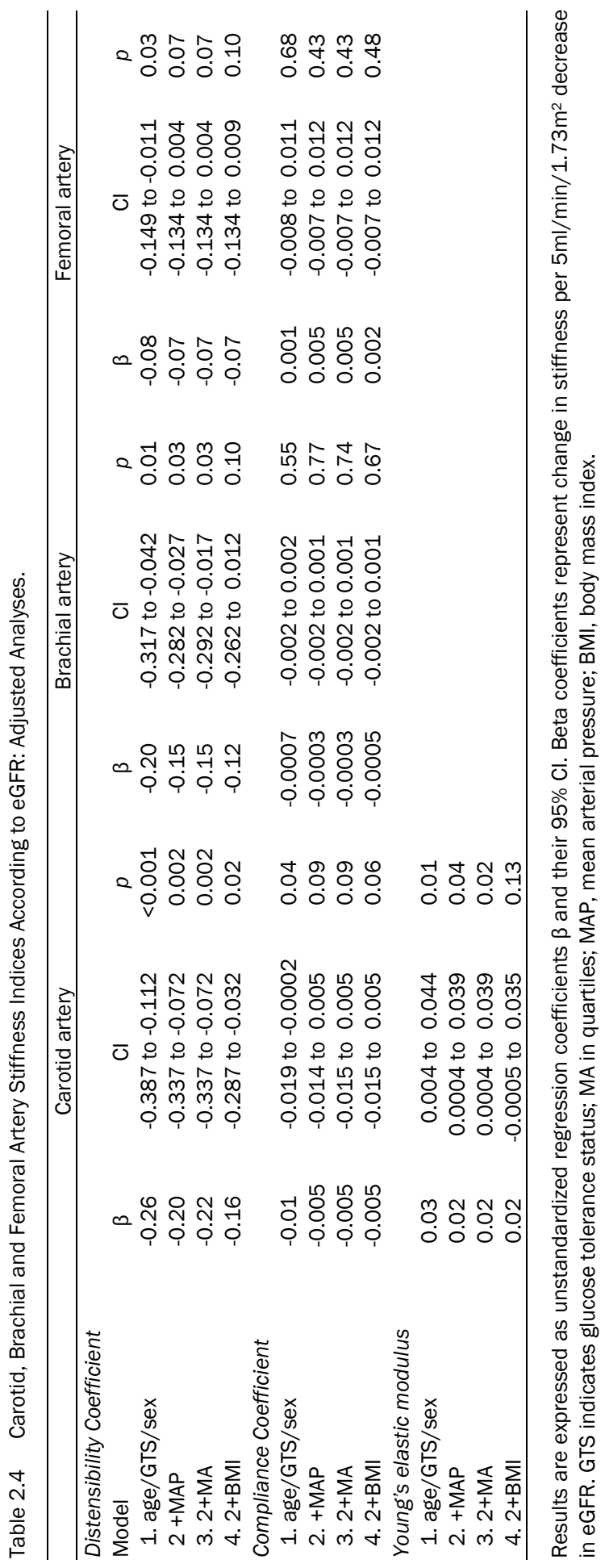




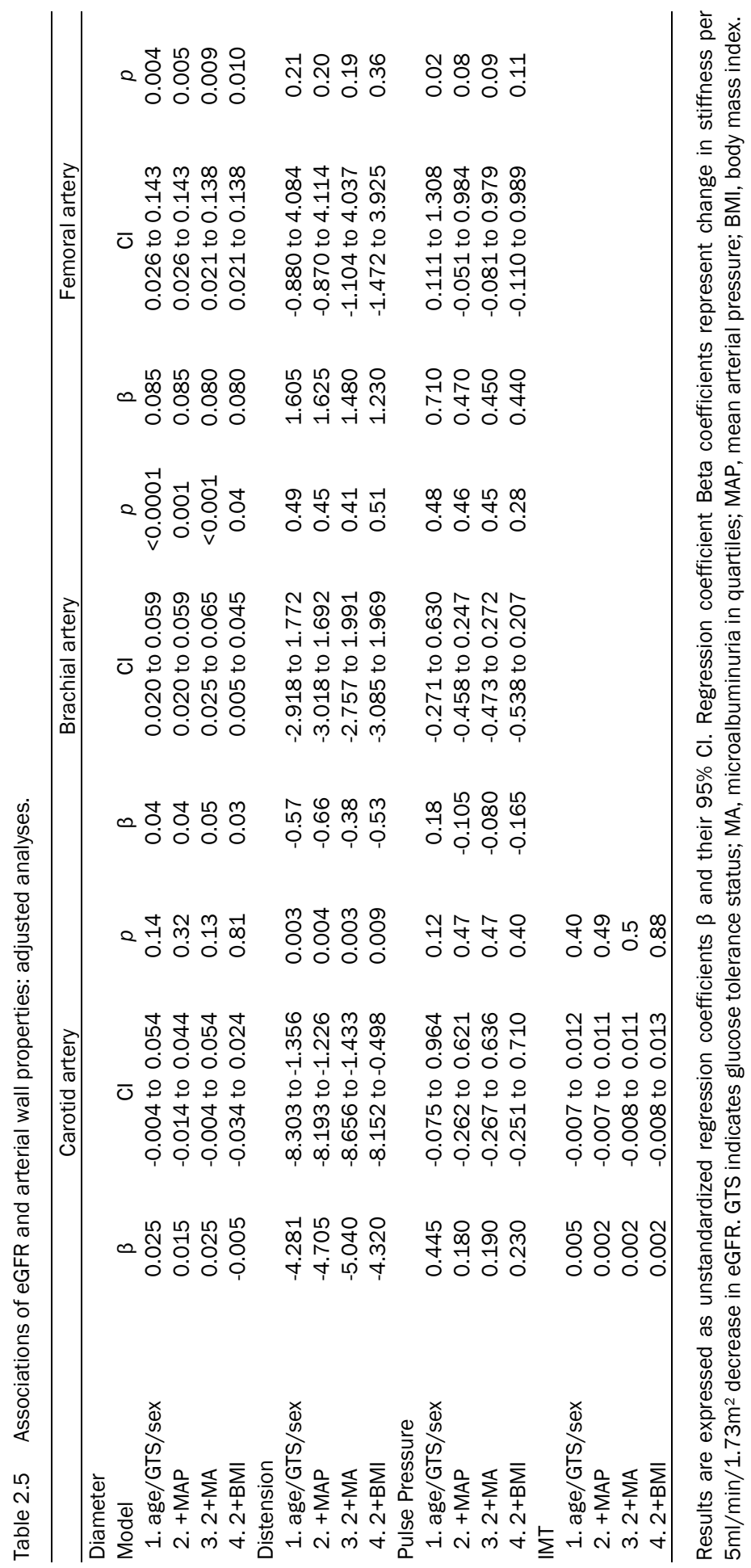


Table 2.6 Arterial wall properties according to quartiles of the urinary albumin-creatinine ratio.

\begin{tabular}{|c|c|c|c|c|c|}
\hline $\begin{array}{l}\text { urinary albumin-creatinine ratio, } \\
\mathrm{mg} / \mathrm{mmol}(\mathrm{n}=794)\end{array}$ & $\begin{array}{c}<0.4 \\
(n=202)\end{array}$ & $\begin{array}{l}0.4-0.6 \\
(n=195)\end{array}$ & $\begin{array}{l}0.6-1.1 \\
(n=199)\end{array}$ & $\begin{array}{c}1.1-30 \\
(n=198)\end{array}$ & $\begin{array}{c}p \\
\text { (trend) }\end{array}$ \\
\hline \multicolumn{6}{|l|}{ Carotid artery } \\
\hline Diameter, mm & $7.7 \pm 0.9$ & $7.8 \pm 1.0$ & $8.1 \pm 1.2$ & $8.3 \pm 1.2$ & $<0.001$ \\
\hline Distension, $\mu \mathrm{m}$ & $354 \pm 103$ & $359 \pm 116$ & $332 \pm 104$ & $340 \pm 115$ & 0.06 \\
\hline Pulse Pressure, $\mathrm{mmHg}$ & $58 \pm 14$ & $63 \pm 17$ & $64 \pm 18$ & $67 \pm 15$ & $<0.001$ \\
\hline Intima media thickness, $\mathrm{mm}$ & $0.83 \pm 0.16$ & $0.84 \pm 0.16$ & $0.87 \pm 0.16$ & $0.90 \pm 0.18$ & $<0.001$ \\
\hline Distensibility coefficient, $10^{-3} \mathrm{kPa}^{-1}$ & $13.1 \pm 4.2$ & $12.1 \pm 4.4$ & $10.8 \pm 4.5$ & $10.2 \pm 4.1$ & $<0.001$ \\
\hline Compliance coefficient, $\mathrm{mm}^{2} \mathrm{kPa}^{-1}$ & $0.59 \pm 0.23$ & $0.56 \pm 0.23$ & $0.53 \pm 0.22$ & $0.53 \pm 0.23$ & 0.01 \\
\hline Young's elastic modulus, $\mathrm{kPa}$ & $0.81 \pm 0.31$ & $0.90 \pm 0.44$ & $1.09 \pm 0.62$ & $1.10 \pm 0.63$ & $<0.001$ \\
\hline \multicolumn{6}{|l|}{ Brachial artery } \\
\hline Diameter, $\mathrm{mm}$ & $4.6 \pm 0.7$ & $4.5 \pm 0.7$ & $4.7 \pm 0.8$ & $4.8 \pm 0.7$ & 0.01 \\
\hline Distension, $\mu \mathrm{m}$ & $139 \pm 66$ & $136 \pm 59$ & $148 \pm 71$ & $150 \pm 73$ & 0.06 \\
\hline Pulse & $61 \pm 1$ & $65 \pm 15$ & $67 \pm 16$ & $70 \pm 15$ & $<0.001$ \\
\hline cient, $10^{-3} \mathrm{kPa}^{-1}$ & $8.0 \pm 4.1$ & $7.4 \pm 3.8$ & $7.5 \pm 3.9$ & $7.2 \pm 4.2$ & 0.06 \\
\hline Compliance coefficient, $\mathrm{mm}^{2} \mathrm{kPa}^{-1}$ & $0.13 \pm 0.07$ & $0.12 \pm 0.06$ & $0.13 \pm 0.07$ & $0.13 \pm 0.08$ & 0.99 \\
\hline Flow-mediated dilatation & $4.65 \pm 4.36$ & $3.46 \pm 3.51$ & $2.90 \pm 3.85$ & $3.08 \pm 3.29$ & $<0.01$ \\
\hline \multicolumn{6}{|l|}{ Femoral artery } \\
\hline Diameter, mm & $10.3 \pm 1.7$ & $10.0 \pm 1.5$ & $9.9 \pm 1.8$ & $9.9 \pm 1.7$ & 0.03 \\
\hline Distension, $\mu \mathrm{m}$ & $215 \pm 73$ & $209 \pm 72$ & $206 \pm 77$ & $190 \pm 73$ & 0.003 \\
\hline Pulse Pressure, $\mathrm{mmHg}$ & $66 \pm 16$ & $71 \pm 18$ & $71 \pm 18$ & $76 \pm 17$ & $<0.001$ \\
\hline Distensibility coefficient, $10^{-3} \mathrm{kPa}^{-1}$ & $5.1 \pm 2.2$ & $4.8 \pm 2.0$ & $4.8 \pm 2.3$ & $4.2 \pm 2.1$ & $<0.001$ \\
\hline Compliance coefficient, $\mathrm{mm}^{2} \mathrm{kPa}^{-1}$ & $0.42 \pm 0.21$ & $0.38 \pm 0.18$ & $0.36 \pm 0.19$ & $0.31 \pm 0.14$ & $<0.001$ \\
\hline \multicolumn{6}{|l|}{ Central artery stiffness } \\
\hline Carotid-femoral transit time, $\mathrm{ms}$ & $60 \pm 15$ & $55 \pm 18$ & $51 \pm 15$ & $50 \pm 17$ & $<0.001$ \\
\hline Aortic augmentation index, \% & $31 \pm 9$ & $33 \pm 8$ & $33 \pm 8$ & $34 \pm 9$ & 0.002 \\
\hline $\begin{array}{l}\text { Total systemic arterial compliance } \\
\text { (sv/aortic pp), } \mathrm{ml} / \mathrm{mmHg}\end{array}$ & $1.13 \pm 0.30$ & $1.03 \pm 0.33$ & $1.00 \pm 0.36$ & $0.94 \pm 0.33$ & $<0.001$ \\
\hline
\end{tabular}

Results are expressed as total numbers, mean \pm standard deviation or percentage. SV/aortic PP indicates stroke volume/ aortic pulse pressure. Carotid-femoral transit time is shown unadjusted for height.

After adjustment for age, sex, GTS and MAP, a greater UACR was associated with less carotid distensibility $(p=0.07)$ and with greater Young's elastic modulus ( $p=0.04$; Table 2.7). Further adjustment for eGFR, the presence of hypertension or prior cardiovascular disease slightly strengthened the associations with carotid distensibility and Young's elastic modulus (Table 2.7). Table 2.8 shows that the associations between UACR and carotid distensibility and Young's elastic modulus were driven mainly by the association with carotid diameter.

With regard to central arterial stiffness indices, a greater UACR was associated with a lower CFTT and total systemic arterial compliance, and an increase in the AIx (Table 2.6). After adjustment for age, sex, GTS and MAP, associations between UACR and measures of central arterial stiffness were not statistically significant except for the association between UACR and CFTT. Age and MAP appeared to be the strongest confounders. Further adjustments for eGFR, hypertension and prior CVD slightly weakened the association between UACR and CFTT (Table 2.9). 


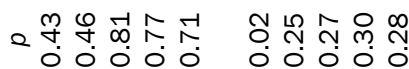

送 $\frac{\bar{t}}{\overline{5}}$

オ

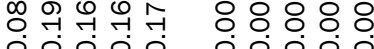

ㄸㅇㅇㅇㅇㅇㅇㅇㅇㅇㅇㅇㅇㅇㅇㅇㅇㅇ

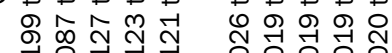

○.

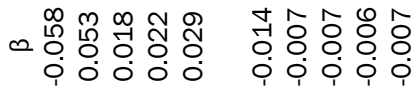

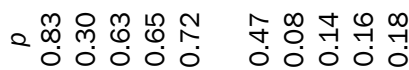

들 흠

竞

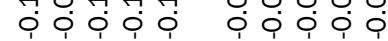

¿ัญ

की

岳

م)

要过

$\stackrel{0}{\tau}$

ఖ

응

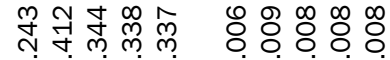

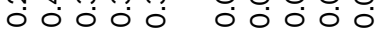

ㄴㅇㅇㅇㅇㅇㅇㅇㅇㅇㅇㅇㅇㅛ

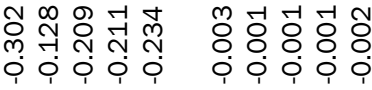

$\frac{0}{\frac{0}{2}} \frac{\bar{\sigma}}{\frac{0}{2}}$

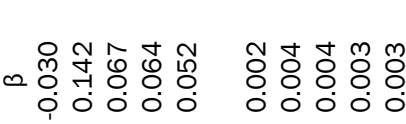

迹 $\frac{1}{00}$

要过

○े

ํำ

ํํㅁ

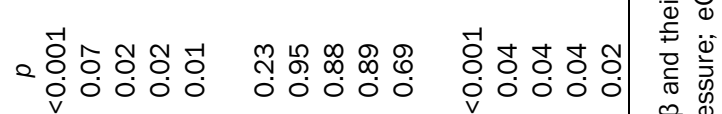

की

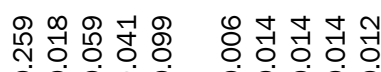

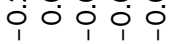

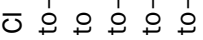

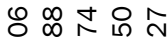

웅ㅇㅇㅇ

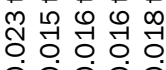

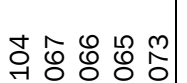

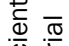

o.

○ं

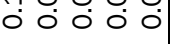

우 웅ㅇ

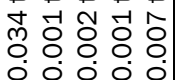

당

을

के ऐ)

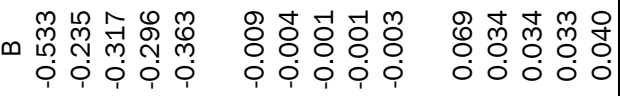

욜 
र

늈

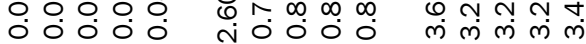

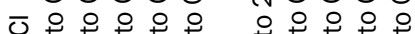

ㅇㅇㅇㅇㅇ

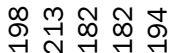

$\infty \infty$ in क व

क $m$ m

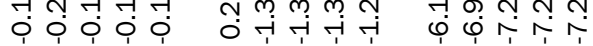

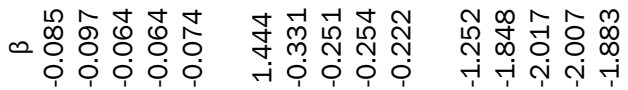

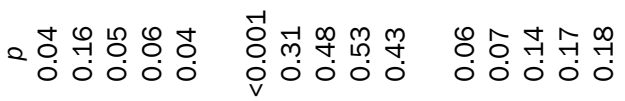

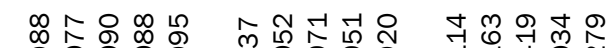

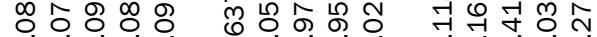

$\circ 0000$ त

$\bar{u}+\%$

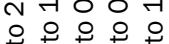

$\circ$ 요요

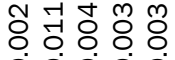

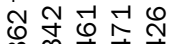

m

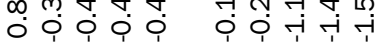

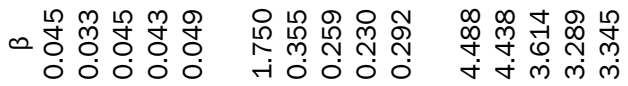

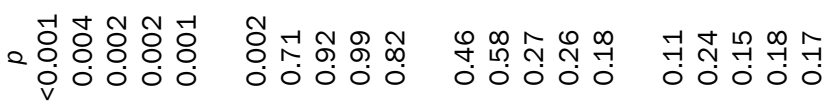

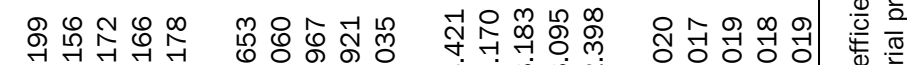
०००००

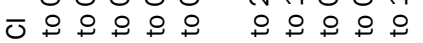

옹ㅇㅇㅇㅇ

$\begin{array}{llll}0 & 0 \\ 0 & 0 & 0 & 0 \\ 0 & 0 & 0 & 0\end{array}$

5
0
0
0

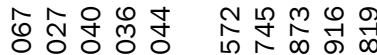

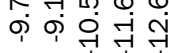

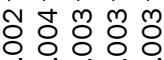

iㅇํㅇํ

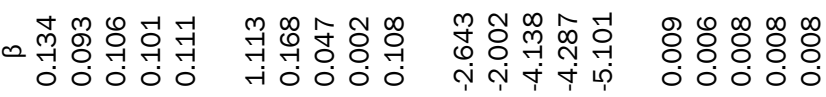

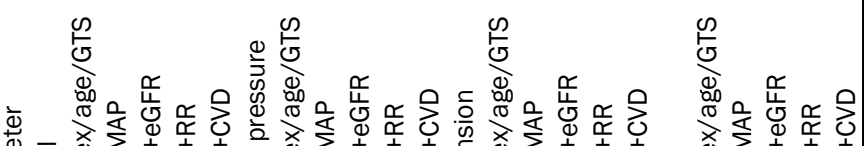

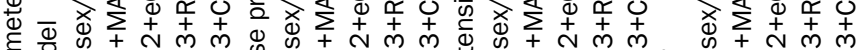

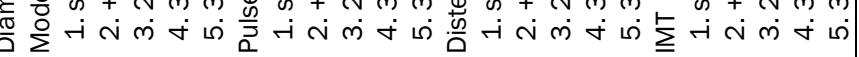


Table 2.9 Associations of urinary albumin-creatinine ratio (in quartiles) and measures of central arterial stiffness: adjusted analyses.

\begin{tabular}{lccl}
\hline Model & $\beta$ & $\mathrm{Cl}$ & $p$ \\
\hline Transit-time & -2.619 & -4.205 to -1.034 & \\
1. sex/age/GTS & -1.669 & -3.242 to -0.096 & 0.001 \\
2. +MAP & -1.550 & -3.157 to 0.057 & 0.04 \\
3. 2+eGFR & -1.502 & -3.103 to 0.099 & 0.06 \\
4. 3+RR & -1.297 & -2.939 to 0.340 & 0.07 \\
5. 3+CVD & & & 0.12 \\
Alx & 0.531 & -0.065 to 1.127 & \\
1. sex/age/GTS & 0.239 & -0.345 to 0.823 & 0.08 \\
2. +MAP & 0.242 & -0.358 to 0.843 & 0.42 \\
3. 2+eGFR & 0.245 & -0.356 to 0.846 & 0.43 \\
4. 3+RR & 0.194 & -0.413 to 0.801 & 0.42 \\
5. 3+CVD & & & \\
SAC SV/PP & -0.032 & -0.053 to -0.012 & 0.002 \\
1. sex/age/GTS & -0.012 & -0.031 to 0.007 & 0.22 \\
2. +MAP & -0.010 & -0.030 to 0.010 & 0.34 \\
3. 2+eGFR & -0.009 & -0.029 to 0.010 & 0.35 \\
4. 3+RR & -0.011 & -0.032 to 0.009 & 0.28 \\
5. 3+CVD & &
\end{tabular}

Results are expressed as unstandardized regression coefficients $\beta$ and their $95 \% \mathrm{Cl}$. Beta coefficients represents change in stiffness per quartile increase in UACR. Alx indicates, aortic augmentation index; SAC SV/PP, systemic arterial compliance estimated from stroke volume/pulse pressure; transit time, carotid-femoral transit time (adjusted for height); GTS, glucose tolerance status; MAP, mean arterial pressure; eGFR, estimated glomerular filtration rate; RR, hypertension; CVD, prior cardiovascular disease.

\section{Additional analyses}

The results did not change materially after additional adjustments for total cholesterol, triglycerides, HDL cholesterol, and LDL cholesterol; use of lipid lowering or anti-hypertensive drugs; or current smoking. With regard to the eGFR analyses, results also did not change after adjustment for prior CVD, diagnosis of hypertension, or waist-to-hip ratio. With regard to the UACR analyses, results did not change after additional adjustment for BMI or waist-to-hip ratio (data not shown). Exclusion of individuals with stage $1(n=9)$ and stage 4 CKD $(n=3)$ did not materially change the results. Furthermore, endothelial dysfunction is known to be related to arterial stiffness and to mortality in renal insufficiency. ${ }^{29,30}$ Therefore, analyses were also adjusted for flow-mediated endothelium dependent vasodilatation of the brachial artery. Also these adjustments did not materially change the results. Interaction analyses showed that the association between eGFR and urinary albumin excretion with arterial stiffness was not substantially influenced by the presence of diabetes. 


\section{Discussion}

This population-based study had four main findings. First, in mild to moderate renal insufficiency (stage 2-3 CKD) a lower eGFR as estimated by the MDRD formula was associated with greater arterial stiffness. Second, a greater urinary albumin excretion, even below levels considered to indicate microalbuminuria, was associated with greater arterial stiffness. Third, lower eGFR and greater urinary albumin excretion were mutually independently associated with a greater arterial stiffness, suggesting that the mechanisms which link these variables to risk of CVD are at least in part independent of each other. Fourth, in contrast to a greater urinary albumin excretion, eGFR was not related to greater central arterial stiffness.

Our results with respect to the association of eGFR with arterial stiffness are partially in line with previous studies. Konings et al. showed, in a small study, that the distensibility coefficient of the CCA was lower in patients with stage 2 to 4 CKD compared to controls. ${ }^{31}$ In contrast to our study, Mourad et al. showed in a population with mild renal insufficiency, a negative association between creatinine clearance and carotid-femoral pulse wave velocity (PWV). ${ }^{32}$ Wang et al. recently showed a greater aortic PWV in patients with stage 1-5 CKD. ${ }^{33} \mathrm{We}$, in agreement with a recently published study by Briet et al. ${ }^{34}$, did not find an association of CFTT, an approximation of the PWV, with eGFR. Also in agreement with that study was our finding of an independent, negative relationship between eGFR and carotid Young's elastic modulus.

In general, with declining renal function, the distensibility of the arteries decreased, while the compliance coefficient remained largely unchanged. To a large part this phenomenon was explained by a greater arterial diameter in individuals with lower eGFR, which, for the brachial and femoral artery, was independent of MAP. It is not clear why there was no relation between eGFR and carotid diameter. In fact, Briet et al. recently found an inverse relation between GFR and carotid internal diameter. The discrepancy with our results may be related to selective mortality in the Hoorn Study, as we have previously shown that both a greater carotid diameter 35 and a lower eGFR ${ }^{3,29}$ are related to increased mortality. A greater carotid diameter is thought to reflect so-called outward remodelling ${ }^{36}$ and may be a defense mechanism to prevent loss of buffering capacity in case of a decrease in distensibility. The causes of a decrease in distensibility in mild renal insufficiency remain largely unclear. In animal models, renal insufficiency is associated with an accumulation of collagen instead of elastin in the aortic wall ${ }^{37}$, and collagen represents the more rigid component of the arterial wall. ${ }^{10}$ Changes in water and salt balance ${ }^{38}$ leading to renin-angiotensin-aldosteron system activation may stimulate the collagen accumulation. ${ }^{39}$ Also other factors such as the accumulation of advanced glycosylation end products, the accumulation of asymmetric 
dimethylarginine (ADMA), an endogenous inhibitor of nitric oxide synthesis, and oxidative stress may negatively influence the distensibility of the arterial wall.40,41 We showed that greater urinary albumin excretion, even in a low-grade albuminuric range, was associated with a greater diameter and $E_{\text {inc }}$ of the CCA and a lower CFTT. In type 1 diabetic patients, several authors have shown an association between microalbuminuria and greater carotid artery stiffness. ${ }^{42,43}$ Recently Yokohama et al. found, in patients with DM-2, that albuminuria was independently associated with carotid IMT.44 This was in line with the finding of Keech et al. who showed, in patients with DM-2, that a greater urinary albumin excretion in the lowalbuminuric range was independently associated with greater carotid IMT.45 However, in agreement with Kramer et al.46, we did not find an association, either in the group as a whole or in the diabetic individuals $(n=318)$ separately (data not shown). Our finding of an association between arterial stiffness and albumin excretion below the current microalbuminuria level is in agreement with studies showing that the association between urinary albumin excretion and CVD starts at levels below microalbuminuria.7,47 Endothelial dysfunction and low-grade inflammation may be important mechanisms linking urinary albumin excretion with arterial stiffness and CVD29,30, but it remains to be shown whether the association of urinary albumin excretion and arterial stiffness actually explains that between urinary albumin excretion and CVD.

The third major finding of our study was the mutual independence of the associations of eGFR and albuminuria with arterial stiffness. This implies that both a decline in GFR and albuminuria, although they might share determinants such as hypertension and diabetes, could be independently associated with CVD in patients with CKD. Indeed, we have recently shown that the association of eGFR with cardiovascular mortality is mostly independent of urinary albumin excretion. ${ }^{29}$

A final finding of our study was that eGFR and urinary albumin excretion differed in their association with central arterial stiffness. Whereas both a lower eGFR and greater albuminuria were associated with a decrease in peripheral arterial stiffness, only greater albuminuria was associated with a lower CFTT (Figure 2.1). As stated in the foregoing, in individuals with mild to moderate renal insufficiency conflicting results exists regarding the relation of eGFR with carotid-femoral PWV. ${ }^{32-34}$ In agreement with our results, in patients with DM-248 and in hypertensive patients ${ }^{49}$, microalbuminuria has been associated with a greater carotid-femoral PWV. Again, one of the links between urinary albumin excretion and central arterial stiffness could be endothelial dysfunction and low-grade inflammation. 50 However, also after adjustment for brachial artery endothelial FMD, the associations between urinary albumin excretion and PWV remained largely unchanged. It is not clear why this relation is not seen between eGFR and central arterial stiffness. 

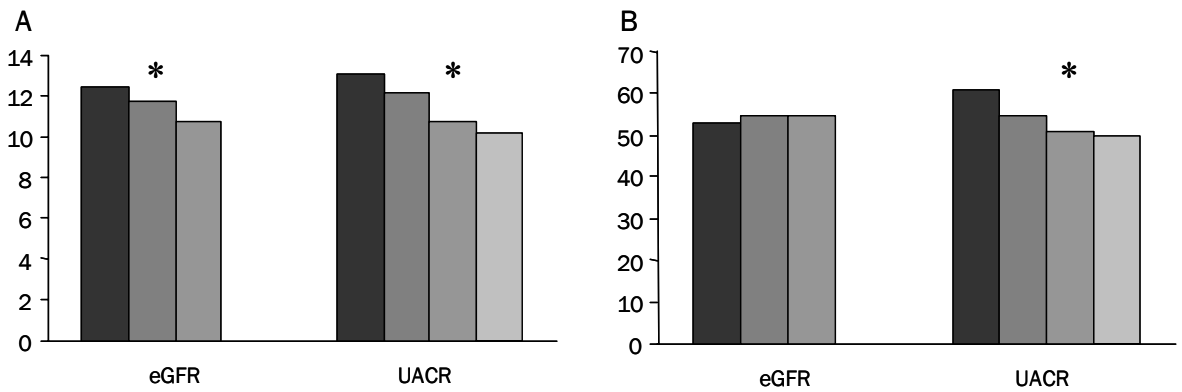

Figure 2.1 Means of distensibility coefficient of carotid artery $\left(10^{3} \mathrm{kPa}^{-1}\right)$ (A) and carotid-femoral transit time (ms) (B) according to a decrease in estimated glomerular filtratration rate (eGFR, in tertiles) and an increase in urinary albumin creatinine ratio (UACR, in quartiles). $* P$ for trend $<0.05$

The potential clinical impact of our findings can be appreciated from the following comparisons. The aortic PWV is an independent predictor of CV morbidity and mortality, and all-cause mortality. ${ }^{27}$ The change in CFTT (\%), an approximation of the PWV, per quartile of UACR was about 3\%, which was associated with an increase of CVD risk of $18 \%$ in the Rotterdam Study ${ }^{51}$, and an increase of all-cause mortality risk of 3\%.52 Although only aortic and carotid stiffness have shown to be of predictive value for CVD in CKD populations ${ }^{27}$, data on femoral artery stiffness are also of potential clinical importance. At least in patients with DM-2, femoral artery stiffness is a predictor of peripheral vascular disease.53,54 To the best of our knowledge no data exist on the relation between femoral artery stiffness and peripheral vascular disease in CKD patients.

This study had several limitations. First, the study population was relatively old. This might have caused underestimation of the relation between eGFR or urinary albumin excretion and arterial stiffness. A "healthy survivor effect" may also have weakened the associations of eGFR or urinary albumin excretion with IMT. Second, our data were cross-sectional and do not provide insight into the mechanisms that are responsible for the observed associations. Third, we studied a white population and it remains to be established whether the results can be generalized to other ethnicities.

In conclusion, in this population-based study we showed that stage 2 to 3 CKD was associated with peripheral but not central arterial stiffness. We also showed that urinary albumin excretion, even below levels conventionally considered to define microalbuminuria, was associated with greater carotid artery stiffness and a decrease in CFTT. This finding questions the current arbitrary cut-of point for microalbuminuria. Furthermore, our findings suggest that in patients with CKD both GFR and albuminuria should be interpreted as independent risk factors of CVD. 
Our data underscore the importance of adequate treatment of patients with mild renal impairment with or without albuminuria. At present, ACE-inhibitors and angiotensin receptor blockers may have the best data on preventing a decline in renal function ${ }^{55}$ and diminishing albuminuria. ${ }^{56}$ Most recently, in a hypertensive population, the combination of a calcium antagonist and an ACE inhibitor resulted in a greater lowering of central aortic pressure and a better cardiovascular outcome compared to a strategy consisting of a $\beta$-blocker plus a diuretic. ${ }^{57}$ Most important however, is a greater awareness of the importance of mild renal impairment and albuminuria for cardiovascular risk. 


\section{References}

1. K/DOQI clinical practice guidelines for chronic kidney disease: evaluation, classification, and stratification. Am J Kidney Dis. 2002;39:S1-266.

2. Foley RN, Parfrey PS, Sarnak MJ. Epidemiology of cardiovascular disease in chronic renal disease. J Am Soc Nephrol. 1998;9:S16-23.

3. Henry RM, Kostense PJ, Bos G, Dekker JM, Nijpels G, Heine RJ, Bouter LM, Stehouwer CD. Mild renal insufficiency is associated with increased cardiovascular mortality: The Hoorn Study. Kidney Int. 2002;62:1402-1407.

4. De Leeuw PW, Thijs L, Birkenhager WH, Voyaki SM, Efstratopoulos AD, Fagard RH, Leonetti G, Nachev C, Petrie JC, Rodicio JL, Rosenfeld JJ, Sarti C, Staessen JA. Prognostic significance of renal function in elderly patients with isolated systolic hypertension: results from the Syst-Eur trial. J Am Soc Nephrol. 2002;13:2213-2222.

5. Stehouwer CD, Nauta JJ, Zeldenrust GC, Hackeng WH, Donker AJ, den Ottolander GJ. Urinary albumin excretion, cardiovascular disease, and endothelial dysfunction in non-insulin-dependent diabetes mellitus. Lancet. 1992;340:319-323.

6. Hillege HL, Fidler V, Diercks GF, van Gilst WH, de Zeeuw D, van Veldhuisen DJ, Gans RO, Janssen WM, Grobbee DE, de Jong PE. Urinary albumin excretion predicts cardiovascular and noncardiovascular mortality in general population. Circulation. 2002;106:1777-1782.

7. Arnlov J, Evans JC, Meigs JB, Wang TJ, Fox CS, Levy D, Benjamin EJ, D'Agostino RB, Vasan RS. Lowgrade albuminuria and incidence of cardiovascular disease events in nonhypertensive and nondiabetic individuals: the Framingham Heart Study. Circulation. 2005;112:969-975.

8. London GM. Alterations of arterial function in end-stage renal disease. Nephron. 2000;84: 111-118.

9. Guerin AP, London GM, Marchais SJ, Metivier F. Arterial stiffening and vascular calcifications in end-stage renal disease. Nephrol Dial Transplant. 2000;15:1014-1021.

10. Safar ME, London GM, Plante GE. Arterial stiffness and kidney function. Hypertension. 2004;43:163-168.

11. Guerin AP, Blacher J, Pannier B, Marchais SJ, Safar ME, London GM. Impact of aortic stiffness attenuation on survival of patients in end-stage renal failure. Circulation. 2001;103:987-992.

12. Blacher J, Safar ME, Guerin AP, Pannier B, Marchais SJ, London GM. Aortic pulse wave velocity index and mortality in end-stage renal disease. Kidney Int. 2003;63:1852-1860.

13. Levey AS, Bosch JP, Lewis JB, Greene T, Rogers N, Roth D. A more accurate method to estimate glomerular filtration rate from serum creatinine: a new prediction equation. Modification of Diet in Renal Disease Study Group. Ann Intern Med. 1999;130:461-470.

14. Mooy JM, Grootenhuis PA, de Vries H, Valkenburg HA, Bouter LM, Kostense PJ, Heine RJ. Prevalence and determinants of glucose intolerance in a Dutch caucasian population. The Hoorn Study. Diabetes Care. 1995;18:1270-1273.

15. Spijkerman AM, Adriaanse MC, Dekker JM, Nijpels G, Stehouwer CD, Bouter LM, Heine RJ. Diabetic patients detected by population-based stepwise screening already have a diabetic cardiovascular risk profile. Diabetes Care. 2002;25:1784-1789.

16. Alberti KG, Zimmet PZ. Definition, diagnosis and classification of diabetes mellitus and its complications. Part 1: diagnosis and classification of diabetes mellitus provisional report of a WHO consultation. Diabet Med. 1998;15:539-553.

17. Henry RM, Kostense PJ, Spijkerman AM, Dekker JM, Nijpels G, Heine RJ, Kamp O, Westerhof N, Bouter LM, Stehouwer CD. Arterial stiffness increases with deteriorating glucose tolerance status: the Hoorn Study. Circulation. 2003;107:2089-2095.

18. Kelly R, Fitchett D. Noninvasive determination of aortic input impedance and external left ventricular power output: a validation and repeatability study of a new technique. J Am Coll Cardiol. 1992;20:952-963.

19. Van Bortel LM, Balkestein EJ, van der Heijden-Spek JJ, Vanmolkot FH, Staessen JA, Kragten JA, Vredeveld JW, Safar ME, Struijker Boudier HA, Hoeks AP. Non-invasive assessment of local arterial pulse pressure: comparison of applanation tonometry and echo-tracking. J Hypertens. 2001;19:1037-1044. 
20. O'Rourke MF, Staessen JA, Vlachopoulos C, Duprez D, Plante GE. Clinical applications of arterial stiffness; definitions and reference values. Am J Hypertens. 2002;15:426-444.

21. Schram MT, Henry RM, van Dijk RA, Kostense PJ, Dekker JM, Nijpels G, Heine RJ, Bouter LM, Westerhof N, Stehouwer CD. Increased central artery stiffness in impaired glucose metabolism and type 2 diabetes: the Hoorn Study. Hypertension. 2004;43:176-181.

22. Nichols WW, O'Rourke, M.F. McDonald's Blood Flow in Arteries. In: Arnold E, ed. London; 1998.

23. van Dijk RA, van Ittersum FJ, Westerhof N, van Dongen EM, Kamp O, Stehouwer CD. Determinants of brachial artery mean $24 \mathrm{~h}$ pulse pressure in individuals with Type II diabetes mellitus and untreated mild hypertension. Clin Sci (Lond). 2002;102:177-186.

24. Davies JI, Struthers AD. Pulse wave analysis and pulse wave velocity: a critical review of their strengths and weaknesses. J Hypertens. 2003;21:463-472.

25. Pannier BM, Avolio AP, Hoeks A, Mancia G, Takazawa K. Methods and devices for measuring arterial compliance in humans. Am J Hypertens. 2002;15:743-753.

26. Chemla D, Hebert JL, Coirault C, Zamani K, Suard I, Colin P, Lecarpentier Y. Total arterial compliance estimated by stroke volume-to-aortic pulse pressure ratio in humans. Am J Physiol. 1998;274:H500-505.

27. Laurent S, Cockcroft J, Van Bortel L, Boutouyrie P, Giannattasio C, Hayoz D, Pannier B, Vlachopoulos C, Wilkinson I, Struijker-Boudier H. Expert consensus document on arterial stiffness: methodological issues and clinical applications. Eur Heart J. 2006;27:2588-2605.

28. De Angelis L, Millasseau SC, Smith A, Viberti G, Jones RH, Ritter JM, Chowienczyk PJ. Sex differences in age-related stiffening of the aorta in subjects with type 2 diabetes. Hypertension. 2004;44:67-71.

29. Stam F, van Guldener C, Becker A, Dekker JM, Heine RJ, Bouter LM, Stehouwer CD. Endothelial dysfunction contributes to renal function-associated cardiovascular mortality in a population with mild renal insufficiency: the Hoorn study. J Am Soc Nephrol. 2006;17:537-545.

30. Amabile N, Guerin AP, Leroyer A, Mallat Z, Nguyen C, Boddaert J, London GM, Tedgui A, Boulanger CM. Circulating endothelial microparticles are associated with vascular dysfunction in patients with end-stage renal failure. J Am Soc Nephrol. 2005;16:3381-3388.

31. Konings CJ, Dammers R, Rensma PL, Kooman JP, Hoeks AP, Kornet L, Gladziwa U, van der Sande FM, Leunissen KM. Arterial wall properties in patients with renal failure. Am J Kidney Dis. 2002;39:1206-1212.

32. Mourad JJ, Pannier B, Blacher J, Rudnichi A, Benetos A, London GM, Safar ME. Creatinine clearance, pulse wave velocity, carotid compliance and essential hypertension. Kidney Int. 2001;59:1834-1841.

33. Wang MC, Tsai WC, Chen JY, Huang JJ. Stepwise increase in arterial stiffness corresponding with the stages of chronic kidney disease. Am J Kidney Dis. 2005;45:494-501.

34. Briet M, Bozec E, Laurent S, Fassot C, London GM, Jacquot C, Froissart M, Houillier P, Boutouyrie P. Arterial stiffness and enlargement in mild-to-moderate chronic kidney disease. Kidney Int. 2006;69:350-357.

35. van Dijk RA, Dekker JM, Nijpels G, Heine RJ, Bouter LM, Stehouwer CD. Brachial artery pulse pressure and common carotid artery diameter: mutually independent associations with mortality in subjects with a recent history of impaired glucose tolerance. Eur J Clin Invest. 2001;31: 756-763.

36. Ward MR, Pasterkamp G, Yeung AC, Borst C. Arterial remodeling. Mechanisms and clinical implications. Circulation. 2000;102:1186-1191.

37. Amann K, Neususs R, Ritz E, Irzyniec T, Wiest G, Mall G. Changes of vascular architecture independent of blood pressure in experimental uremia. Am J Hypertens. 1995;8:409-417.

38. Safar ME, Thuilliez C, Richard V, Benetos A. Pressure-independent contribution of sodium to large artery structure and function in hypertension. Cardiovasc Res. 2000;46:269-276.

39. Blacher J, Amah G, Girerd X, Kheder A, Ben Mais H, London GM, Safar ME. Association between increased plasma levels of aldosterone and decreased systemic arterial compliance in subjects with essential hypertension. Am J Hypertens. 1997;10:1326-1334.

40. London GM, Guerin AP, Pannier B, Marchais SJ, Safar ME. Large artery structure and function in hypertension and end-stage renal disease. J Hypertens. 1998;16:1931-1938. 
41. London GM, Guerin AP, Marchais SJ, Pannier B, Safar ME, Day M, Metivier F. Cardiac and arterial interactions in end-stage renal disease. Kidney Int. 1996;50:600-608.

42. Lambert J, Smulders RA, Aarsen M, Donker AJ, Stehouwer CD. Carotid artery stiffness is increased in microalbuminuric IDDM patients. Diabetes Care. 1998;21:99-103.

43. Giannattasio C, Failla M, Piperno A, Grappiolo A, Gamba P, Paleari F, Mancia G. Early impairment of large artery structure and function in type I diabetes mellitus. Diabetologia. 1999;42:987-994.

44. Yokoyama H, Aoki T, Imahori M, Kuramitsu M. Subclinical atherosclerosis is increased in type 2 diabetic patients with microalbuminuria evaluated by intima-media thickness and pulse wave velocity. Kidney Int. 2004;66:448-454.

45. Keech AC, Grieve SM, Patel A, Griffiths K, Skilton M, Watts GF, Marwick TH, Groshens M, Celermajer DS. Urinary albumin levels in the normal range determine arterial wall thickness in adults with Type 2 diabetes: a FIELD substudy. Diabet Med. 2005;22:1558-1565.

46. Kramer H, Jacobs DR, Jr., Bild D, Post W, Saad MF, Detrano R, Tracy R, Cooper R, Liu K. Urine albumin excretion and subclinical cardiovascular disease. The Multi-Ethnic Study of Atherosclerosis. Hypertension. 2005;46:38-43.

47. Gerstein HC, Mann JF, Yi Q, Zinman B, Dinneen SF, Hoogwerf B, Halle JP, Young J, Rashkow A, Joyce C, Nawaz S, Yusuf S. Albuminuria and risk of cardiovascular events, death, and heart failure in diabetic and nondiabetic individuals. JAMA. 2001;286:421-426.

48. Smith A, Karalliedde J, De Angelis L, Goldsmith D, Viberti G. Aortic pulse wave velocity and albuminuria in patients with type 2 diabetes. J Am Soc Nephrol. 2005;16:1069-1075.

49. Mule G, Cottone S, Vadala A, Volpe V, Mezzatesta G, Mongiovi R, Piazza G, Nardi E, Andronico G, Cerasola G. Relationship between albumin excretion rate and aortic stiffness in untreated essential hypertensive patients. J Intern Med. 2004;256:22-29.

50. Kinlay S, Creager MA, Fukumoto M, Hikita H, Fang JC, Selwyn AP, Ganz P. Endothelium-derived nitric oxide regulates arterial elasticity in human arteries in vivo. Hypertension. 2001;38:10491053.

51. Mattace-Raso FU, van der Cammen TJ, Hofman A, van Popele NM, Bos ML, Schalekamp MA, Asmar R, Reneman RS, Hoeks AP, Breteler MM, Witteman JC. Arterial stiffness and risk of coronary heart disease and stroke: the Rotterdam Study. Circulation. 2006;113:657-663.

52. Willum-Hansen T, Staessen JA, Torp-Pedersen C, Rasmussen S, Thijs L, Ibsen H, Jeppesen J. Prognostic value of aortic pulse wave velocity as index of arterial stiffness in the general population. Circulation. 2006;113:664-670.

53. Kizu A, Koyama H, Tanaka S, Maeno T, Komatsu M, Fukumoto S, Emoto M, Shoji T, Inaba M, Shioi A, Miki T, Nishizawa Y. Arterial wall stiffness is associated with peripheral circulation in patients with type 2 diabetes. Atherosclerosis. 2003;170:87-91.

54. Taniwaki H, Shoji T, Emoto M, Kawagishi T, Ishimura E, Inaba M, Okuno Y, Nishizawa Y. Femoral artery wall thickness and stiffness in evaluation of peripheral vascular disease in type 2 diabetes mellitus. Atherosclerosis. 2001;158:207-214.

55. Ruggenenti P. Angiotensin-converting enzyme inhibition and angiotensin II antagonism in nondiabetic chronic nephropathies. Semin Nephrol. 2004;24:158-167.

56. Parving HH, Andersen S, Jacobsen P, Christensen PK, Rossing K, Hovind P, Rossing P, Tarnow L. Angiotensin receptor blockers in diabetic nephropathy: renal and cardiovascular end points. Semin Nephrol. 2004;24:147-157.

57. Williams B, Lacy PS, Thom SM, Cruickshank K, Stanton A, Collier D, Hughes AD, Thurston H, O'Rourke M. Differential impact of blood pressure-lowering drugs on central aortic pressure and clinical outcomes: principal results of the Conduit Artery Function Evaluation (CAFE) study. Circulation. 2006;113:1213-1225. 


\section{Chapter 3}

Spatial inhomogeneity of common carotid artery intima media is increased in dialysis patients

MMH Hermans, JP Kooman, V Brandenburg, M Ketteler, JGMC Damoiseaux, JW Cohen Tervaert, I Ferreira, PL Rensma, U Gladziwa, AA Kroon, APG Hoeks, CDA Stehouwer, KML Leunissen

Nephrology Dialysis Transplantation. 2007;22:1205-1212 


\section{Abstract}

\section{Background}

Structural abnormalities of the common carotid artery (CCA), as assessed by ultrasound techniques are related to cardiovascular outcome in dialysis patients. An increased intima media thickness (IMT) of the CCA may both represent a reaction to a hemodynamic burden as well as atherosclerosis. With a new ultrasound technique CCA-IMT and IMT-inhomogeneity, a novel parameter of spatial variance of the IMT, were measured and related to traditional and non-traditional risk factors.

\section{Methods}

In a cross-sectional study we included 134 dialysis patients, aged $61 \pm 13$ years (103 on hemodialysis, 31 on peritoneal dialysis) and 41 controls, aged $60 \pm 8$ years. Age, sex, pulse pressure, diabetes, prevalent cardiovascular disease (CVD) and height were included in the basic multiregression analysis. Ultrasound examination of the CCA was performed. We also measured serum fetuin-A, high-sensitivity Creactive protein (hsCRP), antibodies to oxidized low density lipoproteins (anti-oxLDL antibodies), calcium, phosphate, albumin and parathyroid hormone.

\section{Results}

Compared to controls, dialysis patients had a greater CCA-IMT ( $670 \mu \mathrm{m}$ vs. $590 \pm 10 \mu \mathrm{m} ; p=0.002$ ) and a greater CCA-IMT inhomogeneity (11.0 vs. $8.1 \%$; $p=0.013$ ). Dialysis patients with CVD had a greater CCAIMT (734 $\mu \mathrm{m}$ vs. $631 \mu \mathrm{m} ; p=0.001)$ and IMT-inhomogeneity (13.2 vs. 9.7; $p=0.008)$ compared to patients without CVD. IMT-inhomogeneity strongly correlated with IMT $(r=0.65, p<0.0001)$. In multiregression analysis, serum fetuin-A and anti-oxLDL antibodies correlated with IMT-inhomogeneity but not with IMT. HsCRP neither correlated with IMT-inhomogeneity nor with IMT.

\section{Conclusion}

The present study shows that CCA-IMT and IMT-inhomogeneity were increased in dialysis patients compared to controls. Although CCA-IMT and IMT-inhomogeneity are related, the different associations between both measurements and non-traditional risk factors show that they are distinct entities. 


\section{Introduction}

Cardiovascular mortality is greatly increased in dialysis patients, the mean risk of cardiovascular death being thirty times higher than in the general population. ${ }^{1}$

Structural abnormalities of the large arteries as assessed by echographic techniques in dialysis patients are related to cardiovascular outcome. ${ }^{2}$ An increased common carotid artery intima media thickness (CCA-IMT), is considered to be a marker of atherosclerosis. ${ }^{3}$ However, only values above $900 \mu \mathrm{m}$ are considered to represent atherosclerosis. ${ }^{4}$ Moreover, in dialysis patients only IMT values above $1.0 \mathrm{~mm}$ predicted cardiovascular mortality. ${ }^{2}$ Despite their greatly increased cardiovascular risk, several studies have shown that in most dialysis patients CCA-IMT values are well below $1.0 \mathrm{~mm} .5-8$ In some studies, even no difference in CCA-IMT between patients and controls was observed. ${ }^{6-8}$ Among other reasons, this may be due to the relative insensitivity of the commonly used measurement techniques, which either assess IMT at a single-point, or average IMT thickness along an arterial segment. 9 The latter method may be more sensitive than single-point measurement, but advanced lesions (atheroma) and fully developed plaques tend to be localized at specific sites ${ }^{10}$, which is obscured by averaging over relatively long arterial segments.

Recently, a new technique has been developed which is able to detect local inhomogeneities in the IMT by assessing the spatial variance of IMT over an arterial segment. ${ }^{11}$ Application of this technique might increase the sensitivity of IMT measurements and enable the detection of focal atherosclerotic lesions at an earlier stage in the development. Local inhomogeneities of CCA-IMT have not yet been assessed in dialysis patients, or in other patient populations with cardiovascular disease. Given the greatly increased prevalence of cardiovascular disease in dialysis patients, it would appear rational to study this novel parameter in this population.

Cardiovascular disease in dialysis patients is related to traditional and nontraditional risk factors. ${ }^{12}$ Both C-reactive protein (CRP) ${ }^{13}$ and fetuin-A, a potent circulating calcification inhibitor ${ }^{14,15}$ are non-traditional risk factors related to cardiovascular mortality in dialysis patients. Moreover in dialysis patients, a higher CRP is associated with a greater CCA-IMT16 and a lower serum fetuin-A is associated with greater coronary artery calcification. ${ }^{17}$ Oxidative stress as measured by the presence of IgG antibodies to oxidized low-density lipoproteins (oxLDL) is associated with atherosclerosis in the general population ${ }^{18,19}$, but its role as a non-traditional risk factor in uremic patients is less clear. ${ }^{20}$

The aim of the present study was to study the difference in CCA-IMT and inhomogeneities in CCA-IMT between dialysis patients and controls. Secondly, the associations between the IMT and inhomogeneity measurements and several traditional risk factors, as well as anti-oxLDL antibodies, serum fetuin-A levels and high sensitive CRP (hsCRP) were studied. 


\section{Materials and methods}

\section{Subjects and study design}

We performed a cross-sectional study in 134 stable, all but two Caucasian, dialysis patients, undergoing hemodialysis (HD; $n=103,77 \%$ ) or peritoneal dialysis (PD; $n=31,23 \%)$, from three dialysis centres.

End-stage renal disease (ESRD) patients were eligible when they had been on dialysis for more than three months. Patients with an underlying malignancy, infection or heart failure were excluded.

The age- and sex-matched control group $(n=41)$ consisted of spouses and healthy staff members. Controls had to have a negative cardiovascular medical history including hypertension. Cardiovascular disease (CVD) was defined as the presence or history of ischemic heart disease, peripheral vascular disease and/or a cerebrovascular event. Hypertension was defined as a blood pressure $\geq 140 \mathrm{mmHg}$ systolic and/or $\geq 90 \mathrm{mmHg}$ diastolic according to the JNC VII criteria ${ }^{21}$ and/or the current use of antihypertensive medication. In controls renal function was estimated by the modified MDRD formula in $\mathrm{ml} / \mathrm{min}$ and expressed per $1.73 \mathrm{~m}^{2}$ body surface area. ${ }^{22}$ Fasting plasma glucose levels $\geq 7.0 \mathrm{mmol} / \mathrm{I}$ were considered diagnostic for diabetes mellitus.

All participants gave their written informed consent. The study protocol was designed in adherence to the declaration of Helsinki and approved by the ethical committees of the participating centres.

\section{Carotid artery properties}

Structural properties of the carotid artery were obtained by one trained vascular sonographer and assessed with the use of a $7.5 \mathrm{MHz}$ linear array transducer connected to an ultrasound scanner (Picus, Esaote, Maastricht, the Netherlands). The method has been described previously11,23 but was adapted for this study. In short, using standard B-mode the right common carotid artery and the bifurcation was scanned for plaques; hereafter the region of interest $(2-3 \mathrm{~cm}$ proximal to the carotid flow divider) was identified. The ultrasound system was then switched to fast B-mode with a considerably lower echo line density (14 lines covering $16.4 \mathrm{~mm})$, favouring a substantially higher frame update rate $(671 \mathrm{~Hz})$. The radio frequency (RF) signal of the echo system was captured for a time segment of five seconds by a 12 bit data acquisition system with a conversion frequency of $33 \mathrm{MHz}$. and stored on hard disk for further processing. Off-line the RF data were recalled and transformed to a complex format using the Hilbert transform, facilitating the computation of the instantaneous echo-amplitude as function of depth and echo line position which results in an echo image where the amplitude is retained on a linear scale (Figure 3.1). For this study only the images coincident with the R-top of the simultaneously recorded ECG were used for further analysis. 
The adventitia-media and lumen-intima echo transitions of the posterior wall were identified manually, resulting in estimates for the intima-media thickness IMT ( $p, b)$ as function of echo-line position $p$ and beat $b$. Subsequently the IMT was averaged over all considered beats. The processing procedure is completed with the computation of the average and the standard deviation of the estimated IMT over echo-line position. The standard deviation of the spatial distribution of the IMT is used as a measure for the spatial inhomogeneity. Lumen diameter (LD) was calculated from interadventitial diameter (IAD) and IMT as LD = IAD - (2 * IMT).
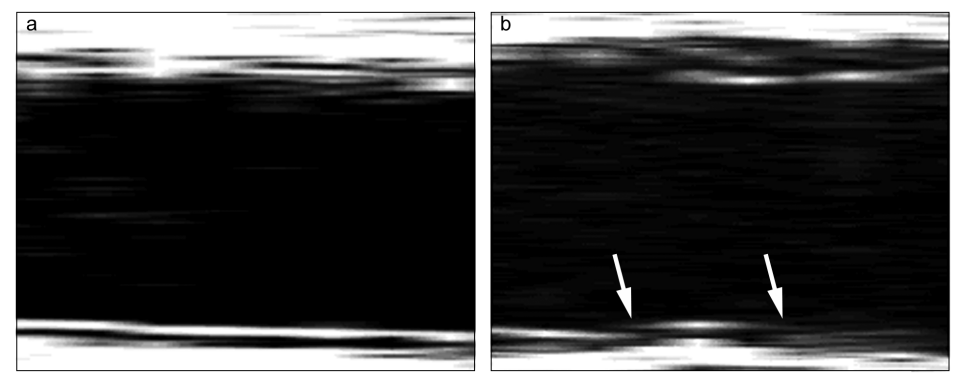

Figure 3.1 B-mode images of the common carotid artery showing a 60-yr old healthy control with a homogeneous aspect of the intima media (a) and a 63-yr old dialysis patient with an inhomogeneous aspect of the intima media with arrows indicating "lesions" of the intima media (b).

\section{Feasibility of measurements}

Of the 134 dialysis patients, CCA-IMT measurement was successful in 128 patients (96\%). Measurement failure was due to a poor visualization quality of the CCA-IMT, mostly in obese patients. Two patients were excluded from analysis because of missing blood samples.

\section{Blood pressure measurement}

Brachial systolic and diastolic pressures were assessed at three minutes intervals with a radial artery tonometrical device (CBM 7000, Colin Medial Instruments, San Antonio, Texas, USA) on the right arm or in case of a right-sided dialysis shunt on the left arm. Mean arterial pressure (MAP) was calculated from the mean of three systolic and diastolic pressures as diastolic pressure + pulse pressure/3, with pulse pressure defined as the difference between systolic and diastolic pressure.

\section{Laboratory analysis}

In the patient group, serum calcium (Ca), phosphate $(\mathrm{P})$ albumin and cholesterol were measured using standard laboratory techniques. In the HD group samples were taken at the start of a short-interval hemodialysis. Time-averaged values of 
$\mathrm{Ca}, \mathrm{P}$ and albumin were calculated as the mean of the routine six weekly measurements of the previous six months. Calcium concentration was calculated after correction for albumin. Intact parathyroid hormone (iPTH) was measured by a two-site chemiluminescence immunoassay (Nichols Institute Diagnostics B.V.; Nijmegen; The Netherlands).

In both groups hsCRP and fetuin-A were measured by nephelometry. Serum was harvested by centrifugation of clotted blood. Serum samples were stored at $-80^{\circ} \mathrm{C}$ prior to analysis. Serum analysis for hsCRP were performed by means of particle enhanced immunonephelometry using a standard "CardioPhase hsCRP" for "BNII" (Dade Behring Holding GmbH, D-65835 Liederbach, Germany). CRPI or CRPII assay protocols were used when appropriate. Interday precision controls revealed coefficience of variance (CV) below $6 \%$.

The nephelometry method for fetuin-A employs the same high specifity antibody as the ELISA method ${ }^{14,24}$ and has been described elsewhere.25 Briefly, the measurement has been evaluated in a side-by-side comparison with immunoblot analysis to exclude cross-reactivity of the antibodies with other serum proteins and proteolytic fragments of fetuin-A. Cross-reaction with fetuin-B was excluded. The assay linear measurement range of human fetuin-A is $0.05 \mathrm{~g} / \mathrm{I}$ up to $3.5 \mathrm{~g} / \mathrm{l}$. The within-run precision obtained from a 20-fold measurement of identical samples yielded a VC of $7.75 \%$. The day-to-day precision obtained from repetitive measurements of control serum was determined as a CV of $8.2 \%$.

Anti-oxLDL antibodies measurement has been previously described. ${ }^{26}$ Briefly, LDL was isolated from the plasma of a healthy subject in a potassium bromide discontinuous gradient according to Redgrave et al. ${ }^{27}$ The LDL content was determined according to Lowry et al. ${ }^{28}$ Malondialdehyde modification (MDA-LDL) was used to oxidize LDL. Specific IgG anti-oxLDL antibodies in patient serum were detected by ELISA and wells were deferentially coated with MDA-LDL and native LDL. Results are expressed as mean anti-oxLDL levels in optical density (OD) and were calculated by subtracting binding to native LDL from binding to oxLDL.

\section{Statistical analysis}

Normally distributed variables are expressed as mean \pm SD, and non-normally distributed variables as median and inter-quartile range (IQR), with $p<0.05$ indicating significance. Non-normally distributed variables were log-transformed for further analysis. Differences in mean values between groups were compared with ttests for continuous and with chi-squared tests for categorized variables. Univariate and multiple linear regression analyses were used to investigate the association between traditional and non-traditional risk factors and IMT and IMTinhomogeneity. Multiple linear models used to investigate the association between non-traditional risk factors and CCA-IMT and CCA inhomogeneity were first adjusted 
for age, sex, pulse pressure, diabetes, cardiovascular disease and height (model 1). We then investigated the potential confounding and/or mediating effects of inflammation, oxidative stress, calcium-phosphate metabolism and fetuin-A, by adding log-hsCRP, anti-oxLDL antibodies, $\mathrm{Ca}, \mathrm{P}$ and $\mathrm{Ca}$ * $\mathrm{P}$ product and fetuin-A to the initial model (model 2-4). Finally, confounding and/or mediation effect of IMT in the associations with IMT-inhomogeneity was investigated by adding IMT to the regression model of the IMT-inhomogeneity analysis (model 5).

\section{Results}

The characteristics of the dialysis group and the controls are shown in Table 3.1. Baseline laboratory values of the dialysis patients are shown in Table 3.2. The major causes of stage 5 chronic kidney disease were diabetes in $17 \%$, nephrosclerosis in 38\%, and glomerulonephritis in $18 \%$ of the patients. Compared to controls, dialysis patients had a larger CCA-lumen diameter, CCA-IMT and IMT inhomogeneity (Table 3.2 and Figure 3.2). Compared to dialysis patients without prevalent cardiovascular disease, patients with cardiovascular disease had a greater IMT $(734 \pm 178 \mu \mathrm{m}$ vs. $631 \pm 136 \mu \mathrm{m} ; p=0.001)$ and a greater IMTinhomogeneity $(13.2 \pm 9.1 \%$ vs. $9.7 \pm 5.4 \% ; p=0.008)$ of the common carotid artery (Figure 3.3). A ROC analysis showed an area under the curve for the prediction of prevalent CVD of $0.63(95 \% \mathrm{Cl} ; 0.53$ to $0.74: p=0.012)$ for IMT-inhomogeneity and of 0.68 (95\% Cl; 0.58 to $0.78: p=0.001)$ for IMT.

Table 3.1 Characteristics of dialysis patients (HD and PD) and controls.

\begin{tabular}{lccc}
\hline & $\begin{array}{c}\text { Controls } \\
(\mathrm{n}=41)\end{array}$ & $\begin{array}{c}\text { Dialysis patients } \\
(\mathrm{n}=126)\end{array}$ & $\begin{array}{c}\text { Controls vs. Patients } \\
(p \text {-value })\end{array}$ \\
\hline Age, years & $60 \pm 8$ & $61 \pm 13$ & 0.55 \\
Sex, \% male & 44 & 55 & 0.33 \\
BMI, kg/m ${ }^{2}$ & $25.5 \pm 3.5$ & $24.8 \pm 4.5$ & \\
Brachial BP, mmHg & $134 \pm 17$ & $138 \pm 21$ & 0.23 \\
Systolic & $75 \pm 8$ & $74 \pm 10$ & 0.35 \\
Diastolic & $95 \pm 10$ & $95 \pm 12$ & 0.85 \\
Mean & $59 \pm 12$ & $65 \pm 18$ & 0.043 \\
Pulse pressure & 27 & 26 & $<0.001$ \\
Smoking, \% & 34 & 82 & $<0.001$ \\
Hypertension, \% & 0 & 30 & 0.002 \\
Diabetes, \% & 0 & 38 & 0.013 \\
CVD, \% & $5.81 \pm 0.71$ & $6.82 \pm 1.04$ & \\
CCA, LD,mm & $590 \pm 10$ & $670 \pm 16$ & \\
CCA-IMT, $\mu m$ & $8.1 \pm 3.7$ & $11.0 \pm 7.2$ & \\
CCA, inhomogeneity, \% & & & \\
\hline
\end{tabular}

Data are mean values \pm SD. PD, peritoneal dialysis; HD, hemodialysis; CVD, cardiovascular disease; CCA, common carotid artery; LD, lumen diameter; IMT, intima media thickness. 
Table 3.2 Baseline laboratory characteristics of dialysis patients $(n=126)$.

\begin{tabular}{lc}
\hline Calcium (Ca), mmol/l & $2.48 \pm 0.16$ \\
Phosphate (P), mmol/I & $1.75 \pm 0.30$ \\
Ca x P product, mmol ${ }^{2} \mathrm{I}^{2}$ & $4.34 \pm 0.76$ \\
Intact Parathroid hormone, pmol//a $^{\text {Albumin, g/l }}$ & $18.0(0.0-121)$ \\
High-sensitivity C-reactive protein, $\mathrm{mg} / \mathrm{la}^{\mathrm{a}}$ & $36.4 \pm 4.6$ \\
Fetuin-A, g/l & $3.8(0.1-89.2)$ \\
Anti-oxLDL antibodies, mean OD & $0.63 \pm 0.16$ \\
\hline
\end{tabular}

Continuous values are mean $\pm \mathrm{SD}$; a median and range; OD, optical density.
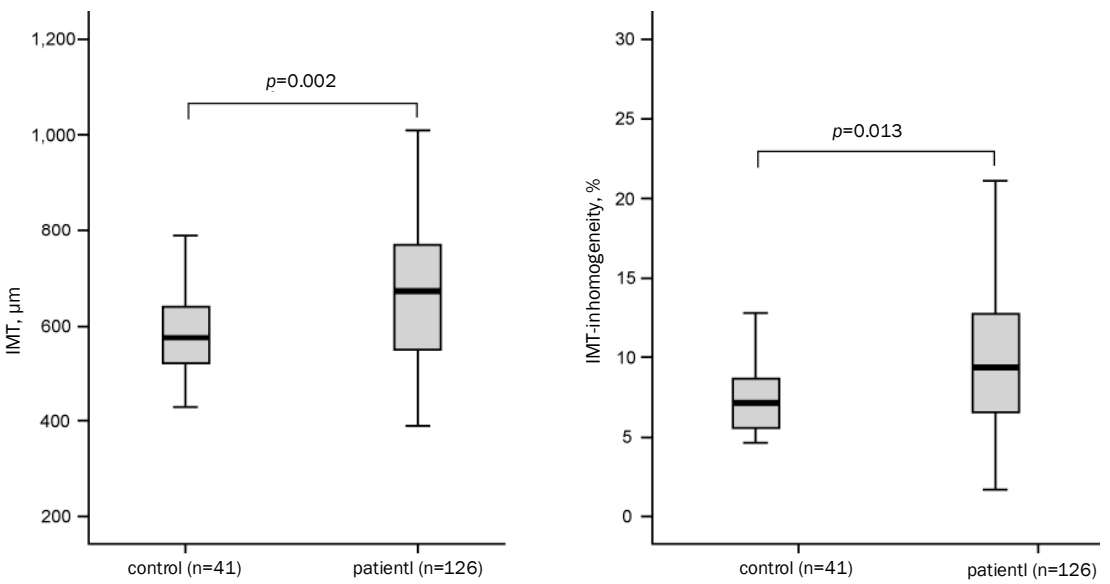

Figure 3.2 Box plot showing mean intima media thickness (IMT, micrometers) and IMT-inhomogeneity (\%) with $95 \%$ confidence intervals in patients and controls.
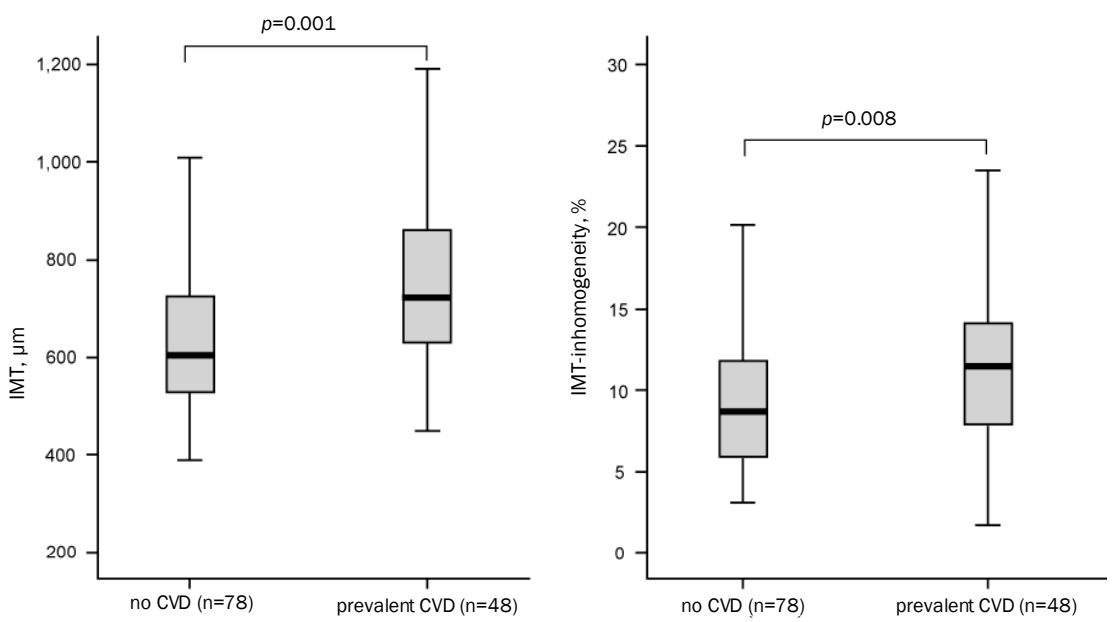

Figure 3.3 Box plot showing CCA-IMT and IMT-inhomogeneity values in 126 dialysis patients with and without CVD. 


\section{Association between IMT and IMT-inhomogeneity in dialysis patients}

After adjustment for age, sex, pulse pressure, diabetes, cardiovascular disease and height, IMT and IMT-inhomogeneity strongly correlated $(\beta=0.59 ; p<0.001)$.

\section{Associations between traditional and non-traditional risk factors with IMT and IMT-inhomogeneity (Table 3.3).}

Table 3.3 Univariate associations between traditional and non-traditional risk factors and carotid intima-media thickness (IMT) and carotid IMT-inhomogeneity in dialysis patients $(n=126)$.

\begin{tabular}{|c|c|c|c|c|c|c|}
\hline \multirow[b]{2}{*}{ Risk factor } & \multicolumn{3}{|c|}{ Carotid IMT $(\mu \mathrm{m})$} & \multicolumn{3}{|c|}{ Carotid IMT-inhomogeneity (\%) } \\
\hline & $\beta$ & $95 \% \mathrm{Cl}$ & $p$ & $\beta$ & $95 \% \mathrm{Cl}$ & $p$ \\
\hline \multicolumn{7}{|l|}{ Traditional risk factors } \\
\hline Male sexa & 11 & -46 to 67 & 0.71 & -1.02 & -3.57 to 1.52 & 0.43 \\
\hline Age, years & 6.1 & 4.3 to 7.9 & $<0.001$ & 0.16 & 0.07 to 0.25 & $<0.001$ \\
\hline Height., cm & -1.6 & -4.3 to 1.4 & 0.30 & -0.17 & -0.30 to -0.00 & 0.02 \\
\hline Body mass index, $\mathrm{kg} / \mathrm{m}^{2}$ & 3.3 & -3.0 to 9.6 & 0.30 & -0.00 & -0.30 to 0.27 & 0.93 \\
\hline Pulse pressure, $\mathrm{mmHg}$ & 1.5 & 0.02 to 3.0 & 0.047 & 0.07 & -0.00 to 0.13 & 0.06 \\
\hline Cholesterol, $\mathrm{mmol} / \mathrm{I}^{\mathrm{b}}$ & 16 & -10 to 41 & 0.23 & -0.25 & -1.53 to 1.03 & 0.70 \\
\hline Diabetes $^{a}$ & 79 & 19 to 139 & 0.01 & 3.0 & 0.3 to 5.7 & 0.03 \\
\hline CVDa $^{a}$ & 103 & 41 to 159 & $<0.001$ & 3.49 & 0.94 to 6.04 & 0.01 \\
\hline Hypertensiona & 16 & -57 to 90 & 0.66 & -0.36 & -3.66 to 2.94 & 0.83 \\
\hline Current smokinga & -13 & -77 to 32 & 0.70 & 0.21 & -2.69 to 3.10 & 0.89 \\
\hline Antihypertensive medicationa & -32 & -102 to 38 & 0.37 & 0.52 & -2.63 to 3.67 & 0.75 \\
\hline \multicolumn{7}{|l|}{ Non-traditional risk factors } \\
\hline Fetuin-A, g/I & -189 & -360 to -18 & 0.03 & -10.6 & -18.2 to -3.0 & 0.007 \\
\hline hsCRP, log mg/dl & 47 & -1 to 96 & 0.06 & 1.57 & -0.64 to 3.77 & 0.17 \\
\hline Anti-oxLDL antibodies, OD & 67 & -27 to 161 & 0.16 & 5.2 & 1.1 to 9.4 & 0.01 \\
\hline Calcium (Ca),mmol/l & 166 & -8 to 340 & 0.06 & 4.53 & -3.38 to 12.43 & 0.26 \\
\hline Phosphate (P), mmol// & -103 & -198 to -9 & 0.03 & -1.25 & -5.56 to 3.07 & 0.57 \\
\hline $\mathrm{Ca} * \mathrm{P}, \mathrm{mmol}^{2} / \mathrm{I}^{2}$ & -24 & -61 to 13 & 0.21 & -0.09 & -1.77 to 1.58 & 0.91 \\
\hline
\end{tabular}

$\beta$, regression coefficient; indicates difference in IMT or IMT inhomogeneity per 1 unit increase in independent variable (continuous variables) or belonging to risk group (categorial variablesa). $\mathrm{Cl}, 95 \%$ confidence interval; b, cholesterol values available in 98 (78\%) subjects only; hsCRP, high sensitive C-reactive protein; OD, optical density; CVD, cardiovascular disease.

\section{Traditional risk factors}

Univariate analyses identified age, pulse pressure, diabetes and prior CVD as positive correlates of both carotid IMT and IMT-inhomogeneity. Body height was an inverse correlate of IMT-inhomogeneity only (Table 3.3). In a multiple regression model including all these variables only age remained independently associated with both IMT $(\beta=0.48 ; p<0.001)$ and IMT-inhomogeneity $(\beta=0.21 ; p=0.04)$.

\section{Non-traditional risk factors}

Univariate analyses identified Fetuin-A as an inverse correlate of both carotid IMT and IMT-inhomogeneity; anti-oxLDL antibodies were positively and significantly 
associated with IMT-inhomogeneity only and hsCRP was positively and (borderline) significantly associated with carotid IMT only (Table 3.4).

In multiple regression models adjusted for age, sex, pulse pressure, diabetes, CVD and body height, fetuin-A was inversely and anti-oxLDL was positively and significantly associated with IMT-inhomogeneity but not to IMT (Table 3.4; model 1). This significant association persisted after further adjustment for markers of inflammation (log-hsCRP), oxidative stress (log-anti-oxLDL) or fetuin-A, and calcium-phosphate metabolism ( $\mathrm{Ca}, \mathrm{P}, \mathrm{Ca}$ * $\mathrm{P}$ product) (models 2-4). Adding IMT to the model resulted in a decrease in the strength of the association between fetuin-A or anti-oxLDL and IMT-inhomogeneity, which nevertheless remained significant (model 5). Log-hsCRP was neither related to IMT nor to IMTinhomogeneity.

Table 3.4 Associations between fetuin-A, log hsCRP and log anti-oxLDL, and carotid intima media thickness (IMT) and IMT inhomogeneity in dialysis patients $(n=126)$.

\begin{tabular}{|c|c|c|c|c|c|}
\hline \multirow[t]{2}{*}{ Independent variable } & \multicolumn{3}{|c|}{ Carotid IMT ( $\mu \mathrm{m})$} & \multicolumn{2}{|c|}{ Carotid IMT inhomogeneity (\%) } \\
\hline & Model & $\beta$ & $95 \% \mathrm{Cl}$ & $\beta$ & $95 \% \mathrm{Cl}$ \\
\hline \multicolumn{6}{|l|}{ Fetuin-A, g/I } \\
\hline & 1 & -0.089 & -0.246 to 0.068 & $-0.009+$ & -0.017 to -0.002 \\
\hline & $2^{a}$ & -0.093 & -0.249 to 0.064 & $-0.009+$ & -0.017 to -0.002 \\
\hline & 3 & -0.083 & -0.241 to 0.074 & $-0.009+$ & -0.016 to -0.001 \\
\hline & 4 & -0.113 & -0.271 to 0.045 & $-0.010+$ & -0.018 to -0.002 \\
\hline & 5 & NA & NA & $-0.006+$ & -0.012 to -0.001 \\
\hline \multicolumn{6}{|l|}{ HsCRP, log mg/dl } \\
\hline & 1 & 0.032 & -0.002 to 0.005 & 0.001 & -0.001 to 0.003 \\
\hline & $2^{\mathrm{b}}$ & 0.033 & -0.10 to 0.076 & 0.001 & -0.001 to 0.003 \\
\hline & 3 & 0.030 & -0.013 to 0.074 & 0.001 & -0.001 to 0.003 \\
\hline & 4 & 0.036 & -0.007 to 0.080 & 0.001 & -0.001 to 0.004 \\
\hline & 5 & NA & NA & 0.000 & -0.001 to 0.002 \\
\hline \multicolumn{6}{|c|}{ Anti-oxLDL antibodies, OD } \\
\hline & 1 & 0.044 & -0.038 to 0.126 & $0.005^{*}$ & 0.001 to 0.009 \\
\hline & $2^{a}$ & 0.039 & -0.043 to 0.121 & $0.005^{*}$ & 0.001 to 0.009 \\
\hline & $3^{c}$ & 0.041 & -0.041 to 0.123 & $0.005^{*}$ & 0.001 to 0.009 \\
\hline & 4 & 0.061 & -0.022 to 0.144 & $0.005^{*}$ & 0.001 to 0.009 \\
\hline & 5 & NA & NA & $0.004^{*}$ & 0.001 to 0.007 \\
\hline
\end{tabular}

$\beta$, regression coefficient; indicates difference in carotid IMT or IMT-inhomogeneity per 1 unit increase in independent variable; $\mathrm{Cl}, 95 \%$ confidence interval, ${ }^{\dagger} p<0.05$; NA, not applicable. Model 1, model adjusted for age, sex, pulse pressure, diabetes, cardiovascular disease, height; Model 2, model $1+\log$ hsCRPa or fetuin-A; $\mathrm{A}^{\mathrm{b}}$ Model 3, model $1+\log$-anti-oxLDL or fetuin- $\mathrm{A}^{\mathrm{c}}$; Model 4 , model $1+\mathrm{Ca}$, $\mathrm{P}$, and $\mathrm{Ca}$ ${ }^{*} \mathrm{P}$; Model 5, model 1 + IMT.

\section{Additional analyses}

The results did not change materially after additional adjustments for dialysis modality, dialysis vintage or adequacy. Also additional adjustment for the use of anti-hypertensive or lipid lowering drugs did not materially change the results. 


\section{Discussion}

The present study has two main findings. Firstly, not only IMT but also IMTinhomogeneity (a new parameter of spatial variance of the IMT over a given length) of the common carotid artery is increased in dialysis patients compared to controls. Secondly, although strongly correlated, IMT and IMT-inhomogeneity seem to represent different entities given the different set of independent correlates identified: IMT was primarily associated with age, diabetes and prior CVD whereas IMT inhomogeneity was primarily determined by decreased levels of fetuin-A and anti-oxLDL.

Carotid IMT is used as a surrogate marker for cardiovascular disease in different populations. However, it has become clear that intima media thickening not merely represents atherosclerosis but also is a reaction to hemodynamic changes. ${ }^{29}$ In the dialysis population with a large hemodynamic burden caused by fluid overload and arterioveneous shunts, IMT values are even more difficult to interpret. In spite of the hemodynamic burden, some authors, including our group did not find a difference in CCA-IMT between patients and controls. ${ }^{6,8}$ In the present study, IMT values in dialysis patients were greater than in controls. This contrasting finding may be due to differences in measurement techniques: instead of a single-point assessment or averaging of the IMT over a longer segment, we measured IMT at 14 adjacent points simultaneously of an artery segment of $16.4 \mathrm{~mm}$. This results in a higher accuracy and sensitivity of the measurements. Due to the new technique it is difficult to compare the absolute IMT values of this study with other studies. We believe that measuring IMT at a single-point may, in case of increased inhomogeneity, yield less reliable results.

This is the first study to report results on CCA-IMT-inhomogeneity measurements in a study population. The greater IMT-inhomogeneity observed in dialysis patients may represent early changes in the structural properties of the arterial wall, which is in line with the increased frequency of plaques among these patients as compared to controls. ${ }^{7,8} \mathrm{~A}$ large number of these plaques are heavily calcified ${ }^{7}$ and Stenvinkel et al. recently showed that ESRD patients with plaques had a lower serum fetuin-A level. ${ }^{15}$ Fetuin-A, a calcification inhibitor ${ }^{30}$, was also negatively correlated with IMT-inhomogeneities in our study. However, whether inhomogeneities are precursors of plaques cannot be concluded from our cross-sectional data.

Both IMT and IMT-inhomogeneities were higher in dialysis patients with prevalent cardiovascular disease. IMT-inhomogeneity therefore could be a potential marker for cardiovascular disease. Future, prospective studies investigating whether IMTinhomogeneity may serve as a marker for cardiovascular disease are warranted.

In the present study we show that carotid artery IMT and IMT-inhomogeneity strongly correlate. However, they should not be interpreted interchangeably, given the different set of potential determinants identified. Indeed, IMT may reflect 
thickness of the medial (rather than the intima) layer that could, for instance result from adaptations to the high hemodynamic burden characteristic of dialysis patients. IMT-inhomogeneity represents a structural change over a given length of the arterial wall. Our findings suggest that these local changes may be caused by an increased calcification process caused by a lower serum fetuin-A level or accelerated atherosclerosis due to an increase in lipid peroxidation represented by higher IgG anti-oxLDL antibody levels (adaptations likely to occur at the intima layer). We thus conclude that despite their strong relationship, IMT and IMTinhomogeneities may be markers of distinct arterial wall adaptation processes to risk factor exposure in dialysis patients. 


\section{References}

1. Wheeler DC. Cardiovascular disease in patients with chronic renal failure. Lancet. 1996;348: 1673-1674.

2. Benedetto FA, Mallamaci F, Tripepi G, Zoccali C. Prognostic value of ultrasonographic measurement of carotid intima media thickness in dialysis patients. J Am Soc Nephrol. 2001; 12:2458-2464.

3. Grobbee DE, Bots ML. Carotid artery intima-media thickness as an indicator of generalized atherosclerosis. J Intern Med. 1994;236:567-573.

4. 2003 European Society of Hypertension-European Society of Cardiology guidelines for the management of arterial hypertension. J Hypertens. 2003;21:1011-1053.

5. London GM, Guerin AP, Marchais SJ, Pannier B, Safar ME, Day M, Metivier F. Cardiac and arterial interactions in end-stage renal disease. Kidney Int. 1996;50:600-608.

6. Konings CJ, Dammers R, Rensma PL, Kooman JP, Hoeks AP, Kornet L, Gladziwa U, van der Sande FM, Leunissen KM. Arterial wall properties in patients with renal failure. Am J Kidney Dis. 2002; 39:1206-1212.

7. Savage T, Clarke AL, Giles M, Tomson CR, Raine AE. Calcified plaque is common in the carotid and femoral arteries of dialysis patients without clinical vascular disease. Nephrol Dial Transplant. 1998;13:2004-2012.

8. Leskinen Y, Lehtimaki T, Loimaala A, Lautamatti V, Kallio T, Huhtala H, Salenius JP, Saha H. Carotid atherosclerosis in chronic renal failure-the central role of increased plaque burden. Atherosclerosis. 2003;171:295-302.

9. Reneman RS, Hoeks AP. Noninvasive vascular ultrasound: an asset in vascular medicine. Cardiovasc Res. 2000;45:27-35.

10. Badimon JJ, Fuster V, Chesebro JH, Badimon L. Coronary atherosclerosis. A multifactorial disease. Circulation. 1993;87:II3-16.

11. Meinders JM, Kornet L, Hoeks AP. Assessment of spatial inhomogeneities in intima media thickness along an arterial segment using its dynamic behavior. Am J Physiol Heart Circ Physiol. 2003;285:H384-391.

12. Sarnak MJ, Levey AS, Schoolwerth AC, Coresh J, Culleton B, Hamm LL, McCullough PA, Kasiske BL, Kelepouris E, Klag MJ, Parfrey P, Pfeffer M, Raij L, Spinosa DJ, Wilson PW. Kidney disease as a risk factor for development of cardiovascular disease: a statement from the American Heart Association Councils on Kidney in Cardiovascular Disease, High Blood Pressure Research, Clinical Cardiology, and Epidemiology and Prevention. Circulation. 2003;108:2154-2169.

13. Zimmermann J, Herrlinger S, Pruy A, Metzger T, Wanner C. Inflammation enhances cardiovascular risk and mortality in hemodialysis patients. Kidney Int. 1999;55:648-658.

14. Ketteler M, Bongartz P, Westenfeld R, Wildberger JE, Mahnken AH, Bohm R, Metzger T, Wanner C, Jahnen-Dechent W, Floege J. Association of low fetuin-A (AHSG) concentrations in serum with cardiovascular mortality in patients on dialysis: a cross-sectional study. Lancet. 2003;361: 827-833.

15. Stenvinkel P, Wang K, Qureshi AR, Axelsson J, Pecoits-Filho R, Gao P, Barany P, Lindholm B, Jogestrand T, Heimburger O, Holmes C, Schalling M, Nordfors L. Low fetuin-A levels are associated with cardiovascular death: Impact of variations in the gene encoding fetuin. Kidney Int. 2005;67:2383-2392.

16. Zoccali C, Benedetto FA, Mallamaci F, Tripepi G, Fermo I, Foca A, Paroni R, Malatino LS. Inflammation is associated with carotid atherosclerosis in dialysis patients. Creed Investigators. Cardiovascular Risk Extended Evaluation in Dialysis Patients. J Hypertens. 2000;18:1207-1213.

17. Moe SM, Reslerova M, Ketteler M, O'Neill K, Duan D, Koczman J, Westenfeld R, Jahnen-Dechent W, Chen NX. Role of calcification inhibitors in the pathogenesis of vascular calcification in chronic kidney disease (CKD). Kidney Int. 2005;67:2295-2304.

18. Yla-Herttuala S, Palinski W, Butler SW, Picard S, Steinberg D, Witztum JL. Rabbit and human atherosclerotic lesions contain IgG that recognizes epitopes of oxidized LDL. Arterioscler Thromb. 1994;14:32-40. 
19. Matsuura E, Kobayashi K, Tabuchi M, Lopez LR. Oxidative modification of low-density lipoprotein and immune regulation of atherosclerosis. Prog Lipid Res. 2006;45:466-486.

20. Drueke TB, Nguyen Khoa T, Massy ZA, Witko-Sarsat V, Lacour B, Descamps-Latscha B. Role of oxidized low-density lipoprotein in the atherosclerosis of uremia. Kidney Int Suppl. 2001;78: S114-119.

21. Chobanian AV, Bakris GL, Black HR, Cushman WC, Green LA, Izzo JL, Jr., Jones DW, Materson BJ, Oparil S, Wright JT, Jr., Roccella EJ. The Seventh Report of the Joint National Committee on Prevention, Detection, Evaluation, and Treatment of High Blood Pressure: the JNC 7 report. JAMA. 2003;289:2560-2572.

22. K/DOQI clinical practice guidelines for chronic kidney disease: evaluation, classification, and stratification. Am J Kidney Dis. 2002;39:S1-266.

23. Meinders JM, Brands PJ, Willigers JM, Kornet L, Hoeks AP. Assessment of the spatial homogeneity of artery dimension parameters with high frame rate 2-D B-mode. Ultrasound Med Biol. 2001;27:785-794.

24. Mehrotra R, Westenfeld R, Christenson P, Budoff M, Ipp E, Takasu J, Gupta A, Norris K, Ketteler M, Adler S. Serum fetuin-A in nondialyzed patients with diabetic nephropathy: relationship with coronary artery calcification. Kidney Int. 2005;67:1070-1077.

25. Hermans MM, Brandenburg V, Ketteler M, Kooman JP, Sande FM, Gladziwa U, Rensma PL, Bartelet K, Konings CJ, Hoeks AP, Floege J, Leunissen KM. Study on the relationship of serum fetuin-A concentration with aortic stiffness in patients on dialysis. Nephrol Dial Transplant. 2006.

26. Damoiseaux J, Jeyasekharan AD, Theunissen R, Cohen Tervaert JW. Cross-reactivity of IgM and IgG anticardiolipin antibodies with oxidized-low density lipoproteins. Ann $N$ Y Acad Sci. 2005;1050:163-169.

27. Redgrave TG, Roberts DC, West CE. Separation of plasma lipoproteins by density-gradient ultracentrifugation. Anal Biochem. 1975;65:42-49.

28. Lowry $\mathrm{OH}$, Rosebrough NJ, Farr AL, Randall RJ. Protein measurement with the Folin phenol reagent. J Biol Chem. 1951;193:265-275.

29. Van Bortel LM. What does intima-media thickness tell us? J Hypertens. 2005;23:37-39.

30. Ketteler M. Fetuin-A and extraosseous calcification in uremia. Curr Opin Nephrol Hypertens. 2005;14:337-342. 


\section{Chapter 4}

Study on the relationship of serum fetuin-A

concentration with aortic stiffness in patients on dialysis

MMH Hermans, V Brandenburg, M Ketteler, JP Kooman, FM van der Sande, U Gladziwa, PL Rensma, K Bartelet, CJAM Konings, APG Hoeks, J Floege, KML Leunissen

Nephrology Dialysis Transplantation. 2006;21:1293-1299 


\section{Abstract}

\section{Background}

An increase in aortic stiffness, as reflected by an increase in pulse wave velocity (PWV) or aortic augmentation index (Alx) is an important predictor of cardiovascular mortality in dialysis patients. Dysregulation of calcification inhibitors such as fetuin-A is involved in vascular pathology in dialysis patients and fetuin-A is inversely related to mortality in dialysis patients. In this study, the relation between serum fetuin-A concentration and parameters of aortic stiffness was investigated in patients with end-stage renal disease (ESRD).

\section{Methods}

In a cross-sectional study we included 131 dialysis patients, aged $62 \pm 14$ years, (33 on peritoneal dialysis (PD), 98 on hemodialysis (HD)), and 41 controls, aged $60 \pm 8$ years.

Time-averaged pre-dialysis values of serum albumin, calcium (Ca), phosphate $(\mathrm{P})$, and parathyroid hormone (iPTH) were included in multiregression analysis, as were high-sensitive C-reactive protein (hsCRP), fetuin-A, age, mean arterial pressure (MAP) and dialysis modality. PWV and Alx were measured with the SphygmoCor device.

\section{Results}

Mean fetuin-A concentration in dialysis patients $(0.63 \mathrm{~g} / \mathrm{I} \pm 0.16)$ did not differ from controls $(0.63 \mathrm{~g} / \mathrm{I} \pm 0.11)$. Median hsCRP levels in dialysis patients were higher compared to controls (4.0 vs. $1.9 \mathrm{mg} / \mathrm{l} ; p=<0.0001)$. PWV but not Alx was higher in dialysis patients than in controls $(9.9 \mathrm{vs} .7 .9 \mathrm{~m} / \mathrm{s}$; $p<0.0001)$. In univariate analysis in dialysis patients, fetuin-A levels were inversely related to both PWV $(\mathrm{r}=-0.25, p=0.007)$ and Alx $(r=-0.26, p=0.006)$, respectively. However, after correction for age, sex, MAP and diabetes mellitus, this relation lost statistical significance.

\section{Conclusion}

In summary, in a dialysis population with a relatively low level of inflammatory activity the soluble calcification inhibitor fetuin-A could not be identified as an independent predictor of aortic stiffness as measured with PWV and Alx. 


\section{Introduction}

ESRD is associated with greatly increased cardiovascular morbidity and mortality. ${ }^{1}$ Apart from occlusive arterial disease as seen in atherosclerosis, arterial stiffening as a feature of predominant medial calcification is a hallmark of vascular pathology in dialysis patients. ${ }^{2,3}$ Increased aortic stiffening, reflected e.g. by an increased pulse wave velocity (PWV) or aortic augmentation index (Alx) is an important determinate of all-cause and cardiovascular mortality in this patient group. ${ }^{4,5}$

Recently, abnormalities in both the calcium and phosphate metabolism have emerged as important risk factors for vascular wall calcifications and mortality, respectively. ${ }^{6,7}$ These abnormalities were consequently found to be related to arterial stiffness, which may be explained by an interrelation between medial calcifications and vascular wall stiffness. ${ }^{4,6}$ However, arterial stiffening is also associated with traditional risk factors such as aging, diabetes and hypertension and non-traditional risk factors such as hyperhomocysteinemia, oxidative stress, dyslipidaemia, accumulation of glycosylation end-products and inflammation. . $^{-9}$

Recent attention has focused on the potential importance of low serum fetuin-A concentration as a non-traditional cardiovascular risk factor in dialysis patients. This glycoprotein is a potent calcification inhibitor and absence of fetuin in fetuin-A knock-out mice results in massive extra-osseous calcification. ${ }^{10}$ Fetuin-A, a negative acute-phase reactant, plays a pivotal role in the inhibition of $\mathrm{Ca} * \mathrm{P}$ precipitation. ${ }^{11,12}$ In hemodialysis (HD) patients, lower fetuin-A concentrations are associated with both a higher overall and cardiovascular mortality. ${ }^{13,14}$ At least a part of the relation between low fetuin-A levels and increased mortality appeared to be explained by the potential down-regulation of fetuin- $A$ in inflammatory states. ${ }^{12,15}$ Moreover, low fetuin-A levels were found to be related to increased vascular calcifications in dialysis patients ${ }^{16}$ and to calcific uremic arteriolopathy. ${ }^{10}$ In peritoneal dialysis (PD) patients, Wang et al. showed an inverse relationship between serum fetuin-A and valvular calcification. ${ }^{15}$ However, it is not clarified whether fetuin-A deficiency in dialysis patients is an independent predictor for the development of vascular stiffness as a consequence of vascular calcification in dialysis patients.

Therefore, the aim of the present study was to evaluate the association between serum fetuin-A concentrations with parameters of vascular stiffness, especially considering the presence of inflammation as a potential trigger for fetuin-A downregulation. 


\section{Materials and methods}

\section{Study design}

The study investigated the relation between fetuin-A and markers of aortic stiffness (Alx and PWV) in a cross-sectional design. In a post-hoc analysis differences with respect to fetuin-A levels and aortic stiffness between controls and dialysis patients were studied.

\section{Subjects}

A total of 131 stable, all but two Caucasian dialysis patients, undergoing HD ( $n=98$, $75 \%)$ and PD ( $n=33,25 \%)$, from three dialysis centres were included.

ESRD patients were eligible when they were on dialysis for more than three months. Patients with an underlying malignancy, infection or heart failure were excluded. Because fetuin-A is produced in the liver, patients with liver failure, liver cirrhosis or hepatitis B or C were excluded.

The 41, age- and sex-matched, controls consisted of spouses and healthy staff members. Controls had to have a negative cardiovascular medical history including hypertension. Cardiovascular disease (CVD) was defined as the presence or history of ischaemic heart disease, peripheral vascular disease and/or a cerebrovascular event. Hypertension was defined as a blood pressure $\geq 140 \mathrm{mmHg}$ systolic and/or $\geq 90 \mathrm{mmHg}$ diastolic according to the JNC VII criteria ${ }^{17}$ and/or the current use of antihypertensive medication. In controls renal function was estimated by the modified MDRD formula in $\mathrm{ml} / \mathrm{min}$ and expressed per $1.73 \mathrm{~m}^{2}$ body surface area. ${ }^{18}$ Fasting plasma glucose levels $\geq 7.0 \mathrm{mmol} / \mathrm{l}$ were considered diagnostic for diabetes mellitus.

All participants gave their written informed consent. The study protocol was designed in adherence to the declaration of Helsinki and approved by the ethical committees of the participating centres.

\section{Feasibility of PWV and Al measurements:}

Of the 131 dialysis patients PWV and Alx measurements were successful in 110 $(84 \%)$ and $114(87 \%)$ of the cases, respectively. Most failures $(n=11)$ were due to heart rhythm disturbances or technically failed because of vascular access surgery. PWV and Alx measurements were successful in all but three controls (93\%). In two cases the radial artery signal was too weak and one person had an irregular heart rate.

\section{Methods}

Aortic stiffness was evaluated by measurement of pulse wave velocity (PWV) and aortic augmentation index (AIx). 
In both groups measurement of blood pressure, PWV and Alx were done after 15 minutes of supine rest. The HD patients were investigated one hour before the dialysis-session. PD patients were investigated with an empty abdomen. Brachial systolic and diastolic pressures were assessed at three minutes intervals with a radial artery tonometrical device (CBM 7000, Colin Medial Instruments, San Antonio, Texas, USA) on the right arm or in case of a right-sided dialysis shunt on the left arm. Mean arterial pressure (MAP) was calculated from the mean of three systolic and diastolic pressures as (2 * diastolic pressure + systolic pressure)/3.

The PWV was measured using the SphygmoCor (AtCor Medical Ltd., Moreton-inMarsh, UK). Briefly, a carotid and a femoral artery waveform were obtained consecutively with a high-fidelity applanation tonometer (Millar SPT-301; Millar Instruments Inc., Houston, Texas, USA). Transit time was obtained by subtraction from the delays between ECG and both pulses.

The SphygmoCor device was also used to determine the Alx. The Alx is a measure of the additional load to which the left ventricle is subjected as a result of wave reflection and was performed with the above described applanation tonometer. Alx is a composite parameter because it reflects the reflective properties of the peripheral distal arterial bed and elastic properties of large arteries. PWV and Alx are related but not synonymous. ${ }^{19}$ The Alx was derived from the right radial arterial pulse by means of a transfer function. ${ }^{20}$ In our analysis we used the Alx corrected for heart rate. The methods for measuring PWV and Alx have been described and evaluated elsewhere. ${ }^{21}$

\section{Laboratory analysis}

In the patient group, serum calcium, phosphate and albumin were measured using standard laboratory techniques. In the HD group samples were taken at the start of a short-interval hemodialysis. Time averaged values of calcium (Ca), phosphate (P) and albumin were calculated as the mean of the routine six weekly measurements of the previous six months. Calcium concentration was calculated after correction for albumin. Intact parathyroid hormone (iPTH) was measured by a two-site chemiluminescence immunoassay (Nichols Institute Diagnostics B.V.; Nijmegen; The Netherlands). In controls we measured fasting serum glucose, calcium, phosphate and creatinine. In both groups hsCRP and fetuin-A were measured by nephelometry. Serum was harvested by centrifugation of clotted blood. Serum samples were stored at $-80^{\circ} \mathrm{C}$ prior to analysis. Serum analysis for hsCRP were performed by means of particle enhanced immunonephelometry using a standard "CardioPhase hsCRP" for "BNII" (Dade Behring Holding GmbH, D-65835 Liederbach, Germany). CRPI or CRPII assay protocols were used when appropriate. Interday precision controls revealed variation coefficients (VC) below $6 \%$.

The nephelometry method for fetuin-A employs the same high specifity antibody as the ELISA method previously described. ${ }^{13,22}$ The nephelometric method for fetuin-A 
serum measurement has been evaluated in a side-by-side comparison with immunoblot analysis to exclude cross-reactivity of the antibodies with other serum proteins and proteolytic fragments of fetuin-A. Cross-reaction with fetuin-B was excluded. Serum samples were cleared by centrifugation (60min at $15000 \mathrm{~g}$ ) and diluted 1:4 with $400 \mu \mathrm{l}$ phosphate buffered saline (N Diluent, Dade Behring Holding, Liederbach, Germany). Nephelometric assays were performed manually using an automatic nephelometer (BNII, Dade Behring Holding, Liederbach, Germany). The assay linear measurement range of human fetuin- $A$ is $0.05 \mathrm{~g} / \mathrm{l}$ up to $3.5 \mathrm{~g} / \mathrm{l}$. The within run precision obtained from a 20 -fold measurement of identical samples yielded a VC of $7.75 \%$. The day-to-day precision obtained from repetitive measurements of control serum was determined as a VC of $8.2 \%$.

\section{Statistical analysis}

The zero hypothesis to be tested was that no relation existed between serum fetuin-A levels and aortic stiffness. We estimated the sample size on the basis of the alternative hypothesis that a correlation coefficient of 0.4 exists between fetuin levels and aortic stiffness. With an alfa significance level of 0.05 and a power of 0.8, 48 patients would be needed to test this hypothesis. In order to allow for multivariate analysis, we chose to include at least 100 patients to test the hypothesis. Normally distributed variables are expressed as mean \pm SD and nonnormally distributed variables as median and range, with $p<0.05$ indicating significance. All continuous data were tested for a normal distribution before further statistical analysis. Not normally distributed variables were log-transformed. Differences in frequency of nominal variables were compared using chi-square analysis. Comparison between two groups was done with unpaired Student's t test. Univariate and multiple regression analysis were used in dialysis patients to test the associations of variables related to PWV and Alx. The variables were entered one after another with a maximum of five. Two-sided univariate analysis was used to analyse the fetuin level between the HD and PD group with correction for confounders. Analyses were performed with SPSS for Windows version 11.0 (SPSS, Chicago, IL, USA).

\section{Results}

The characteristics of the dialysis group and the controls are shown in Table 4.1. The major causes of stage 5 CKD were diabetes in 18\%, nephrosclerosis in $30 \%$, and glomerulonephritis in $18 \%$ of the patients.

PWV was significantly higher in dialysis patients compared to controls (9.9 vs. 7.9 $\mathrm{m} / \mathrm{s} ; \mathrm{p}<0.0001$ ), whereas Alx was not significantly different. 
Table 4.1 Characteristics of dialysis patients and controls.

\begin{tabular}{|c|c|c|c|c|c|c|}
\hline & $\begin{array}{l}\text { Controls } \\
(n=41)\end{array}$ & $\begin{array}{l}\text { Patients } \\
(\text { HD+PD) } \\
(n=131)\end{array}$ & $\begin{array}{c}p \\
\text { Controls vs. } \\
\text { Patients } \\
\end{array}$ & $\begin{array}{c}P D \\
(n=33)\end{array}$ & $\begin{array}{c}\mathrm{HD} \\
(\mathrm{n}=98)\end{array}$ & $\begin{array}{c}p \\
\text { HD vs.PD }\end{array}$ \\
\hline Age, years & $60 \pm 8$ & $62 \pm 14$ & NS & $57 \pm 14$ & $63 \pm 13$ & 0.03 \\
\hline Sex,$\%$ male & 54 & 53 & NS & 63 & 50 & NS \\
\hline Body Mass Index, kg/m² & $25.5 \pm 3.6$ & $24.8 \pm 4.5$ & NS & $24.8 \pm 4.0$ & $24.9 \pm 4.6$ & NS \\
\hline Hypertension, \% & 33 & 83 & $<0.0001$ & 79 & 85 & NS \\
\hline Smoking, \% & 29 & 29 & NS & 36 & 25 & NS \\
\hline Diabetes, \% & & 31 & & 30 & 31 & NS \\
\hline CVD, \% & & 38 & & 27 & 42 & NS \\
\hline \multicolumn{7}{|l|}{ Brachial BP, mmHg } \\
\hline Systolic & $135 \pm 17$ & $139 \pm 25$ & NS & $130 \pm 18$ & $143 \pm 27$ & 0.01 \\
\hline Diastolic & $77 \pm 8$ & $74 \pm 13$ & NS & $73 \pm 9$ & $74 \pm 14$ & NS \\
\hline Mean arterial & $96 \pm 9$ & $95 \pm 14$ & NS & $92 \pm 10$ & $96 \pm 14$ & 0.04 \\
\hline Pulse pressure & $58 \pm 13$ & $66 \pm 26$ & 0.02 & $57 \pm 17$ & $68 \pm 28$ & 0.03 \\
\hline PWV, m/s (n) & $\begin{array}{c}7.9 \pm 1.6 \\
(39)\end{array}$ & $\begin{array}{l}9.9 \pm 3.0 \\
(110)\end{array}$ & $<0.0001$ & $9.4 \pm 2.6$ & $10.1 \pm 3.0$ & NS \\
\hline Alx, \% (n) & $\begin{array}{c}28 \pm 13 \\
(39)\end{array}$ & $\begin{array}{c}27 \pm 12 \\
(114)\end{array}$ & NS & $23 \pm 9$ & $29 \pm 12$ & 0.01 \\
\hline Duration of dialysis, months & & $41 \pm 40$ & & $25 \pm 18$ & $47 \pm 44$ & $<0.01$ \\
\hline Total Kt/V weekly & & & & $2.40 \pm 0.43$ & & \\
\hline Kt/V (double pooled) & & & & & $1.3 \pm 0.21$ & \\
\hline \multicolumn{7}{|l|}{ Anti-hypertensive drugs, $\%$} \\
\hline ACE inhibitors & & & & 55 & 47 & NS \\
\hline Beta blockers & & & & 70 & 55 & NS \\
\hline Ca antagonists & & & & 36 & 32 & NS \\
\hline ARB & & & & 21 & 11 & NS \\
\hline ACE inhibitors & & & & 55 & 47 & NS \\
\hline Hemoglobin, mmol/l & & & & $7.5 \pm 0.9$ & $7.0 \pm 0.7$ & $<0.01$ \\
\hline $\mathrm{CRP}, \mathrm{mg} / \mathrm{I}^{\mathrm{b}}$ & $\begin{array}{c}1.9 \\
(0.1-15.3)\end{array}$ & $\begin{array}{c}4.0 \\
(0.1-89.1)\end{array}$ & $<0.0001$ & $\begin{array}{c}3.8 \\
(0.1-89.1)\end{array}$ & $\begin{array}{c}4.0 \\
(0.4-66.4)\end{array}$ & NS \\
\hline $\begin{array}{l}\text { Fetuin, } \mathrm{g} / \mathrm{l} \\
\text { eGFR } \mathrm{ml} / \mathrm{min} / 1.73 \mathrm{~m}^{2}\end{array}$ & $\begin{array}{c}0.63 \pm 0.11 \\
87 \pm 15\end{array}$ & $0.63 \pm 0.16$ & NS & $0.73 \pm 0.16$ & $0.59 \pm 0.15$ & $<0.0001$ \\
\hline $\mathrm{Ca}, \mathrm{mmol} / \mathrm{l}$ & $2.35 \pm 0.11$ & $2.37 \pm 0.16$ & NS & $2.49 \pm 0.15$ & $2.48 \pm 0.16$ & NS \\
\hline Albumin, $g / l$ & $42 \pm 3$ & $36 \pm 5$ & $<0.0001$ & $34 \pm 5$ & $37 \pm 4$ & 0.001 \\
\hline $\mathrm{P}, \mathrm{mmol} / \mathrm{I}$ & $1.21 \pm 0.14$ & $1.75 \pm 0.3$ & $<0.0001$ & $1.71 \pm 0.29$ & $1.76 \pm 0.30$ & NS \\
\hline iPTH, pmol//b & & $\begin{array}{c}25 \\
(0-121) \\
\end{array}$ & & $\begin{array}{c}20 \\
(2-62) \\
\end{array}$ & $\begin{array}{c}16 \\
(1-121) \\
\end{array}$ & NS \\
\hline
\end{tabular}

a Continuous variables are mean \pm SD ${ }^{\mathrm{b}}$ Median and range. HD, hemodialysis; PD, peritoneal dialysis, $\mathrm{CVD}=$ cardiovascular disease, $\mathrm{ARB}=$ angiotensine receptor blocker, $\mathrm{PWV}=$ pulse wave velocity, $\mathrm{Al}=\mathrm{x}=\mathrm{aortic}$ augmentation index, Kt/V=urea clearance

Serum fetuin-A concentrations did not differ significantly between patients and controls (0.63 \pm 0.16 vs. $0.63 \pm 0.11 \mathrm{~g} / \mathrm{l} ; p=0.59)$ Serum fetuin-A levels were not related to log-hsCRP, Ca, $\mathrm{P}, \mathrm{Ca} * \mathrm{P}$ product, albumin, log-iPTH and duration of dialysis (data not shown). In dialysis patients, but not in controls, serum fetuin-A concentration was inversely related to age $(r=-0.24 ; p=0.005)$. In a post-hoc analysis fetuin-A concentration in PD patients was, also after correction for age, duration of dialysis, log-hsCRP and albumin, significantly higher than in HD patients (0.73 \pm 0.16 vs. $0.60 \pm 0.15 \mathrm{~g} / \mathrm{l} ; p<0.0001)$. 


\section{Predictors of PWV in ESRD}

In dialysis patients, fetuin-A was significantly and inversely related to PWV $(r=-0.26$, $p=0.007$ ) (Figure 4.1). In a univariate analysis, age, MAP, presence of diabetes mellitus and fetuin-A were significant predictors of PWV, whereas sex, log-hsCRP, log-iPTH, Ca, $\mathrm{P}$, and the $\mathrm{Ca} * \mathrm{P}$ product and dialysis modality were not. After adjustment for age, sex, MAP and diabetes, fetuin-A lost the statistical significant association to PWV (Table 4.2).

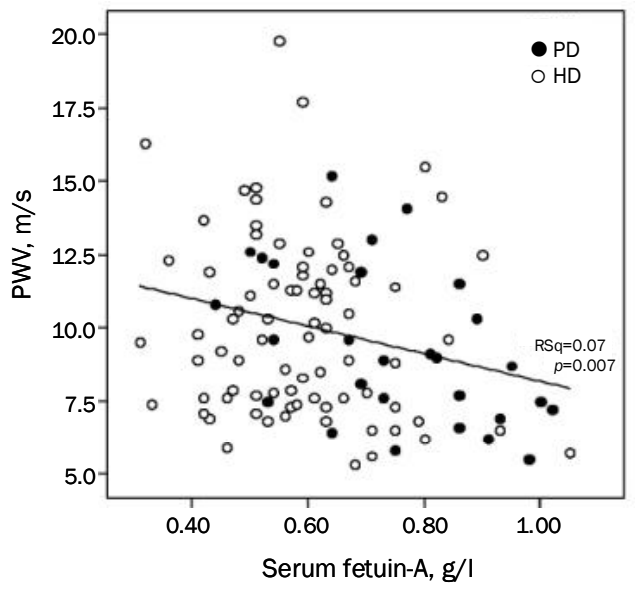

Figure 4.1 The correlation ( $R s q=0.07 ; p=0.007$ ) between serum fetuin-A and pulse wave velocity in 110 dialysis patients.

Table 4.2 Pulse Wave Velocity (PWV) and Augmentation Index (Alx) according to fetuin-A in dialysis patients and controls; adjusted analysis.

\begin{tabular}{|c|c|c|c|c|}
\hline \multirow[b]{2}{*}{ Model } & \multicolumn{2}{|c|}{ Patients } & \multicolumn{2}{|c|}{ Controls } \\
\hline & PWV & Alx & PWV & $\mathrm{Al}$ \\
\hline 1 fetuin & $-0.5^{a}$ & $-1.8^{a}$ & $0.8^{\mathrm{a}}$ & $4.0^{b}$ \\
\hline & $(-0.8$ to -0.1$)$ & $(-3.0$ to -0.5$)$ & (0.3 to 1.2 ) & (0.8 to 7.3 ) \\
\hline 2 1+age & -0.1 ns. & -1.1 ns. & $0.7 *$ & $3.0 \mathrm{~ns}$. \\
\hline & $(-0.4$ to 0.2$)$ & $(-2.4$ to 0.2$)$ & (0.2 to 1.1 ) & $(-0.1$ to 6.1$)$ \\
\hline $32+\operatorname{sex}$ & $\begin{array}{c}-0.1 \text { ns. } \\
(-0.4 \text { to } 0.2)\end{array}$ & $\begin{array}{l}-1.1 \text { ns. } \\
(-2.2 \text { to } 0.1)\end{array}$ & $\begin{array}{c}0.7^{*} \\
(0.2 \text { to } 1.1)\end{array}$ & $\begin{array}{c}2.9 \text { ns. } \\
(-0.2 \text { to } 6.0)\end{array}$ \\
\hline $43+$ MAP & $\begin{array}{c}0.2 \text { ns. } \\
(-0.3 \text { to } 0.3)\end{array}$ & $\begin{array}{c}-0.7 \text { ns. } \\
(-1.8 \text { to } 0.5)\end{array}$ & $\begin{array}{c}0.4 \text { ns. } \\
(-0.1 \text { to } 0.8)\end{array}$ & $\begin{array}{c}2.0 \mathrm{~ns} . \\
(-1.2 \text { to } 5.2)\end{array}$ \\
\hline 54 + Diabetes & $\begin{array}{c}-0.5 \text { ns. } \\
(-0.4 \text { to } 0.3)\end{array}$ & $\begin{array}{c}-0.6 \text { ns. } \\
(-1.8 \text { to } 0.5)\end{array}$ & & \\
\hline
\end{tabular}

Results are expressed as regression coefficients and their 95\% Confidence Interval $(\mathrm{Cl})$. Serum fetuin- $\mathrm{A}$ is expressed per $0.1 \mathrm{~g} / \mathrm{l}$ increase. a $p<0.01,{ }^{\mathrm{b}} p<0.05$, ns.; non- significant. 


\section{Predictors of Alx in ESRD}

Fetuin-A concentration was also significantly and inversely related to Alx $(r=-0.26$, $p=0.006$ ) (Figure 4.2). Age, MAP, sex and fetuin-A were significant predictors of Alx. Log-hsCRP, log-iPTH, Ca, P, presence of diabetes mellitus, and the $\mathrm{Ca} * \mathrm{P}$ product were not related to Alx. After adjustment for age, sex MAP and diabetes, fetuin-A lost the statistical significant association to Alx (Table 4.2).

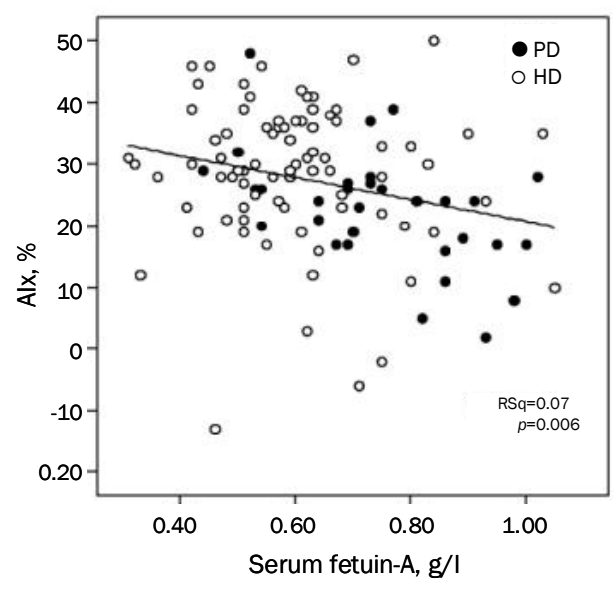

Figure 4.2 The correlation ( $\mathrm{Rsq}=0.07 ; p=0.006$ ) between serum fetuin-A and augmentation index (Alx) in 114 dialysis patients .

\section{Predictors of PWV in controls}

In contrast to the above, fetuin-A serum concentration in controls was significantly positively related to PWV ( $r=0.50 ; p=0.001$ ) (Figure 4.3). In a univariate analysis, MAP, age and fetuin-A were significant predictors of PWV, whereas sex, log-hsCRP, $\mathrm{Ca}, \mathrm{P}$ and the $\mathrm{Ca}$ * $\mathrm{P}$ product were not. After correction for age, sex and MAP the significance was lost for the correlation between fetuin-A and PWV (Table 4.2). 


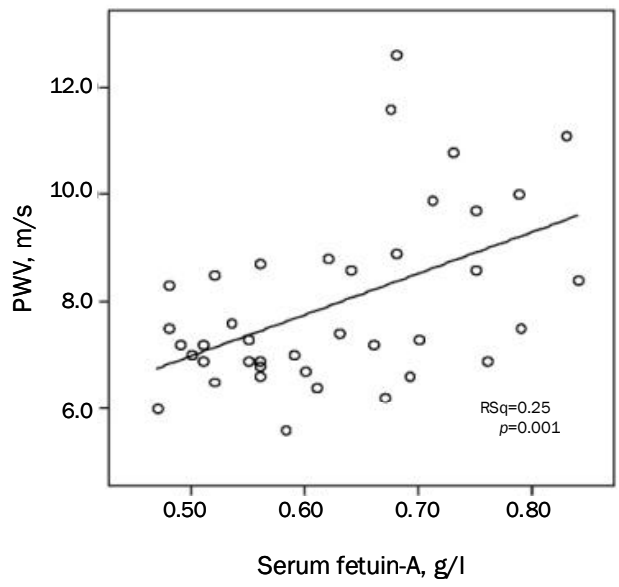

Figure 4.3 The correlation between serum fetuin-A and (Rsq=0.25; $p=0.001)$ and pulse wave velocity (PWV) in 39 controls.

\section{Predictors of Alx in controls}

Fetuin-A concentration in controls was significantly positively related to Alx $(r=0.37$; $p=0.017$ ) (Figure 4.4). In a univariate analysis, age, fetuin-A and MAP were predictors of Alx. After correction for age and MAP, the significant correlation between fetuin-A and Alx disappeared (Table 4.2).

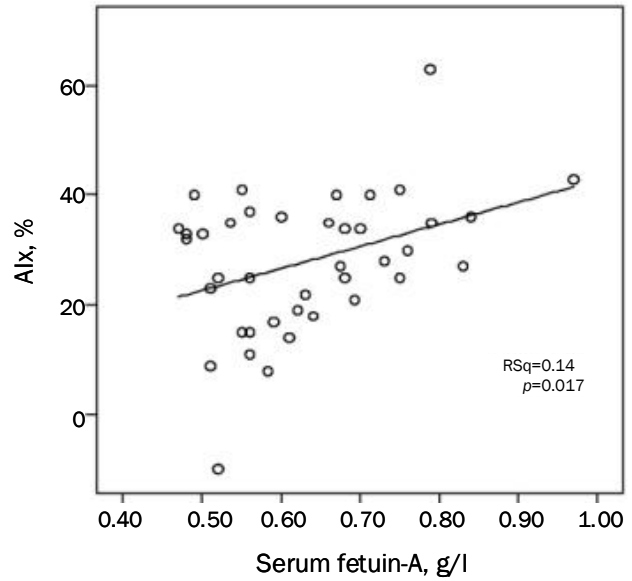

Figure 4.4 The correlation between serum fetuin-A and $(\mathrm{Rsq}=0.14 ; p=0.017)$ and Augmentation index (Alx) in 39 controls. 


\section{Discussion}

This is the first study assessing the association between serum fetuin-A levels and aortic stiffness in dialysis patients. Fetuin-A levels negatively correlated with Alx and PWV in ESRD patients, but could not be identified as an independent risk factor for the development of arterial stiffness. Adjustment for age, MAP, diabetes (PWV) and age, MAP, and sex (AIx), respectively, made the statistically significant correlation with serum fetuin-A disappear. Various authors have shown that serum fetuin-A levels were associated with morphological arterial parameters. In ESRD patients a significant relation between low fetuin-A levels and coronary calcifcation $^{23}$, prevalence of carotid plaques $^{14}$ and valvular calcification ${ }^{15}$ have been shown. Our study showed an absence of a relation between fetuin-A levels and a functional arterial parameter (stiffness). Interpreting the absence of such a potential independent influence of fetuin-A upon PWV and Alx it is important to point out that age and MAP are the major predictors of arterial stiffness overriding the association with fetuin-A.

In contrast to PWV, Alx did not differ between patients an controls. As stated in the methods section, it is important to realise that these measures are not interchangeable. In a multivariate analysis in a study by Kelly et al. Alx did not even correlate with PWV. ${ }^{24}$ Several authors have shown that PWV and Alx react different on volume reduction with hemodialysis. ${ }^{25,26}$ Pulse wave velocity did not change, or even rose, where Alx decreased or even normalised after hemodialysis, compared to controls. The lower post dialysis blood pressure thus had more effect on the Alx than on the PWV. We hypothesize that the relative adequate blood pressure control in our patients could be an explantation for the lower Alx.

In contrast to Moe, Stenvinkel, and Wang, Mehrotra et al. found a direct relationship between fetuin-A levels and coronary artery calcifications in nondialyzed patients with diabetic nephropathy in CKD stages 1-4.22 These data point towards a complex relation between fetuin- $A$ and calcification in different settings. In contrast to our dialysis cohort we found a direct relationship between fetuin-A and PWV and Alx in the control group. This analysis was not the primary goal of our study but merely a posthoc analysis. Therefore, the result should be interpreted with caution. Nevertheless, since fetuin-A deposition is strongly deposited at sites of vascular calcifications ${ }^{15}$, fetuin-A may be a functional defense system against overt unwanted calcifications in populations without or with early stages of CKD as in our control group, but may finally become down-regulated and exhausted in the uremic state.

In contrast to a previous study by Ketteler et al. ${ }^{13}$ fetuin-A levels in our dialysis patients were not different from fetuin-A levels in the control group. The reason for the missing difference in fetuin-A levels between patients and controls appears to be the low mean serum fetuin-A level in spouses and healthy staff members. In the previous study by Ketteler et al., mean fetuin-A levels in dialysis patients were 
significantly lower than compared to controls (0.66 vs. $0.72 \mathrm{~g} / \mathrm{l}, p=0.014$ ) but comparable to the levels obtained in our dialysis patients. A definite explanation for this surprising finding cannot be provided. Demographic differences between our study and earlier studies might have played a role. Although all controls anamnestically had a cardiovascular negative medical history it is quite remarkable that one third were hypertensive according to the JNC VII criteria. Thus they might have been less "healthy" compared to the blood donors studied by Ketteler et al. Also the renal function was decreased in some controls corresponding to stage 1 to 2 CKD.

Also in contrast to recent studies ${ }^{13,14}$, in the present study no relation was seen between serum fetuin-A concentrations and hsCRP as well as between fetuin-A and serum albumin levels. Possibly the lower level of inflammation in our study compared to earlier studies might play a role. Compared to the Ketteler cohort (mean CRP $16.3 \pm 25.1 \mathrm{mg} / \mathrm{l}$ ) and the Stenvinkel cohort (mean CRP 4.2 for patients without and $13.0 \mathrm{mg} / \mathrm{l}$ with cardiovascular disease) our ESRD patients exhibited low CRP levels ( $4.0 \mathrm{mg} / \mathrm{l}$ for the entire group). This interpretation is supported by cross-sectional data from non-dialyzed patients in whom no drop of fetuin-A is detectable with CRP levels below $10 \mathrm{mg} / \mathrm{l}$ (Ketteler, Brandenburg, unpublished data).

An interesting finding of a post hoc analysis of our study was the significantly higher fetuin-A level in PD patients. This finding however requires further confirmation, especially since another study could not detect such a difference in $\mathrm{PD}$ versus $\mathrm{HD}$ patients. ${ }^{14}$

Our study is limited by its cross-sectional nature. Parameters such as fetuin-A and CRP levels were only assessed at a single-point in time instead of having time averaged values, and related to markers of arterial stiffness which develop over many years. Furthermore, arterial stiffness is a complex phenomenon and just represents a surrogate parameter of medial calcification.

In summary, in a, with respect to inflammation relative "healthy" dialysis population, the calcification inhibitor fetuin-A was found to be inversely related to PWV and Alx in univariate analyses. Statistical significance was lost after correction for confounders. Fetuin-A therefore appeared not to be an independent predictor of aortic stiffness in a dialysis population with a low level of inflammatory activity. 


\section{References}

1. Foley RN, Parfrey PS, Sarnak MJ. Epidemiology of cardiovascular disease in chronic renal disease. J Am Soc Nephrol 1998;9:S16-23.

2. Savage T, Clarke AL, Giles M, Tomson CR, Raine AE. Calcified plaque is common in the carotid and femoral arteries of dialysis patients without clinical vascular disease. Nephrol Dial Transplant 1998;13:2004-2012.

3. London GM. Alterations of arterial function in end-stage renal disease. Nephron 2000;84: 111-118.

4. Blacher J, Safar ME, Guerin AP, Pannier B, Marchais SJ, London GM. Aortic pulse wave velocity index and mortality in end-stage renal disease. Kidney Int 2003;63:1852-1860.

5. London GM, Blacher J, Pannier B, Guerin AP, Marchais SJ, Safar ME. Arterial wave reflections and survival in end-stage renal failure. Hypertension 2001;38:434-438.

6. Guerin AP, London GM, Marchais SJ, Metivier F. Arterial stiffening and vascular calcifications in end-stage renal disease. Nephrol Dial Transplant 2000;15:1014-1021.

7. Safar ME, London GM, Plante GE. Arterial stiffness and kidney function. Hypertension 2004; 43:163-168.

8. Mourad JJ, Girerd X, Boutouyrie P, Laurent S, Safar M, London G. Increased stiffness of radial artery wall material in end-stage renal disease. Hypertension 1997;30:1425-1430.

9. London GM, Marchais SJ, Guerin AP, Metivier F, Adda H, Pannier B. Inflammation, arteriosclerosis, and cardiovascular therapy in hemodialysis patients. Kidney Int Suppl 2003:S88-93.

10. Schafer C, Heiss A, Schwarz A, Westenfeld R, Ketteler M, Floege J, Muller-Esterl W, Schinke T, Jahnen-Dechent $W$. The serum protein alpha 2 -Heremans-Schmid glycoprotein/fetuin-A is a systemically acting inhibitor of ectopic calcification. J Clin Invest 2003;112:357-366.

11. Jahnen-Dechent W, Schinke T, Trindl A, Müller-Esterl W, Sablitzky F, Kaiser S, Blessing M. Cloning and targeted deletion of the mouse fetuin gene. J Biol Chem 1997;272:31496-31503.

12. Ketteler M, Wanner C, Metzger T, Bongartz P, Westenfeld R, Gladziwa U, Schurgers L, Vermeer C, Jahnen-Dechent W, Floege J. Deficiencies of calcium-regulatory proteins in dialysis patients: a novel concept of cardiovascular calcification in uremia. Kidney Int Suppl 2003:S84-87.

13. Ketteler M, Bongartz P, Westenfeld R, Wildberger JE, Mahnken AH, Böhm R, Metzger T, Wanner C, Jahnen-Dechent W, Floege J. Association of low fetuin-A (AHSG) concentrations in serum with cardiovascular mortality in patients on dialysis: a cross-sectional study. Lancet 2003;361: 827-833.

14. Stenvinkel P, Wang K, Qureshi AR, Axelsson J, Pecoits-Filho R, Gao P, Barany P, Lindholm B, Jogestrand T, Heimbürger O, Holmes C, Schalling M, Nordfors L. Low fetuin-A levels are associated with cardiovascular death: Impact of variations in the gene encoding fetuin. Kidney Int 2005;67:2383-2392.

15. Wang AY, Woo J, Lam CW, Wang M, Chan IH, Gao P, Lui SF, Li PK, Sanderson JE. Associations of serum fetuin-A with malnutrition, inflammation, atherosclerosis and valvular calcification syndrome and outcome in peritoneal dialysis patients. Nephrol Dial Transplant 2005;20: 1676-1685.

16. Moe SM, Chen NX. Inflammation and vascular calcification. Blood Purif 2005;23:64-71.

17. Chobanian AV, Bakris GL, Black HR, Cushman WC, Green LA, Izzo JL Jr, Jones DW, Materson BJ, Oparil S, Wright JT Jr, Roccella EJ; National Heart, Lung, and Blood Institute Joint National Committee on Prevention, Detection, Evaluation, and Treatment of High Blood Pressure; National High Blood Pressure Education Program Coordinating Committee. The Seventh Report of the Joint National Committee on Prevention, Detection, Evaluation, and Treatment of High Blood Pressure: the JNC 7 report. JAMA 2003;289:2560-2572.

18. K/DOQI clinical practice guidelines for chronic kidney disease: evaluation, classification, and stratification. Am J Kidney Dis 2002;39:S1-266.

19. Covic A, Gusbeth-Tatomir P, Goldsmith DJ. Arterial stiffness in renal patients: an update. Am J Kidney Dis 2005;45:965-977.

20. O'Rourke MF. Wave travel and reflection in the arterial system. J Hypertens 1999;17:S45-47. 
21. Pannier BM, Avolio AP, Hoeks A, Mancia G, Takazawa K. Methods and devices for measuring arterial compliance in humans. Am J Hypertens 2002;15:743-753.

22. Mehrotra R, Westenfeld R, Christenson P, Budoff M, Ipp E, Takasu J, Gupta A, Norris K, Ketteler M, Adler S. Serum fetuin-A in nondialyzed patients with diabetic nephropathy: relationship with coronary artery calcification. Kidney Int 2005;67:1070-1077.

23. Moe SM, Reslerova M, Ketteler M, O'neill K, Duan D, Koczman J, Westenfeld R, Jahnen-Dechent W, Chen NX. Role of calcification inhibitors in the pathogenesis of vascular calcification in chronic kidney disease (CKD). Kidney Int 2005;67:2295-2304.

24. Kelly RP, Millasseau SC, Ritter JM, Chowienczyk PJ. Vasoactive drugs influence aortic augmentation index independently of pulse-wave velocity in healthy men. Hypertension 2001;37: 1429-1433.

25. Tycho Vuurmans JL, Boer WH, Bos WJ, Blankestijn PJ, Koomans HA. Contribution of volume overload and angiotensin II to the increased pulse wave velocity of hemodialysis patients. J Am Soc Nephrol 2002;13:177-183.

26. Covic A, Goldsmith DJ, Gusbeth-Tatomir P, Covic M. Haemodialysis acutely improves endotheliumindependent vasomotor function without significantly influencing the endothelium-mediated abnormal response to a beta 2-agonist. Nephrol Dial Transplant 2004;19:637-643. 


\section{Chapter 5}

Associations of serum fetuin-A concentrations with mortality in peritoneal and hemodialysis patients

MMH Hermans, V Brandenburg (equally contributing author), M Ketteler, JP Kooman, FM van der Sande, EW Boeschoten, KML Leunissen, RT Krediet, FW Dekker, for the Netherlands cooperative study on the adequacy of Dialysis (NECOSAD)

Kidney International. 2007;72:202-207 


\section{Abstract}

\section{Background}

Low levels of fetuin-A are associated with mortality in dialysis patients. Fetuin-A is down-regulated by inflammation. In incident hemodialysis (HD) and peritoneal dialysis (PD) patients we studied the association of fetuin-A and all-cause, cardiovascular (CV) as well as non-CV mortality, and addressed the relative impact of inflammation.

\section{Methods}

In a prospective, multicenter cohort study (Netherlands Cooperative Study on the Adequacy of Dialysis, NECOSAD) we included 987 dialysis patients, 664 on HD and 323 on PD. Parameters were measured three months after start of dialysis treatment. Cox-regression models were used to calculate mortality risks.

\section{Results}

An increase of serum fetuin-A of $0.1 \mathrm{~g} / \mathrm{I}$ was associated with a reduction in all-cause mortality of $13 \%$ (hazard ratio (HR) 0.87 ; $95 \%$ confidence interval $(\mathrm{Cl}) 0.80$ to 0.93 ), in non-CV mortality of $17 \%$ (HR 0.83 ; $\mathrm{Cl} 0.75$ to 0.92 ), and a trend towards CV-mortality reduction (HR 0.90; $\mathrm{Cl} 0.81$ to 1.00; $p=0.06$ ), independently of age, sex, diabetes, cardiovascular disease, current smoking, primary kidney disease and dialysis modality. After additional adjustments for high sensitivity C-reactive protein, body mass index, albumin and subjective global assessment, the reduction of all-cause mortality remained significant (HR 0.91; $\mathrm{Cl} 0.84$ to 0.98) and there was a trend towards a lower CV and non-CV mortality. The associations of fetuin-A and mortality rates were comparable in HD and PD patients.

\section{Conclusions}

Low fetuin-A levels are independently related to all-cause mortality in both PD and HD patients. Fetuin-A is not only related to CV-mortality but also to non-CV mortality and can be seen as a general predictor for mortality in dialysis patients. 


\section{Introduction}

Cardiovascular mortality in patients with end-stage renal disease (ESRD) is markedly increased and substantially related to accelerated calcifying atherosclerosis. ${ }^{1-4}$ In this context, derangements of calcium-phosphate metabolism seem to play an important role.5,6 Disturbances of the calcium-phosphate metabolism are also associated with a greater mortality in both peritoneal (PD) and hemodialysis (HD) patients.7,8

Recently it has been shown that the calcification process as seen in calcifying atherosclerosis is an active, cellular process which is controlled by calcification inhibitors and inducers. ${ }^{9,10}$ Fetuin-A, a glycoprotein with a molecular weight of about $60 \mathrm{kDa}$, is synthesized by hepatocytes and, based on current knowledge, represents the most powerful circulating calcification inhibitor of hydroxyapatite formation. Fetuin-A reacts as a negative acute phase protein, thus down-regulation may occur in acute and chronic inflammatory states. ${ }^{11,12}$ In ESRD patients, serum fetuin-A concentrations were associated with increased coronary arterial and valvular calcification scores. . $^{13,14}$

Until now four studies have been published on the relationship between serum fetuin-A concentrations with all-cause and cardiovascular mortality in dialysis patients. ${ }^{14-17}$ All studies showed that a lower serum fetuin-A concentration was associated with increased mortality. There is, however, still controversy whether fetuin-A deficiency should be regarded as an inflammation-dependent or independent risk predictor, since results vary in this context.

Another point of discussion is whether fetuin-A is primarily related to $\mathrm{CV}$ or non-CV mortality. Whereas in the study by Ketteler et al. the association between fetuin-A concentrations and cardiovascular mortality was less pronounced compared to allcause mortality ${ }^{15}$, Stenvinkel et al., showed that fetuin-A was even a stronger predictor of $\mathrm{CV}$ mortality than CRP. ${ }^{16}$ Moreover, there is no study in a larger cohort enabling comparisons between HD and PD patients on this issue. ${ }^{14}$ This differentiation might be of importance, since we observed significantly higher fetuin-A levels in PD patients compared to HD patients in a recently published smaller study cohort. ${ }^{18}$

The aim of the present large, prospective, observational, cohort study was to evaluate the association of serum fetuin-A with mortality in Dutch incident HD and PD patients. Our primary hypothesis was that fetuin-A was not only related to cardiovascular, but also to non-cardiovascular mortality. The second hypothesis was that fetuin-A was equally associated with mortality in HD and PD patients. Our last hypothesis was that inflammation influenced the association between fetuin-A and mortality. 


\section{Materials and methods}

\section{Patients}

The Netherlands Cooperative Study on the Adequacy of Dialysis (NECOSAD) is a large, prospective, multicenter cohort study in which patients with end-stage renal disease are followed up from the initiation of dialysis therapy until transplantation or death. All incident patients with ESRD in 38 of 48 dialysis units in The Netherlands were consecutively invited to participate in the study. Patients had to be at least 18 years of age or older, with dialysis as their first renal replacement therapy and had to give informed consent before inclusion.

For the current analysis, we included incident HD and PD patients who survived the first three months of dialysis and started on long-term dialysis treatment between 1997 and October 2005.

\section{Data collection procedures}

Data on demography, primary kidney disease and comorbidity were collected at the time of entry in the study. Data on residual renal function ( $r K t /$ Vurea and urine production), biochemistry and dialysis characteristics (current modality, dKt/Vurea) were collected three months after initiation of dialysis (baseline visit).

Primary kidney function and causes of death were classified according to the codes of the European Renal Association-Dialysis and Transplantation-Association (ERAEDTA). ${ }^{21}$ The following codes were classified as cardiovascular mortality: 0 (cause of death uncertain/not determined), 11 (myocardial ischemia and infarction), 12 (hyperkalemia), 14 (other causes of cardiac failure), 15 (cardiac arrest, cause unknown), 17 (hypokalemia), 18 (fluid overload), 22 (cerebrovascular accident), 26 (hemorrhage from ruptured vascular aneurysm) and 29 (mesenteric infarction). All other codes were regarded as deaths of non-cardiovascular origin, of which codes 31-39 were classified as deaths due to infection.

Prevalent cardiovascular disease (CVD) was defined as the presence or history of ischemic heart disease, peripheral vascular disease, heart failure and/or cerebrovascular disease. Comorbity was defined according to the risk criteria of Khan et al. ${ }^{22}$ The Khan index is a combination of age and comorbidity leading to three risk groups: low, medium and high.

Residual renal function was expressed as glomerular filtration rate, calculated as the mean of creatinine and urea clearance adjusted for body surface area (in milliliters per minute per $1.73 \mathrm{~m}^{2}$ ). Dialysis dose, expressed as Kt/V urea per week, was calculated as dialysis urea clearance divided by urea distribution volume (V) according to Watson et al.23 For HD patients, dialysis urea clearance was calculated by using a second-generation Daugirdas formula ${ }^{24}$, and for PD patients peritoneal Kt/V was calculated by using 24-hour dialysate collection. 
All laboratory analyses were obtained from blood drawings obtained three months after the initiation of dialysis treatment. In HD patients blood samples were taken just before the start of a hemodialysis session after a short interval.

Plasma calcium (Ca), phosphorus (P) and albumin were measured using standard laboratory techniques in the different centers. Calcium concentration ( $\mathrm{mmol} / \mathrm{I})$ was corrected for albumin concentration.

Both single-point high sensitive CRP (hsCRP) and fetuin-A levels were measured by nephelometry. Serum samples were stored at $-80^{\circ} \mathrm{C}$ prior to analysis. Serum analysis for hsCRP were performed by means of particle enhanced immunonephelometry using a standard "CardioPhase hsCRP" for "BNII" (Dade Behring Holding GmbH, D-65835 Liederbach, Germany). CRPI or CRPII assay protocols were used when appropriate. Interday precision controls revealed variation coefficients (VC) below $6 \%$.

The nephelometry method for fetuin-A employs the same high specificity antibody as the ELISA method previously described ${ }^{15,25}$ with establishing reproducible standard curves after testing for appropriate dilution. Thermostability of fetuin-A was tested prior to nephelometry establishment. Repetitive cycles of thawing and defrosting did not alter fetuin-A levels compared to the reference storage method: NECOSAD samples were stored at $-80^{\circ} \mathrm{C}$ after sampling and serum preparation and transported at dry ice. The nephelometric method for fetuin-A serum measurement has been previously described. ${ }^{18,20}$ It was evaluated in a side-by-side comparison with immunoblot analysis to exclude cross-reactivity of the antibodies with other serum proteins and proteolytic fragments of fetuin-A. For both methods, a polyclonal rabbit anti-human fetuin-A antibody was used that does not cross-react with fetuin-B. Final serum fetuin-A concentrations were calculated by regression analysis of a serial dilution curve obtained from standard serum. For comparison, a control solution of purified serum fetuin-A powder (Boehringer Mannheim GmbH, Mannheim, Dade-Behrging, Marburg, Germany) was prepared. Serum samples were cleared by centrifugation (60 min at $15000 \mathrm{~g}$ ) and diluted 1:4 with $400 \mu \mathrm{l}$ phosphate buffered saline ( $N$ Diluent, Dade Behring Holding, Liederbach, Germany). Nephelometric assays were performed using an automatic nephelometer (BNII, Dade Behring Holding, Liederbach, Germany). The assay linear measurement range of human fetuin- $\mathrm{A}$ is $0.05 \mathrm{~g} / \mathrm{l}$ up to $3.5 \mathrm{~g} / \mathrm{l}$. The within run precision obtained from a 20 -fold measurement of identical samples yielded a VC of $7.8 \%$. The day-to-day precision obtained from repetitive measurements of control serum was determined as a VC of $8.5 \%$.

The nutritional status was scored on the seven-point scale of the subjective global assessment (SGA), which is a standardized method based on the clinical judgment of the dialysis nurse. ${ }^{26}$ Patients with an SGA score of five or less were considered malnourished. 


\section{Statistical analysis}

Normally distributed variables were expressed as mean \pm SD, and non-normally distributed variables as median and range. Before analysis non-normally distributed variables were log-transformed. Patients were divided into tertiles according to fetuin-A concentrations. Kaplan-Meier analysis was used to analyze crude cardiovascular and non-cardiovascular mortality, according to fetuin-A concentration in tertiles. The survival time of a patient was censored the time of transplantation, withdrawal from the study or at the end of the study period (October 1, 2005).

To study fetuin-A concentration as an independent predictor of mortality we used four, on clinical judgment predefined multivariate Cox proportional-hazards models. The first was a crude model, which only contained serum fetuin-A as a continuous variable. The second model contained age, sex, diabetes mellitus, primary kidney disease, cardiovascular disease, current smoking and dialysis modality. Model three was comparable to the second model, but parameters of nutritional state such as SGA, albumin and body mass index (BMI) and log-hsCRP were added. At last, model four was comparable to model three with the additional adjustment for Ca and $P$.

We also studied the potential difference in HD and PD patients of the associations between fetuin-A and mortality. Therefore hazards ratios (HR's) of the observed associations in HD and PD patients were compared.

In order to study the influence of inflammation on the relationship between fetuin-A and mortality, the population was divided by tertiles of hsCRP. We then compared the HR's of the different CRP-fetuin combinations to study whether there was an additive risk of a higher CRP on the association between fetuin-A and mortality.

Standard descriptive statistics were used to examine differences between HD and PD patients. Student t-tests were applied for testing differences in continuous variables, and chi-square tests were used to compare distributions of dichotomous or categorical data Regression analysis was used to adjust for confounders. For all analyses, $p<0.05$ was considered statistical significant. Statistical analyses were performed using SPSS software, version 11.0 (SPSS, Inc, Chicago, IL)

\section{Results}

Between January 1997 and October 2004 serum samples were available for fetuin-A measurements in 996 patients. Eight patients were excluded from the analysis because of missing data concerning survival and dialysis modality. Of the remaining 987 patients, 664 (67\%) were on HD and 323 (33\%) on PD. Of the 323 PD patients 136 (42\%) underwent a kidney transplantation compared to 154 
(23\%) of the HD patients. Censoring due to regaining of renal function, refusal of further participation in the study or changing to a non-NECOSAD related dialysis center was observed in $91 \mathrm{HD}$ (14\%) patients and 37(11\%) PD patients. Of the 987 patients included in the final analysis, 93\% were Caucasian, 5\% Asian, and 2\% were of African or Carribean origin. Baseline characteristics of the patients are shown in Table 5.1. Compared to PD patients, HD patients were older (63 vs. 53 years; $p<0.001$ ), had more CVD (40 vs. $27 \% ; p<0.001)$ and a lower residual renal function (3.5 vs. $4.3 \mathrm{ml} / \mathrm{min} ; p<0.001$ ).

Table 5.1 Baseline characteristics.

\begin{tabular}{|c|c|c|c|c|}
\hline & $\begin{array}{c}\text { All } \\
(n=987)\end{array}$ & $\begin{array}{c}H D \\
(n=664)\end{array}$ & $\begin{array}{c}P D \\
(n=323)\end{array}$ & $\begin{array}{c}p \\
\text { HD vs. PD }\end{array}$ \\
\hline Age, years & $60 \pm 14$ & $63 \pm 14$ & $53 \pm 14$ & $<0.001$ \\
\hline Sex, \% men & 59 & 57 & 64 & 0.028 \\
\hline \multicolumn{5}{|l|}{ Primary kidney disease, \% } \\
\hline Diabetes & 15 & 16 & 15 & NS \\
\hline Glomerulonephritis & 13 & 11 & 19 & $<0.001$ \\
\hline Renal vascular disease & 19 & 21 & 13 & 0.002 \\
\hline Diabetes (\%) & 22 & 24 & 20 & NS \\
\hline Cardiovascular disease, \% & 35 & 40 & 27 & $<0.001$ \\
\hline Current smoking, \% & 23 & 21 & 25 & NS \\
\hline Residual GFR & $3.8 \pm 2.8$ & $3.5 \pm 2.7$ & $4.3 \pm 2.8$ & $<0.001$ \\
\hline SGA, \% malnourished & 27 & 32 & 19 & $<0.001$ \\
\hline Body Mass Index, kg/m² & $24.8 \pm 4.2$ & $24.7 \pm 4.4$ & $24.9 \pm 3.8$ & NS \\
\hline HsCRP, g/l & $4.9(0.1-375)$ & $5.8(0.1-375.0)$ & $3.1(0.1-160.0)$ & $<0.001$ \\
\hline Albumin, g/l & $36 \pm 0.7$ & $35 \pm 0.7$ & $36 \pm 0.5$ & 0.02 \\
\hline Fetuin-A, g/I & $0.64 \pm 0.17$ & $0.60 \pm 0.15$ & $0.72 \pm 0.17$ & $<0.001$ \\
\hline Calcium, mmol/l & $2.36 \pm 0.28$ & $2.31 \pm 0.39$ & $2.43 \pm 0.30$ & $<0.001$ \\
\hline Phosphorus, mmol/l & $1.83 \pm 0.58$ & $1.88 \pm 0.63$ & $1.71 \pm 0.51$ & $<0.001$ \\
\hline
\end{tabular}

Al continuous data expressed as mean $\pm \mathrm{SD}$ aMedian and range; GFR=glomerular filtration rate/ml/min/1.73m²; SGA=subjective global assessment; hsCRP=high sensitive C-reactive protein.

\section{Relation between fetuin-A and other relevant parameters}

Serum fetuin-A negatively correlated with hsCRP $(r=-0.27 ; p<0.01)$ and age $(r=-0.26 ; p<0.01)$ and positively correlated with serum albumin $(r=0.18 ; p<0.01)$ and serum $\mathrm{Ca}$ levels, which were corrected for serum albumin before analysis $(r=0.13 ; p<0.01)$. After adjustment for age, dialysis modality, hsCRP, Ca, albumin and diabetes mellitus, women had higher serum-fetuin-A levels compared to men (0.67 g/l vs. $0.62 \mathrm{~g} / \mathrm{l} ; p<0.01)$

\section{Survival analyses}

Overall, during follow-up time of 987 subjects, 396 died, 93 of 323 PD patients (29\%) and 303 of 664 HD patients (46\%). Kaplan-Meier survival curves show the associations between serum fetuin-A concentrations divided in tertiles with respect to low $(0.25$ to $0.55 \mathrm{~g} / \mathrm{I})$, median $(0.56$ to $0.69 \mathrm{~g} / \mathrm{l})$ and high values $(0.70$ to 
$1.53 \mathrm{~g} / \mathrm{l})$ for all-cause $(\mathrm{n}=396)$ (Figure 5.1) and cardiovascular $(\mathrm{n}=187)$ (Figure $5.2 A)$ and non-cardiovascular mortality $(n=209)$ (Figure 5.2B). Maximal follow-up time was 8.5 years (1997 to 2005), median follow-up time was 2.8 years. A decrease from high to low levels in serum fetuin-A concentration was associated with a significantly increase in cardiovascular (log-rank 13.0; $p<0.001$ ) and noncardiovascular mortality (log-rank 21.2; $p<0.001$ ).

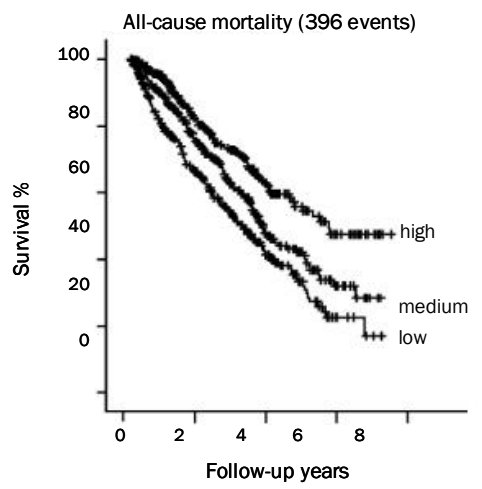

Figure 5.1 Kaplan-Meier curve showing all-cause mortality, by tertile of serum fetuin-A concentration (low $(0.25$ to $0.55 \mathrm{~g} / \mathrm{I})$, median $(0.56$ to $0.69 \mathrm{~g} / \mathrm{I})$ high $(0.70$ to $1.53 \mathrm{~g} / \mathrm{I})$ ) in all dialysis patients.
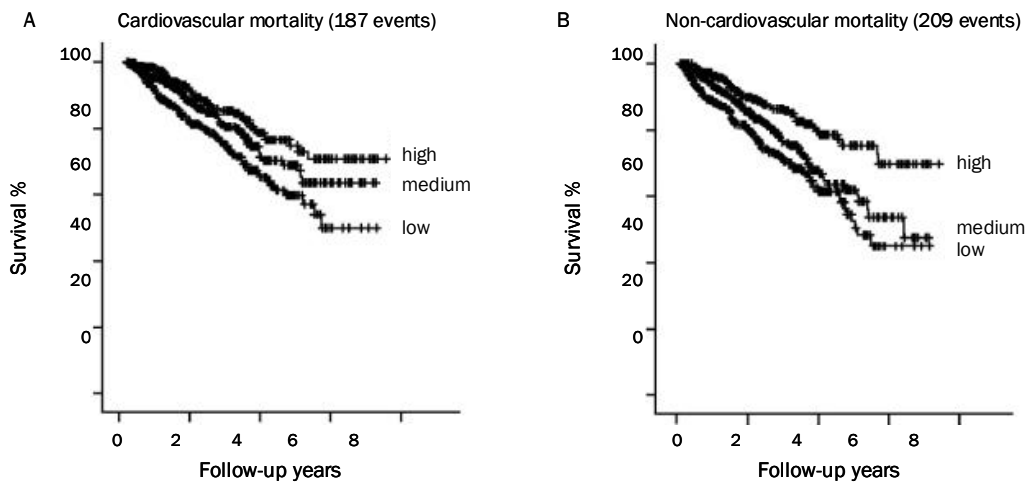

Figure 5.2 Kaplan-Meier curve showing cardiovascular mortality (A) and non-cardiovascular mortality (B), by tertile of serum fetuin-A concentration (low (0.25 to $0.55 \mathrm{~g} /$ /), median (0.56 to $0.69 \mathrm{~g} / \mathrm{I})$ high $(0.70$ to $1.53 \mathrm{~g} / \mathrm{I}))$ in all dialysis patients.

First, a Cox-regression analysis was performed to calculate the adjusted hazard ratios (HR) for overall, cardiovascular and non-cardiovascular death in the total dialysis population (HD and PD patients). Table 5.2 shows the crude and adjusted HRs of an increase of $0.1 \mathrm{~g} / \mathrm{I}$ fetuin-A for the different models. After adjustment for age, sex, diabetes mellitus, primary kidney disease, CVD, dialysis modality and current smoking an increase in serum fetuin-A of $0.1 \mathrm{~g} / \mathrm{I}$ was associated with a HR 
of 0.87 (95\% Cl 0.80 to $0.93 ; p<0.001)$ for all-cause mortality, a HR of 0.90 (95\% $\mathrm{Cl} 0.81$ to $1.00 ; p=0.09)$ for cardiovascular mortality and a HR of $0.83(95 \% \mathrm{Cl}$ 0.75 to $0.92 ; p=0.001$ ) for non-cardiovascular mortality. Further adjustment with addition of the inflammation parameter log-hSCRP and addition of parameters of nutritional state, albumin, BMI and SGA (model 3) resulted in a small increase in the HRs for all categories of mortality. Further adjustments for $\mathrm{Ca}$ and $\mathrm{P}$ did not materially change the results (model 4).

No significant difference was observed in the association of fetuin-A with mortality between the lowest and highest hsCRP tertiles (data not shown). We tested formal interaction between fetuin-A and CRP on the association between fetuin-A and cardiovascular and non-cardiovascular mortality. No significant interaction was observed ( $p=0.25$ and 0.19 respectively).

Table 5.2 Cox-regression showing association of serum fetuin-A concentration with overall, cv and non-cv mortality (expressed per $0.1 \mathrm{~g} / \mathrm{I}$ increase in fetuin-A, hazard ratio with $95 \%$ confidence intervals) in all patients $(n=987)$.

\begin{tabular}{|c|c|c|c|c|c|c|c|}
\hline & \multirow[b]{2}{*}{ Model } & \multicolumn{2}{|c|}{$\begin{array}{l}\text { Overall mortality } \\
(n=396)\end{array}$} & \multicolumn{2}{|c|}{$\begin{array}{l}\text { CV-mortality } \\
(n=187)\end{array}$} & \multicolumn{2}{|c|}{$\begin{array}{l}\text { Non-CV mortality } \\
\quad(n=209)\end{array}$} \\
\hline & & $\mathrm{HR}$ & $95 \% \mathrm{Cl}$ & HR & $95 \% \mathrm{Cl}$ & $\mathrm{HR}$ & $95 \% \mathrm{Cl}$ \\
\hline \multirow[t]{4}{*}{ Fetuin-A } & 1 & 0.80 & 0.75 to 0.86 & 0.83 & 0.75 to 0.91 & 0.76 & 0.69 to 0.84 \\
\hline & 2 & 0.87 & 0.80 to 0.93 & 0.90 & 0.81 to 1.00 & 0.83 & 0.75 to 0.92 \\
\hline & 3 & 0.91 & 0.84 to 0.98 & 0.91 & 0.80 to 1.02 & 0.90 & 0.80 to 1.00 \\
\hline & 4 & 0.91 & 0.84 to 0.99 & 0.92 & 0.82 to 1.05 & 0.89 & 0.79 to 1.00 \\
\hline
\end{tabular}

$\mathrm{HR}$, hazard ratio; Cl, confidence interval. Model 1, crude; Model 2, model adjusted for age, sex, diabetes mellitus, primary kidney disease, cardiovascular disease, dialysis modality and current smoking; Model 3, model 2 + adjustments for, log-hsCRP, albumin, Subjective Global Assessment and BMI; Model 4, model $3+$ adjustments for calcium and phosphate.

\section{Additional analysis.}

Additional adjustment for residual renal function and Khan comorbidity score, did not materially alter the results.

\section{Comparison between PD and HD patients}

Compared to PD patients, HD patients had a lower fetuin-A concentration (0.60 vs. $0.72 \mathrm{~g} / \mathrm{l} ; p<0.001$ ) and a higher hsCRP (5.8 vs. $3.1 \mathrm{~g} / \mathrm{l} ; p=0.002)$. The difference in fetuin-A concentration persisted after adjustment for potential confounders, including age, sex, diabetes, residual renal function, the presence of CVD, hsCRP, $\mathrm{Ca}, \mathrm{P}$ and albumin (Figure 5.3). Forty-two percent of the HD patients had fetuin-A levels below $0.55 \mathrm{~g} / \mathrm{l}$, compared to $15 \%$ of the PD patients. Nonetheless no significant difference was observed in the association of fetuin-A with CV or non-CV mortality between the two dialysis modalities. (dialysis modality interaction analysis, $p=0.07$ ). 


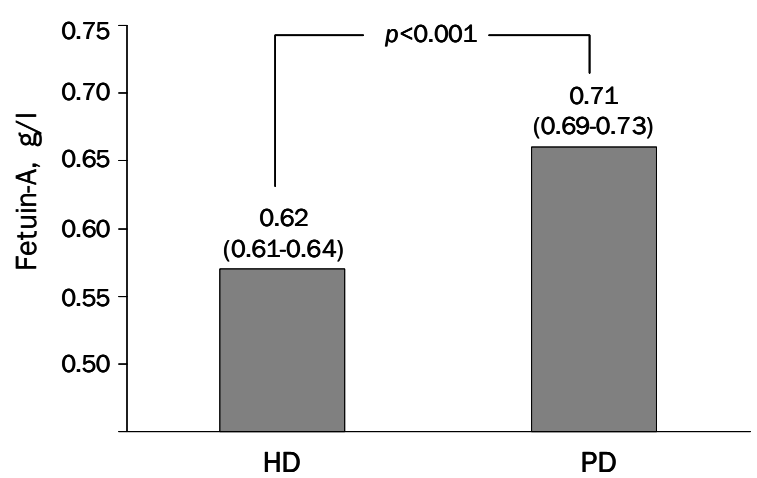

Figure 5.3 Bar chart showing the means (95\% confidence interval) of serum fetuin-A concentration (g/l) in HD and PD patients after adjustment for age, sex, diabetes, residual renal function, hsCRP, CVD, Ca, P and albumin.

\section{Fetuin-A and hsCRP levels in CVD patients}

Compared to patients without CVD, fetuin-A levels in patients with CVD were not different after adjustment for age, sex, hsCRP and the presence of diabetes mellitus. After correction for age, sex and the presence of diabetes mellitus, dialysis patients with prevalent CVD had increased hsCRP levels.

\section{Discussion}

The general strength of this study was the large and well-defined Dutch cohort of incident dialysis patients $(n=987)$ and the ability to study the impact of fetuin-A on different types of mortality, simultaneously both in HD and PD patients. Three main findings were observed. First, a lower serum fetuin-A concentration, three months after the initiation of dialysis treatment, is independently associated with an increased all-cause mortality. Second, survival benefits of a higher serum fetuin-A concentration are seen both with cardiovascular and non-cardiovascular survival, although both these relationships weakened after adjustment for confounders. Third, the found associations did not differ significantly between HD and PD patients, respectively.

Until now, serum fetuin-A was found to be associated with all-cause and cardiovascular mortality in dialysis patients, in four smaller studies with a total of 875 patients. ${ }^{14-17}$ None of these studies had separately analyzed noncardiovascular mortality. Wang et al. ${ }^{14}$ and Ketteler et al. ${ }^{15}$ showed that the association of fetuin-A to all-cause mortality was stronger than to cardiovascular mortality and that the association disappeared after adding inflammation to the regression model. This was in contrast to the findings of Stenvinkel et al. who 
found that fetuin-A was even stronger related to cardiovascular mortality than CRP. ${ }^{16}$

Our data extend the previously publised studies in terms of cohort size as well as follow-up time and show that serum fetuin-A deficiency is a predictor of both noncardiovascular and cardiovascular mortality. Moreover fetuin-A predicted all-cause mortality even after various adjustments.

This finding is of interest, since it was always suspected that the major link between low fetuin-A levels and mortality was caused by accelerated cardiovascular calcification with consecutively increased cardiovascular mortality. ${ }^{13,14}$ This view is supported by data showing that the burden of arterial calcifications in dialysis patients is associated with cardiovascular and all-cause mortality. ${ }^{3}$ However, fetuin-A exerts multiple physiological effects beyond extraosseous calcification inhibition (e.g. TGF-beta antagonism, modification of insulin-receptor-mediated growth effects). ${ }^{19}$ Subgroup analysis in the presented cohort showed that $22 \%$ of the non-cardiovascular death was caused by infection. However, in a multiple regression model containing age, sex, diabetes mellitus, primary kidney disease, CVD, dialysis modality, current smoking, SGA and albumin, neither fetuin-A, nor CRP levels predicted independently death by infection (HR 0.86 ; $\mathrm{Cl} 0.68$ to $1.09(p=0.20)$ and $1.17 ; 0.88$ to $1.60(p=0.28)$ respectively). Finally, because of a possible different role of fetuin- $A$ in diabetics and nondiabetics $^{20}$ we evaluated the possibility of interaction between the presence of diabetes and fetuin-A levels on mortality. However no such interaction was observed $(p>0.4)$.

Finally, we found significantly higher fetuin-A concentrations in PD patients compared to HD patients. This is in line with the results of our previous study in a smaller number of prevalent dialysis patients. ${ }^{18}$ However, Stenvinkel et al. did not find a difference in fetuin-A levels in HD and PD patients after 12 months of renal replacement therapy. ${ }^{16}$ Because of its molecular weight of about $60 \mathrm{kD}$, fetuin- $\mathrm{A}$ will not be lost to a significant degree during hemodialysis treatment ${ }^{19}$, while it could potentially be lost in peritoneal drain effluents in a similar way as albumin. On the other hand, in our population, HD patients had higher CRP levels and this could result in a pronounced down-regulation of fetuin-A. Also, PD patients were younger, had lesser CVD and a greater residual renal function. However, adjustment for all these confounders did not sufficiently explain the consistently observed differences in fetuin-A levels between $H D$ and $P D$ patients. It is noteworthy, that despite these differences in fetuin-A levels, associations between serum fetuin-A concentration and mortality did not differ significantly between HD and PD patients in the presented cohort.

Our study had several potential limitations. The mortality data rely on observations of the treating physicians. This could induce some error in the definition of the exact cause of mortality. Second, no imaging technique was applied to evaluate the amount of arterial calcification in this population. The relations between 
calcifications, mortality and fetuin-A levels therefore could not be explored in the present study.

In summary, the present study shows that in a large dialysis population, low fetuinA levels are associated with increased all-cause mortality, also after adjustment for inflammation and malnutrition. This is both true for HD and PD patients. Fetuin-A was found to be as strongly associated with cardiovascular as with noncardiovascular mortality. Therefore although often exclusively regarded as a cardiovascular risk factor, a low fetuin-A level is most likely a general risk factor for mortality in dialysis patients. 


\section{References}

1. Foley RN, Parfrey PS, Sarnak MJ. Epidemiology of cardiovascular disease in chronic renal disease. J Am Soc Nephrol 1998;9(12 Suppl):S16-23.

2. Goodman WG, London G, Amann K, Block GA, Giachelli C, Hruska KA, Ketteler M, Levin A, Massy Z, McCarron DA, Raggi P, Shanahan CM, Yorioka N; Vascular Calcification Work Group. Vascular calcification in chronic kidney disease. Am J Kidney Dis 2004;43:572-579.

3. Blacher J, Guerin AP, Pannier B, Marchais SJ, London GM. Arterial calcifications, arterial stiffness, and cardiovascular risk in end-stage renal disease. Hypertension 2001;38:938-942.

4. Lindner A, Charra B, Sherrard DJ, Scribner BH. Accelerated atherosclerosis in prolonged maintenance hemodialysis. N Engl J Med 1974;290:697-701.

5. London GM, Guérin AP, Marchais SJ, Métivier F, Pannier B, Adda H. Arterial media calcification in end-stage renal disease: impact on all-cause and cardiovascular mortality. Nephrol Dial Transplant 2003;18:1731-1740.

6. Goodman WG, Goldin J, Kuizon BD, Yoon C, Gales B, Sider D, Wang Y, Chung J, Emerick A, Greaser L, Elashoff RM, Salusky IB. Coronary-artery calcification in young adults with end-stage renal disease who are undergoing dialysis. N Engl J Med 2000;342:1478-1483.

7. Noordzij M, Korevaar JC, Boeschoten EW, Dekker FW, Bos WJ, Krediet RT; Netherlands Cooperative Study on the Adequacy of Dialysis (NECOSAD) Study Group. The Kidney Disease Outcomes Quality Initiative (K/DOQI) guideline for bone metabolism and disease in CKD: association with mortality in dialysis patients. Am J Kidney Dis 2005;46:925-932.

8. Block GA, Hulbert-Shearon TE, Levin NW, Port FK. Association of serum phosphorus and calcium $x$ phosphate product with mortality risk in chronic hemodialysis patients: a national study. Am J Kidney Dis 1998;31:607-617.

9. Shanahan CM. Vascular calcification. Curr Opin Nephrol Hypertens 2005;14:361-367.

10. El-Abbadi M, Giachelli CM. Arteriosclerosis, calcium phosphate deposition and cardiovascular disease in uremia: current concepts at the bench. Curr Opin Nephrol Hypertens 2005;14: 519-524.

11. Schafer C, Heiss A, Schwarz A, Westenfeld R, Ketteler M, Floege J, Muller-Esterl W, Schinke T, Jahnen-Dechent W. The serum protein alpha 2-Heremans-Schmid glycoprotein/fetuin-A is a systemically acting inhibitor of ectopic calcification. J Clin Invest 2003;112:357-366.

12. Lebreton JP, Joisel F, Raoult JP, Lannuzel B, Rogez JP, Humbert G. Serum concentration of human alpha $2 \mathrm{HS}$ glycoprotein during the inflammatory process: evidence that alpha $2 \mathrm{HS}$ glycoprotein is a negative acute-phase reactant. J Clin Invest 1979;64:1118-1129.

13. Moe SM, Reslerova M, Ketteler M, O'neill K, Duan D, Koczman J, Westenfeld R, Jahnen-Dechent W, Chen NX. Role of calcification inhibitors in the pathogenesis of vascular calcification in chronic kidney disease (CKD). Kidney Int 2005;67:2295-2304.

14. Wang AY, Woo J, Lam CW, Wang M, Chan IH, Gao P, Lui SF, Li PK, Sanderson JE. Associations of serum fetuin-A with malnutrition, inflammation, atherosclerosis and valvular calcification syndrome and outcome in peritoneal dialysis patients. Nephrol Dial Transplant 2005;20: 1676-1685.

15. Ketteler M, Bongartz P, Westenfeld R, Wildberger JE, Mahnken AH, Böhm R, Metzger T, Wanner C, Jahnen-Dechent W, Floege J. Association of low fetuin-A (AHSG) concentrations in serum with cardiovascular mortality in patients on dialysis: a cross-sectional study. Lancet 2003;361: 827-833.

16. Stenvinkel P, Wang K, Qureshi AR, Axelsson J, Pecoits-Filho R, Gao P, Barany P, Lindholm B, Jogestrand T, Heimbürger $\mathrm{O}$, Holmes $\mathrm{C}$, Schalling M, Nordfors L. Low fetuin-A levels are associated with cardiovascular death: Impact of variations in the gene encoding fetuin. Kidney Int 2005; 67:2383-2392.

17. Honda H, Qureshi AR, Heimbürger O, Barany P, Wang K, Pecoits-Filho R, Stenvinkel P, Lindholm B. Serum albumin, C-reactive protein, interleukin 6 , and fetuin a as predictors of malnutrition, cardiovascular disease, and mortality in patients with ESRD. Am J Kidney Dis 2006;47:139-148. 
18. Hermans MM, Brandenburg V, Ketteler M, Kooman JP, van der Sande FM, Gladziwa U, Rensma PL, Bartelet K, Konings CJ, Hoeks AP, Floege J, Leunissen KM. Study on the relationship of serum fetuin-A concentration with aortic stiffness in patients on dialysis. Nephrol Dial Transplant 2006;21:1293-9.

19. Ketteler M. Fetuin-A and extraosseous calcification in uremia. Curr Opin Nephrol Hypertens 2005;14:337-342.

20. Ix JH, Shlipak MG, Brandenburg VM, Ali S, Ketteler M, Whooley MA. Association between human fetuin-A and the metabolic syndrome: data from the Heart and Soul Study. Circulation 2006;113:1760-1767.

21. van Dijk PC, Jager KJ, de Charro F, Collart F, Cornet R, Dekker FW, Grönhagen-Riska C, Kramar R, Leivestad T, Simpson K, Briggs JD; ERA-EDTA registry. Renal replacement therapy in Europe: the results of a collaborative effort by the ERA-EDTA registry and six national or regional registries. Nephrol Dial Transplant 2001;16:1120-1129.

22. Khan IH, Catto GR, Edward N, Fleming LW, Henderson IS, MacLeod AM. Influence of coexisting disease on survival on renal-replacement therapy. Lancet 1993;341:415-418.

23. Watson PE, Watson ID, Batt RD. Total body water volumes for adult males and females estimated from simple anthropometric measurements. Am J Clin Nutr 1980;33:27-39.

24. Daugirdas JT. Second generation logarithmic estimates of single-pool variable volume $\mathrm{Kt} / \mathrm{V}$ : an analysis of error. J Am Soc Nephrol 1993;4:1205-1213.

25. Mehrotra R, Westenfeld R, Christenson P, Budoff M, Ipp E, Takasu J, Gupta A, Norris K, Ketteler M, Adler S. Serum fetuin-A in nondialyzed patients with diabetic nephropathy: relationship with coronary artery calcification. Kidney Int 2005;67:1070-1077.

26. Visser R, Dekker FW, Boeschoten EW, Stevens P, Krediet RT. Reliability of the 7-point subjective global assessment scale in assessing nutritional status of dialysis patients. Adv Perit Dial 1999;15:222-225. 


\section{Chapter 6}

Undercarboxylated matrix-Gla protein levels are decreased in dialysis patients and related to parameters of calcium-phosphate metabolism and aortic augmentation index

MMH Hermans, C Vermeer, JP Kooman, V Brandenburg, M Ketteler, U Gladziwa, PL Rensma, KML Leunissen, $\sqcup$ Schurgers

Blood Purification, in press 


\section{Abstract}

\section{Background}

Vascular calcifications are related to cardiovascular mortality and morbidity in dialysis patients. Limited data exist on the role of calcification inhibitors, such as matrix Gla-protein (MGP) in dialysis patients.

\section{Methods}

In 120 dialysis patients and 41 age-matched healthy controls, circulating undercarboxylated (uc)MGP levels were measured with a novel ELISA-based competitive assay. The association between ucMGP levels and determinants of bone mineral metabolism, including the calcification inhibitor fetuin-A, was studied. Moreover, the relation between ucMGP levels and arterial stiffness was investigated.

\section{Results}

The ucMGP level was significantly lower in dialysis patients compared to controls $(173 \pm 70 \mathrm{nmol} / \mathrm{l}$ versus $424 \pm 126 \mathrm{nmol} / / ; p<0.0001$ ). After adjustment for age, sex and duration of dialysis an independent negative association between time averaged phosphate levels (regression coefficient $\beta$ with $95 \%$ confidence interval, -64 [-107 to -21]) and a positive association between serum ucMGP and fetuin-A (131 [55 to 208]) was observed. Duration of dialysis was inversely correlated with ucMGP ( $r=-0.24$, $p=0.007)$. ucMGP levels were not related to hsCRP or time averaged calcium levels. After adjustment for age, sex, cardiovascular disease, diabetes, height and MAP, UCMGP levels were negatively associated with the aortic augmentation index (-0.036 [-0.061 to -0.010$])$, but not with pulse wave velocity or pulse pressure.

\section{Conclusion}

Significantly lower serum ucMGP levels were observed in dialysis patients compared to healthy controls. ucMGP levels were inversely associated with phosphate and positively associated with serum fetuin-A levels. Furthermore, ucMGP levels were inversely associated with the aortic augmentation index. These data suggest that low ucMGP levels may be a marker of active calcification. 


\section{Introduction}

The presence of vascular calcifications is a strong predictor for mortality in dialysis patients. ${ }^{1}$ It has become evident that vascular calcification is an active process, in which the presence of circulating and local inhibitors play a strong regulatory role. ${ }^{2,3}$

Fetuin-A, a circulating inhibitor of calcification, was found to be inversely related to mortality in hemodialysis patients and might serve as a link between inflammation and vascular calcifications in dialysis patients. ${ }^{4-6}$ Most, but not all studies showed lower serum fetuin-A levels in dialysis patients, although the overlap with controls was substantial. ${ }^{6-8}$ Fetuin-A is a negative acute phase protein and therefore, the discrepancy between the results of the previous studies could possibly be due to the different levels of inflammation in the studied populations.

In the dialysis population, much less is known about the potential significance of the local calcification inhibitor, matrix $\gamma$-carboxyglutamic acid (Gla) protein (MGP). MGP is a vitamin K-dependent protein synthesized by chondrocytes and vascular smooth muscle cells. ${ }^{9}$ MGP knockout mice develop severe calcifications of the arterial media. ${ }^{10}$ MGP polymorphisms were found to be related to mortality in dialysis patients ${ }^{11}$, but very limited data exist on circulating MGP levels in dialysis patients, nor on its potential relation with fetuin-A. In non-uremic patients with coronary artery disease, serum MGP levels were decreased compared to control subjects. ${ }^{9}$

Furthermore, not only the quantity of MGP, but also its carboxylation status appears to be of vital importance for the inhibition of calcification. Inhibition of MGP $\gamma$-carboxylation by the vitamin $\mathrm{K}$-antagonist warfarin resulted in extensive calcification of arteries in vitro ${ }^{12}$ and in vivo. ${ }^{13-15}$ This is explained by the fact that during warfarin treatment undercarboxylated MGP (UCMGP) is synthesized, which is inactive. Using immunohistochemistry, Schurgers et al. found a strong association between vascular calcification and local deposition of ucMGP in arteries of nonuremic patients with atherosclerosis and Mönckeberg's sclerosis. ${ }^{9}$

With current MGP assays, no distinction can be made between the active, carboxylated MGP and inactive, undercarboxylated MGP in serum. However, we recently succeeded in developing an assay which enables the specific and accurate quantification of ucMGP in serum. We have found that ucMGP levels were lower in a patient population prone to vascular calcification as compared to non-age and sex-matched controls (unpublished data).

The aim of the present study was to compare ucMGP serum levels in dialysis patients with those of healthy controls, and to study the relation between clinical parameters of mineral metabolism, fetuin-A, and ucMGP levels in dialysis patients. Moreover, the relation between ucMGP and arterial stiffness was studied. 


\section{Materials and methods}

\section{Subjects and study design}

We performed a cross-sectional study in 120 stable, all but two Caucasian, dialysis patients, undergoing hemodialysis (HD; $n=89,74 \%$ ) or peritoneal dialysis (PD; $n=31,26 \%$ ), from three dialysis centers. End-stage renal disease (ESRD) patients were eligible when they had been on dialysis for more than 3 months (median duration 41 months (Inter-quartile range, 38 months)). Patients with an underlying malignancy, infection or heart failure were excluded, as well as patients on warfarin therapy.

The age- and sex-matched control group $(n=41)$ consisted of spouses and healthy staff members. Controls had to have a negative cardiovascular medical history. All participants gave their written informed consent. The study protocol was designed in adherence to the declaration of Helsinki and approved by the ethical committees of the participating centers.

\section{Laboratory analysis}

In the patient group, serum calcium (Ca), phosphate $(\mathrm{P})$ albumin and cholesterol were measured using standard laboratory techniques. In the HD group samples were taken at the start of a short-interval hemodialysis $(2 d$ and $3 d$ dialysis session of the week). Time-averaged values of $\mathrm{Ca}, \mathrm{P}$ and albumin were calculated as the mean of the routine six weekly measurements of the previous six months, which were part of the quality guidelines of the participating hospitals. Calcium concentration was calculated after correction for albumin. Intact parathyroid hormone (iPTH) was measured by a two-site chemiluminescence immunoassay (Nichols Institute Diagnostics; California; USA).

In both groups hsCRP and fetuin-A were measured by nephelometry. Serum was harvested by centrifugation of clotted blood. Serum samples were stored at $-80^{\circ} \mathrm{C}$ prior to analysis. Serum analysis for hsCRP was performed by means of particle enhanced immunonephelometry using a standard "CardioPhase hsCRP" for "BNII" (Dade Behring Holding GmbH, D-65835 Liederbach, Germany). CRPI or CRPII assay protocols were used when appropriate. Interday precision controls revealed variation coefficient (VC) below $6 \%$.

\section{Fetuin-A assay}

The nephelometry method for fetuin-A employs the same high specifity antibody as the ELISA method and has been described elsewhere. ${ }^{8,16}$ Briefly, the measurement has been evaluated in a side-by-side comparison with immunoblot analysis to exclude cross-reactivity of the antibodies with other serum proteins and proteolytic fragments of fetuin-A. Cross-reaction with fetuin-B was excluded. The assay linear 
measurement range of human fetuin-A is $0.05 \mathrm{~g} / \mathrm{l}$ up to $3.5 \mathrm{~g} / \mathrm{l}$. The within-run precision obtained from a 20 -fold measurement of identical samples yielded a VC of $7.75 \%$. The day-to-day precision obtained from repetitive measurements of control serum was determined as a VC of $8.2 \%$.

\section{ucMGP assay}

Undercarboxylated MGP was measured as follows. Anti-ucMGP (VitaK BV, Maastricht, The Netherlands) was coupled to the microtiter plate via polyclonal Rabbit-anti-Mouse IgG (Dako, Heeverlee, Belgium). Next the plate was incubated with anti-ucMGP in $2 \%$ Hepes $\mathrm{NaCl}, \mathrm{pH} 7.4$; bovine serum albumin (HNBSA), for four hours at room temperature. The remaining sites were blocked with $2 \%$ HNBSA and incubated overnight at $4{ }^{\circ} \mathrm{C}$. After stringent washing five $\mu$ of serum sample or standard was diluted in $70 \mu \mathrm{l}$ of $2 \%$ HNBSA and $20 \mu \mathrm{l}$ of this solution was supplemented with $100 \mu \mathrm{l}$ of tracer (biotinylated 35-54 MGP). After gentle mixing, $100 \mu \mathrm{l}$ of this solution were transferred to the microtiter plate and incubated overnight at $4^{\circ} \mathrm{C}$. After washing with HEPES-Tween washing buffer, the plate was incubated with $100 \mu \mathrm{l}$ Streptavidine-peroxidase (Zymed, Breda, The Netherlands), and after washing stained with $100 \mu \mathrm{lMB}$ (KPL, Gennep, The Netherlands). The process was stopped by adding $50 \mu \mathrm{l}$ of $1.0 \mathrm{~mol} / \mathrm{l} \mathrm{H} 2 \mathrm{SO}_{4}$, and the plate was read at $450 \mathrm{~nm}$. The ucMGP concentration was calculated with the aid of a calibration curve of synthetic full-length ucMGP. As will be detailed elsewhere (E.C.M. Cranenburg et al., unpublished data) Western blot analysis showed that the antibodies used in this assay recognize a protein with an apparent molecular weight of $11 \mathrm{kD}$, which was identified unequivocally by mass spectronomy (MALDI TOF/TOF) as full length MGP. The intra-assay variation coefficient was $5.9 \%$. From repetitive measurement of control serum, inter-assay VC of $16.4 \%$ was determined.

\section{Arterial stiffness measurement}

In both groups measurement of blood pressure, aortic pulse wave velocity (PWV) and augmentation index (Alx) were done after 15 minutes of supine rest. The hemodialysis patients were investigated one hour before the dialysis-session. Peritoneal dialysis patients were investigated with an empty abdomen. Brachial systolic and diastolic pressures were assessed at three minutes intervals with a radial artery tonometrical device (CBM 7000, Colin Medial Instruments, San Antonio, Texas, USA) on the right arm or in case of a right-sided dialysis shunt on the left arm. Mean arterial pressure (MAP) was calculated from the mean of three systolic and diastolic pressures as (2 * diastolic pressure + systolic pressure)/3.

PWV was measured using the SphygmoCor (AtCor Medical Ltd., Moreton-in-Marsh, UK). Briefly, a carotid and a femoral artery waveform were obtained consecutively with a high-fidelity applanation tonometer (Millar SPT-301; Millar Instruments Inc., 
Houston, Texas, USA). Transit time was obtained by subtraction from the delays between ECG and both pulses.

The SphygmoCor devise was also used to determine Alx. The Alx is a measure of the additional load to which the left ventricle is subjected as a result of (aortic) wave reflection and was performed with the above described applanation tonometer. The Alx was derived from the right radial arterial pulse by means of a transfer function. In our analysis we used the Alx corrected for heart rate. The methods for measuring PWV and Alx have been described and evaluated elsewhere. ${ }^{17}$

\section{Statistical analysis}

Normally distributed variables are expressed as mean \pm SD, and non-normally distributed variables as median and inter-quartile range (IQR), with $p<0.05$ indicating significance. Non-normally distributed variables were log-transformed for further analysis. ucMGP levels were normally distributed in the patient and control groups. Differences in mean values between groups were compared with t-tests for continuous and with chi-squared tests for categorized variables. Univariate and multiple linear regression analyses were used to investigate the association between ucMGP levels and possible determinants. Multiple linear regression models were first adjusted for age, sex and duration of dialysis (model 1). We then investigated the potential confounding and/or mediating effects of bone mineral metabolism and fetuin-A, by adding calcium, phosphate, fetuin-A and iPTH to the initial model (model 2).

The relation between ucMGP levels and arterial stiffness was studied using univariate and multivariate analysis. The multivariate model included age, sex, cardiovascular disease diabetes and MAP.

\section{Results}

Characteristics of dialysis patients and controls are shown in Table 6.1. ucMGP levels were normally distributed in the two groups. In two patients UcMGP deviated $>5$ SD of the mean (Figure 6.1) and they were marked as outliers. Those patients were withdrawn from further analysis, although results did not change materially after exclusion. As displayed in Figure 6.1, ucMGP levels were significantly lower in dialysis patients compared to control subjects $(173 \pm 70 \mathrm{nmol} / \mathrm{l}$ versus $424 \pm 126 \mathrm{nmol} / \mathrm{l} ; p<0.0001$ ). In univariate analysis, age, sex and hsCRP were not related to ucMGP levels. Duration of dialysis was inversely associated with ucMGP levels $(r=-0.24 ; p=0.007)$. The association remained statistically significant after adjustment for age, sex, phosphate and iPTH. 
Table 6.1 Patient characteristics.

\begin{tabular}{|c|c|c|c|}
\hline & $\begin{array}{c}\text { Controls } \\
n=41\end{array}$ & $\begin{array}{c}\text { Patients } \\
n=118\end{array}$ & $p$ \\
\hline Age, years & $60 \pm 8$ & $61 \pm 14$ & n.s. \\
\hline Male, \% & 52 & 52 & \\
\hline $\mathrm{BMI}, \mathrm{kg} / \mathrm{m}^{2}$ & $26 \pm 4$ & $25 \pm 5$ & n.s. \\
\hline \multicolumn{4}{|c|}{ Blood Pressure, mmHg } \\
\hline SBP & $134 \pm 17$ & $140 \pm 21$ & 0.07 \\
\hline DBP & $75 \pm 8$ & $74 \pm 11$ & n.s. \\
\hline PP & $59 \pm 12$ & $67 \pm 22$ & 0.02 \\
\hline Hypertension, \% & 34 & 83 & $<0.001$ \\
\hline CVD, $\%$ & 0 & 36 & \\
\hline Diabetes, \% & 0 & 31 & \\
\hline Smoking, \% & 27 & 27 & \\
\hline hsCRPa , mg/l & $1.9(3.0)$ & $3.6(6.8)$ & $<0.001$ \\
\hline Calcium, mmol/l & n.a & $2.48 \pm 0.16$ & \\
\hline Phosphate, mmol/l & n.a & $1.76 \pm 0.30$ & \\
\hline iPTH, pg/mla & n.a & $17.4(23.2)$ & \\
\hline Fetuin-A, g/I & $0.63 \pm 0.11$ & $0.63 \pm 0.16$ & n.s. \\
\hline ucMGP, nmol/l & $424 \pm 126$ & $173 \pm 70$ & $<0.0001$ \\
\hline
\end{tabular}

Continuous variables are mean \pm SD, aMedian and interquartile range, CVD, cardiovascular disease; hsCRP, high-sensitivity C-reactive protein; iPTH, intact parathyroid hormone.

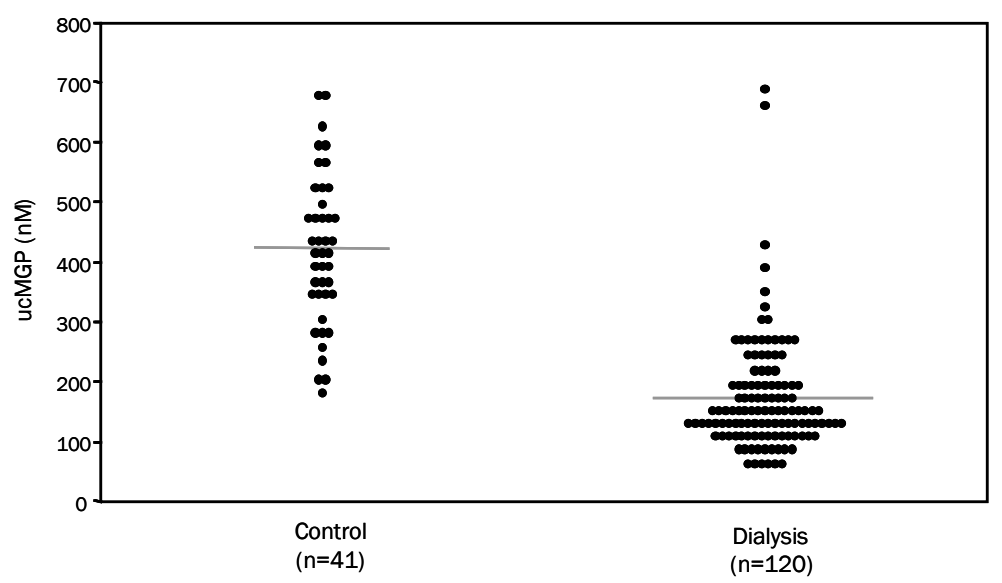

Figure 6.1 Undercarboxylated MGP (ucMGP) levels of dialysis patients $(n=120)$ and controls $(n=41)$

\section{Associations between ucMGP and determinants of bone mineral metabolism}

An inverse significant univariate association was found between ucMGP and phosphate $(r=-0.20 ; p=0.03)$ and a positive association between ucMGP and fetuin-A ( $r=0.34 ; p<0.001)$. No univariate association was found between ucMGP and calcium and iPTH respectively. As summarized in Table 6.2, in multivariate 
analysis, phosphate levels remained inversely associated with ucMGP. Fetuin-A and iPTH were positively correlated with ucMGP levels. In contrast, time averaged phosphate levels, calcium and iPTH levels were not independently related to serum fetuin-A levels (data not shown).

Table 6.2 Associations between calcium, phosphate, iPTH and fetuin-A and ucMGP in dialysis patients; Adjusted analysis

\begin{tabular}{|c|c|c|c|c|}
\hline \multirow{2}{*}{$\frac{\text { Independent variable }}{\text { Calcium, mmol/I }}$} & \multirow{3}{*}{$\begin{array}{l}\text { Model } \\
1\end{array}$} & \multicolumn{3}{|c|}{ Undercarboxylated MGP } \\
\hline & & $\beta$ & $\mathrm{Cl}$ & $p$ \\
\hline & & -7 & -89 to 75 & 0.90 \\
\hline & 2 & -30 & -109 to 50 & 0.46 \\
\hline \multicolumn{5}{|l|}{ Phosphate, mmol/l } \\
\hline & 1 & -64 & -107 to -21 & 0.004 \\
\hline & $2^{a}$ & -62 & -103 to -20 & 0.004 \\
\hline \multicolumn{5}{|l|}{ Log iPTH, pmol/I } \\
\hline & 1 & 23 & -5 to 52 & 0.10 \\
\hline & $2^{b}$ & 36 & 9 to 62 & 0.002 \\
\hline \multicolumn{5}{|l|}{ Fetuin-A, g/l } \\
\hline & 1 & 131 & 55 to 208 & 0.001 \\
\hline & $2^{c}$ & 136 & 62 to 210 & $<0.001$ \\
\hline
\end{tabular}

$\beta$, regression coeficient; indicates difference in ucMGP per 1 unit increase in independent variable; $\mathrm{Cl}$, 95\% confidence interval, log iPTH=log-transformed parathyroid hormone. Model 1, model adjusted for age, sex, duration of dialysis; Model 2, model $1+$ phosphate, iPTH, fetuin-A and calcium. ${ }^{a}$ calcium in stead of phosphate; ${ }^{b}$ calcium in stead of $\mathrm{iPTH}$; ${ }^{\mathrm{c}}$ calcium in stead of fetuin-A

\section{Associations between ucMGP and CVD, DM and markers of arterial stiffness}

Of the 118 dialysis patients PWV and Alx measurements were successful in 99 $(84 \%)$ and $103(87 \%)$ of the cases, respectively. Most failures $(n=11)$ were due to heart rhythm disturbances or technically failed because of vascular access surgery. Mean PWV was $9.8 \pm 3.0 \mathrm{~m} / \mathrm{s}$ and mean Alx was $27 \pm 12 \%$, respectively. In univariate analysis, ucMGP inversely correlated with pulse pressure $(r=-0.19$, $p=0.04)$ and Alx ( $r=-0.30, p=0.002)$. No correlation was found between ucMGP and DM, PWV and prior CVD. After adjusting for CVD, DM, age, sex, height and MAP, ucMGP levels remained negatively associated with Alx ( $\beta,-0.036 ; 95 \% \mathrm{Cl},-0.061$ to $-0.010 ;=0.007$ ). Figure 6.2. shows the adjusted means of Alx (\%) by tertile of ucMGP (low; 60-135, medium; 136-181, high; 182-427 nmol/l). 


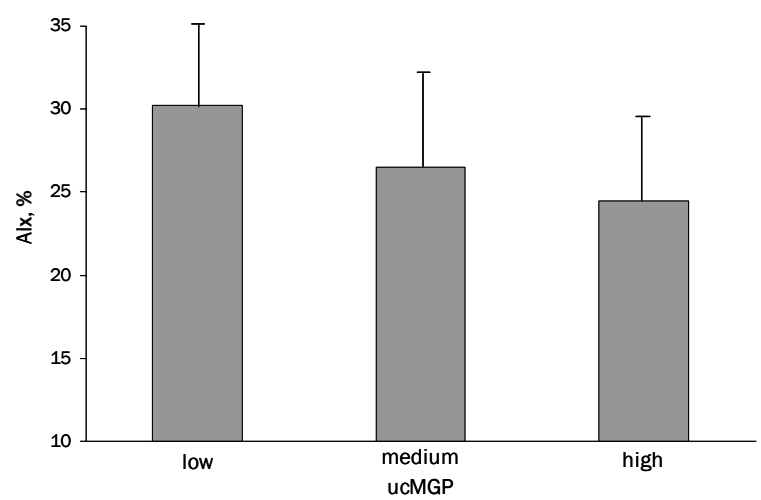

Figure 6.2 Means of Augmentation Index (Alx,\%) with standard deviations, according to serum ucMGP levels (in tertiles) ( $p$ for trend <0.04).

\section{Discussion}

The present study demonstrates significantly lower ucMGP levels in dialysis patients compared to age-matched controls. To the best of our knowledge, MGP or ucMGP levels have not been compared thus far in age-matched healthy controls and dialysis patients. In a previous study in 54 hemodialysis patients, ucMGP levels were lower in hemodialysis patients compared to reference values obtained in nonage matched healthy subjects and comparable to those of non-uremic patients with severe aortic calcification (unpublished data). Moreover, the present study is the first one in which the associations between ucMGP levels and the calciumphosphate metabolism as well as functional vascular parameters are investigated in a well defined clinical cohort of ESRD patients.

In arteries of non-uremic patients with severe atherosclerosis or Mönckeberg's sclerosis, accumulation of ucMGP was observed in intimal and medial lesions, respectively, whereas the active form of MGP was only observed at sites without atherosclerosis. $^{9}$ We hypothesized that the deposition of ucMGP, but not carboxylated (active) MGP in the arterial wall of patients with vascular disease might be due to subclinical vitamin $K$ deficiency. ${ }^{9}$ In patients with ongoing calcifications, locally produced ucMGP may possibly be deposited directly in the calcified arteries and hence not be released into the systemic circulation. The molecular mechanism behind the low ucMGP levels in dialysis patients remains to be determined, however.

Whether the low ucMGP levels have prognostic significance in dialysis patients cannot be determined from the present study. Interestingly, Brancaccio et al found a relation between -7 and -138 MGP gene polymorphisms and cardiovascular mortality in dialysis patients: MGP-138TT homozygotes and -7AA homozygotes or 
-7GA heterozygotes appeared to have a worse cardiovascular prognosis compared to other polymorphisms.11 Whether these polymorphisms coincided with differences in serum MGP levels was not assessed. However, in another study, MGP-138TT homozygotes had 30\% lower levels compared to 136CC homozygotes. ${ }^{18}$ Interestingly, Brancaccio et al. observed a significantly higher frequency of MGP 138-TT homozygotes in hemodialysis patients compared to controls. ${ }^{12}$

In our study, time-averaged phosphate levels during the previous months were independent negative predictors of ucMGP levels. Interestingly, no relation between phosphate and fetuin-A levels was observed in the present cohort, as described previously. ${ }^{8}$ The stronger relation between hyperphosphatemia and ucMGP levels compared to fetuin-A points to a more direct relation of ucMGP with active calcification than fetuin-A, since hyperphosphatemia seems to be a driving force in vascular calcification. ${ }^{19,20}$ This suggestion is strengthened by the fact that we also observed a positive association between iPTH and UcMGP levels. In univariate analysis ucMGP was not significantly related to iPTH. After adjustment for phosphate, fetuin-A and calcium in, ucMGP was significantly related to iPTH. This indicates that the relation between ucMGP and IPTH is independent of phosphate and calcium. In addition, low PTH stages have been associated with low bone turnover states and vascular calcification and in hemodialysis patients with calcium-containing phosphate binding medication, low PTH levels have been associated with vascular calcification. ${ }^{21}$

The difference in ucMGP levels between dialysis patients and controls was remarkably stronger than in levels of fetuin-A, a circulating calcification inhibitor. ${ }^{6,8}$ However, whether this difference coincides with a stronger prognostic power for calcification risk or a stronger relation with existing vascular calcifications remains to be awaited. Moreover, in our cohort of dialysis patients, serum ucMGP levels were significantly correlated with fetuin-A, phosphate and iPTH levels. Although the underlying mechanism for such correlations needs to be clarified, it might be hypothesized that in patients prone to vascular calcification due to low fetuin-A, low iPTH and high phosphate levels, ucMGP levels decline because of local deposition in active vascular lesions. It is of special interest to see the strong and independent correlation between fetuin-A and ucMGP levels in our cohort. This correlation is in line with in vitro data that indicate that MGP and fetuin-A work hand-in-hand to counteract vascular calcification. ${ }^{22}$

UcMGP levels were not related with PWV. However, an inverse relation between ucMGP levels and the Alx, an indirect marker of vascular stiffness, was observed, even after adjustment for confounders. PWV represents the distensibility of the aorta and is a parameter of arterial stiffness. Alx depends on many factors such as age, height and PWV. ${ }^{23}$ Important however, is the PWV independent association between Alx and mortality in patients with ESRD. ${ }^{24}$ The main difference between Alx and PWV is its dependence of peripheral reflectance. ${ }^{24}$ Therefore, the 
association between ucMGP levels and Alx may be based on the relation between ucMGP and peripheral reflectance which is influenced by physical properties, vasomotor tone and the number of smaller (calcified) resistive arteries and branch points. ${ }^{24}$

Drawbacks of the present study are its cross-sectional design, the absence of prognostic data, and the absence of direct assessments of vascular calcification. Arterial calcification, e.g. by electron beam CT, was not assessed in the present study. Longitudinal studies exploring the relation between ucMGP levels with cardiovascular morbidity and direct assessment of vascular calcification are needed to establish the potential prognostic role of ucMGP in this aspect or its role as a marker of active vascular calcification. Therefore the results of the present study warrant further investigations concerning the prognostic role and clinical utility of ucMGP levels in larger cohorts. Furthermore, as it is known that cardiovascular morbidity already rises in stage CKD 2-4, it would be of interest to investigate ucMGP levels in those populations. It is an exciting knowledge that MGP, unlike other calcification inhibitors, might provide a direct target for intervention studies, e.g. with vitamin K therapy.

In conclusion, using a novel assay we have found strikingly lower serum ucMGP levels in dialysis patients compared to age-matched healthy controls. ucMGP levels were negatively associated with phosphate levels and positively with fetuin-A and iPTH levels, suggesting that low ucMGP levels may be a marker of active calcification. More studies have been scheduled to assess the prognostic role of ucMGP and its relation with vascular calcifications and outcome in dialysis patients. 


\section{References}

1. Guerin AP, London GM, Marchais SJ, Metivier F. Arterial stiffening and vascular calcifications in end-stage renal disease. Nephrol Dial Transplant. 2000;15:1014-1021.

2. Jono S, Shioi A, Ikari Y, Nishizawa Y. Vascular calcification in chronic kidney disease. J Bone Miner Metab. 2006;24:176-181.

3. Shanahan CM. Vascular calcification--a matter of damage limitation? Nephrol Dial Transplant. 2006;21:1166-1169.

4. Ketteler M, Schlieper G, Floege J. Calcification and cardiovascular health: new insights into an old phenomenon. Hypertension. 2006;47:1027-1034.

5. Ketteler M, Vermeer C, Wanner C, Westenfeld R, Jahnen-Dechent W, Floege J. Novel insights into uremic vascular calcification: role of matrix Gla protein and alpha-2-Heremans Schmid glycoprotein/fetuin. Blood Purif. 2002;20:473-476.

6. Ketteler M, Bongartz P, Westenfeld R, Wildberger JE, Mahnken AH, Bohm R, Metzger T, Wanner C, Jahnen-Dechent W, Floege J. Association of low fetuin-A (AHSG) concentrations in serum with cardiovascular mortality in patients on dialysis: a cross-sectional study. Lancet. 2003;361: 827-833.

7. Stenvinkel P, Wang K, Qureshi AR, Axelsson J, Pecoits-Filho R, Gao P, Barany P, Lindholm B, Jogestrand T, Heimburger O, Holmes C, Schalling M, Nordfors L. Low fetuin-A levels are associated with cardiovascular death: Impact of variations in the gene encoding fetuin. Kidney Int. 2005; 67:2383-2392.

8. Hermans MM, Brandenburg V, Ketteler M, Kooman JP, van der Sande FM, Gladziwa U, Rensma PL, Bartelet K, Konings CJ, Hoeks AP, Floege J, Leunissen KM. Study on the relationship of serum fetuin-A concentration with aortic stiffness in patients on dialysis. Nephrol Dial Transplant. 2006; 21:1293-1299.

9. Schurgers $\amalg$, Teunissen KJ, Knapen MH, Kwaijtaal M, van Diest R, Appels A, Reutelingsperger CP, Cleutjens JP, Vermeer C. Novel conformation-specific antibodies against matrix gammacarboxyglutamic acid (Gla) protein: undercarboxylated matrix Gla protein as marker for vascular calcification. Arterioscler Thromb Vasc Biol. 2005;25:1629-1633.

10. Luo G, Ducy P, McKee MD, Pinero GJ, Loyer E, Behringer RR, Karsenty G. Spontaneous calcification of arteries and cartilage in mice lacking matrix GLA protein. Nature. 1997;386:78-81.

11. Brancaccio D, Biondi ML, Gallieni M, Turri O, Galassi A, Cecchini F, Russo D, Andreucci V, Cozzolino M. Matrix GLA protein gene polymorphisms: clinical correlates and cardiovascular mortality in chronic kidney disease patients. Am J Nephrol. 2005;25:548-552.

12. Price PA, Chan WS, Jolson DM, Williamson MK. The elastic lamellae of devitalized arteries calcify when incubated in serum: evidence for a serum calcification factor. Arterioscler Thromb Vasc Biol. 2006;26:1079-1085.

13. Spronk HM, Soute BA, Schurgers $\sqcup$, Thijssen HH, De Mey JG, Vermeer C. Tissue-specific utilization of menaquinone-4 results in the prevention of arterial calcification in warfarin-treated rats. J Vasc Res. 2003;40:531-537.

14. Koos R, Mahnken AH, Muhlenbruch G, Brandenburg V, Pflueger B, Wildberger JE, Kuhl HP. Relation of oral anticoagulation to cardiac valvular and coronary calcium assessed by multislice spiral computed tomography. Am J Cardiol. 2005;96:747-749.

15. Schurgers $\sqcup$, Aebert H, Vermeer C, Bultmann B, Janzen J. Oral anticoagulant treatment: friend or foe in cardiovascular disease? Blood. 2004;104:3231-3232.

16. Ix JH, Shlipak MG, Brandenburg VM, Ali S, Ketteler M, Whooley MA. Association between human fetuin-A and the metabolic syndrome: data from the Heart and Soul Study. Circulation. 2006;113:1760-1767.

17. Pannier BM, Avolio AP, Hoeks A, Mancia G, Takazawa K. Methods and devices for measuring arterial compliance in humans. Am J Hypertens. 2002;15:743-753.

18. Farzaneh-Far A, Davies JD, Braam LA, Spronk HM, Proudfoot D, Chan SW, O'Shaughnessy KM, Weissberg PL, Vermeer C, Shanahan CM. A polymorphism of the human matrix gammacarboxyglutamic acid protein promoter alters binding of an activating protein-1 complex and is associated with altered transcription and serum levels. J Biol Chem. 2001;276:32466-32473. 
19. Giachelli CM, Jono S, Shioi A, Nishizawa Y, Mori K, Morii H. Vascular calcification and inorganic phosphate. Am J Kidney Dis. 2001;38:S34-37.

20. Jono S, McKee MD, Murry CE, Shioi A, Nishizawa Y, Mori K, Morii H, Giachelli CM. Phosphate regulation of vascular smooth muscle cell calcification. Circ Res. 2000;87:E10-17.

21. Chertow GM, Raggi P, Chasan-Taber S, Bommer J, Holzer H, Burke SK. Determinants of progressive vascular calcification in haemodialysis patients. Nephrol Dial Transplant. 2004;19: 1489-1496.

22. Reynolds JL, Skepper JN, McNair R, Kasama T, Gupta K, Weissberg PL, Jahnen-Dechent W, Shanahan CM. Multifunctional roles for serum protein fetuin-a in inhibition of human vascular smooth muscle cell calcification. J Am Soc Nephrol. 2005;16:2920-2930.

23. Davies Jl, Struthers AD. Pulse wave analysis and pulse wave velocity: a critical review of their strengths and weaknesses. J Hypertens. 2003;21:463-472.

24. London GM, Blacher J, Pannier B, Guerin AP, Marchais SJ, Safar ME. Arterial wave reflections and survival in end-stage renal failure. Hypertension. 2001;38:434-438. 
108 


\title{
Chapter 7
}

Extra-osseous calcification in a dialysis patient with diabetes mellitus type 2

\author{
MMH Hermans, U Gladziwa
}

Dutch Journal of Medicine, accepted for publication 


\section{Abstract}

Diagnostic image: extra-osseous calcification in a dialysis patient with type 2 diabetes mellitus.

An X-ray of the abdomen of a diabetic dialysis patient showed typical signs of extra-osseous calcification with mediasclerosis and calcification of the vasa deferentia. 


\section{Diagnostic Imaging}

We present a 64-year old male patient with a long-standing history of diabetes mellitus type 2 (DM-2) complicated by micro- and macrovascular complications and end-stage renal disease (ESRD) caused by diabetic nephropathy treated with peritoneal dialysis. An X-ray of the abdomen was made to localize the dialysis catheter and showed apart from a properly located catheter a marked calcification of the pelvic arteries (Figure 7.1.). Next to these vascular structures two symmetrical radiolucent cords were seen, which, because of the localization were most compatible with circumferential calcified vasa deferentia.

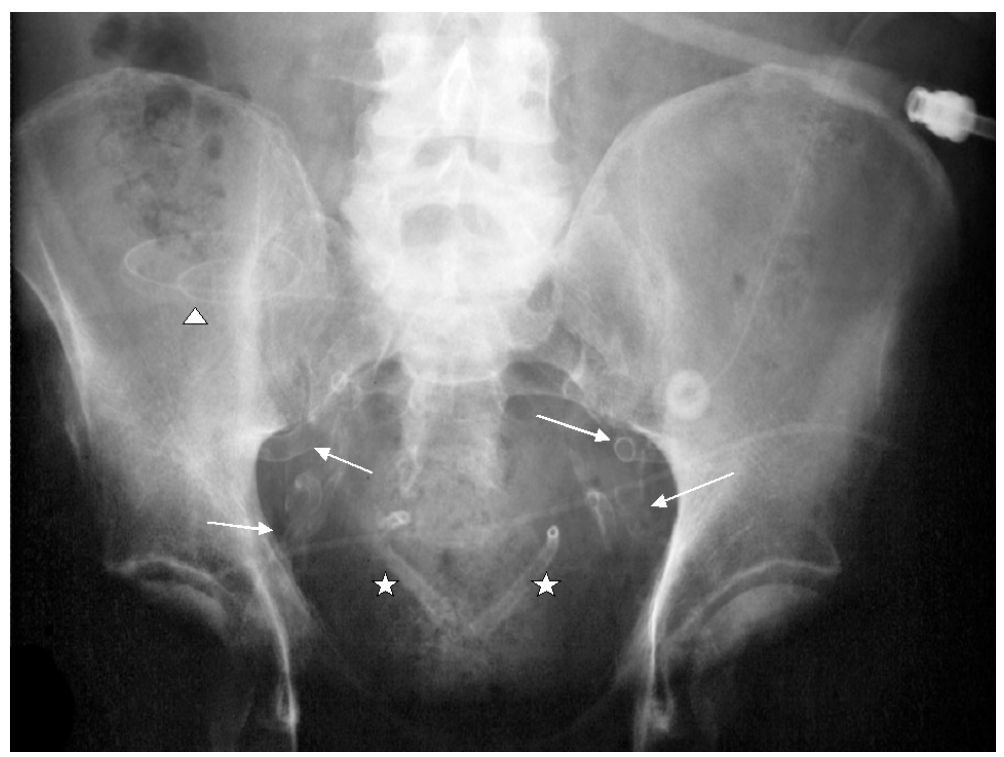

Figure 7.1 X-ray of the abdomen, showing mediasclerosis of the internal and external iliac arteries $(\rightarrow)$ and a pronounced calcification of the vasa deferentia ( $\vec{c}$ ) in a 64-year old male peritoneal dialysis patient; $\Delta=$ peritoneal dialysis catheter.

The picture is illustrative for the extra-osseous calcification encountered in dialysis patients and patients with diabetes. Apart from the well-known atherosclerosis, a primary intimal process, mediasclerosis, also known as Mönckeberg's sclerosis, is a prominent finding. In contrast to the typical irregular wall-densities seen in atherosclerosis, mediasclerosis is characterized by a more continuous, diffuse, often circumferential radio-opacity. Clinically, atherosclerosis causes ischemic 
events due to stenotic lesions. Mediasclerosis is associated with an increase in arterial stiffness. Both arterial wall abnormalities have been associated with a marked increase in cardiovascular morbidity and mortality in dialysis patients. ${ }^{1}$ Recently it has been shown that the extra-osseous calcification process is an active process involving factors of the bone-metabolism in which the osteogenification of vascular smooth muscle cells play a pivotal role. ${ }^{2}$ We supposed that this could be the link between calcification of the pelvic vasculature and the vasa deferentia. $A$ biopsy of the vasa deferentia of another patient revealed the presence of alpha smooth muscle antigen, which supports this hypothesis (Figure 7.2.).

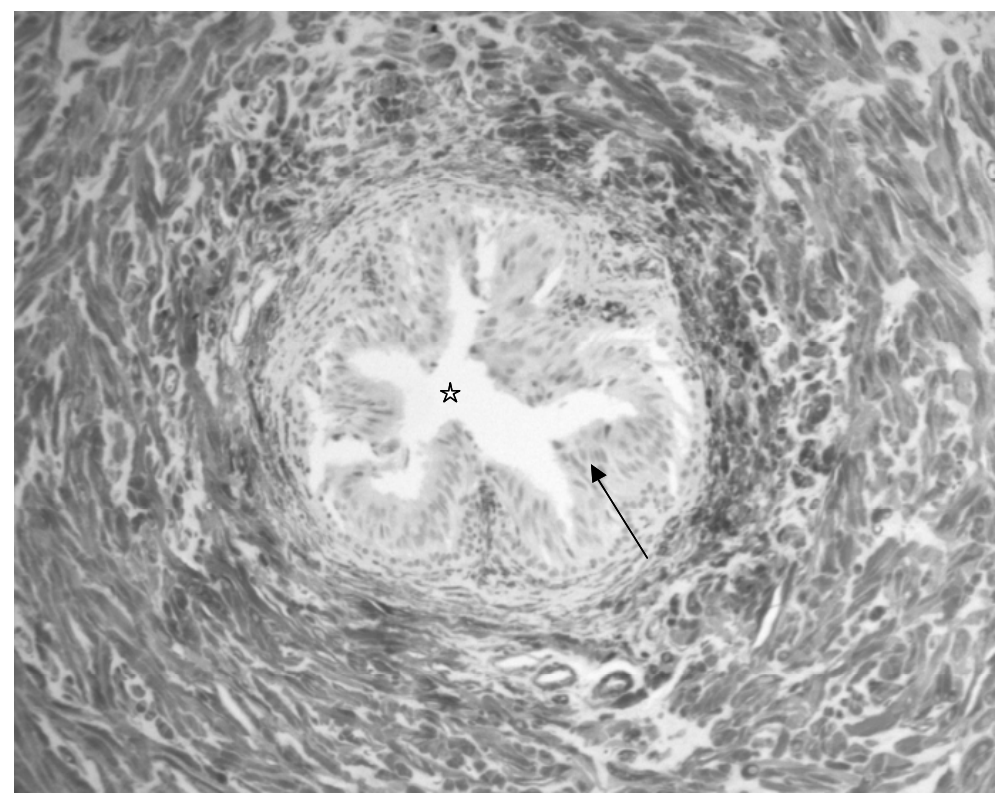

Figure 7.2 Biopsy specimen of a vas deferens ( $\hat{\tau}=$ lumen) surrounded by a layer of urothelial cells $(\rightarrow$ ) showing the abundant presence of smooth muscle cells by immunohistochemical staining with smooth muscle antigen (SMA1) (dark grey cells) . 


\section{References}

1. London GM, Guerin AP, Marchais SJ, Metivier F, Pannier B, Adda H. Arterial media calcification in end-stage renal disease: impact on all-cause and cardiovascular mortality. Nephrol Dial Transplant. 2003;18:1731-1740.

2. Trion A, van der Laarse A. Vascular smooth muscle cells and calcification in atherosclerosis. Am Heart J. 2004;147:808-814. 
114 


\section{Chapter 8}

General discussion 
116 Chapter 8 


\section{General discussion}

\section{Renal insufficiency and cardiovascular disease; a pivotal role for the arterial wall}

Because of the actual obesity pandemic associated with diabetes mellitus type 2 and hypertension, a gradual rise in the prevalence of chronic kidney disease (CKD) is to be expected. Although in the last decennia innovative therapies, including dialysis techniques improved, the cardiovascular morbidity and mortality among dialysis patients is still shockingly high. The greater cardiovascular mortality is not limited to dialysis patients, but in recent years it has become clear that cardiovascular mortality is also increased in mild renal insufficiency. ${ }^{1}$ Atherosclerosis, vascular calcification and arterial stiffness play a pivotal role in the high burden of cardiovascular disease in CKD. These factors all involve the arterial wall and were the central key players in the present thesis.

Atherosclerosis is the main cause of cardiovascular disease in both the general population and in CKD patients and responsible for ischemic events. The atherogenic mechanisms are complex and involve both traditional "Framingham" risk factors as well as non-traditional risk factors including anemia, homocysteinemia, oxidized stress with forming of vasculotoxic lipids like oxidized LDL, inflammation and deregulation of the calcium-phosphate hemostasis. Atherosclerosis primarily involves the intima, and the carotid-IMT is used as a marker of atheroslcerosis. With the use of an innovative ultrasound technique, not only the IMT, but also the irregularity of the IMT, the IMT-inhomogeneity, can be studied. We used this technique to investigate whether IMT and IMTinhomogeneities differed between controls and dialysis patients, and whether they were related to traditional and non-traditional risk factors.

Increased arterial stiffness, often encountered in CKD 4-5 (severe CKD) results in a loss of the so called "cushioning" function of the vessels. A hallmark is an increased pulse pressure, closely related to left ventricular hypertrophy, and a decrease in coronary perfusion. Whether arterial stiffness is increased in CKD 2-3 (mild to moderate CKD) is less clear. Both albuminuria and glomerular filtration rate (GFR) are parameters of renal disease, independently associated with cardiovascular disease. We studied whether arterial stiffness is increased in CKD 2-3 and whether a lower GFR and/or a greater albuminuria are associated with a greater arterial stiffness. Vascular calcification, a hallmark of vascular pathology in dialysis patients, is the third central theme of the present thesis. It is a complex phenomenon typically involving the medial layer of the arterial wall resulting in an increase in arterial stiffness. Simply, vascular calcification is the result from an imbalance between calcification stimulatory factors such as a high phosphate serum concentration, and calcification inhibitory factors. A low level of calcification inhibitors, such as fetuin-A and matrix Gla protein (MGP), is supposed to result in 
arterial calcification. We studied whether a decrease in calcification inhibitor levels was associated with arterial stiffness. Furthermore the associations between calcification inhibitors and parameters of the bone mineral metabolism were studied. At last the role of fetuin-A as a predictor of mortality in a dialysis population was studied.

From the above it may be clear that the integrity of the arterial wall is a major prerequisite for a good cardiovascular health. In CKD this integrity is threatened by numorous traditional and non-traditional risk factors. The purpose of this thesis was to study (markers of) atherosclerosis, determinants of vascular calcification and arterial stiffness in patients with different stages of CKD. Furthermore we tried to elucidate the relation of traditional and non-traditional risk factors with arterial wall abnormalities.

\section{Chapter 2: Renal function and arterial stiffness. GFR or albuminuria; who is the culprit?}

Chronic kidney disease is defined as a decline in GFR and/or the presence of albuminuria. In the Hoorn study mild renal insufficiency has been associated with a greater cardiovascular disease. ${ }^{2}$

In the same population we investigated whether eGFR and albuminuria were associated with arterial stiffness, a well known risk factor for cardiovascular mortality in CKD patients ${ }^{3,4}$ and therefore a potential link between CKD and cardiovascular mortality.

A host of indices exist to measure arterial stiffness. Peripheral arterial stiffness can be measured locally as carotid, brachial and femoral artery distensibility and compliance coefficients. Of these, only carotid artery stiffness correlated with cardiovascular mortality in a dialysis cohort. ${ }^{5}$ The distensibility coefficient reflects the arterial elastic properties whereas the compliance coefficient reflects the arterial buffering capacity. The aortic pulse wave velocity (PWV) is the gold standard to measure the aortic compliance, also referred to as central arterial stiffness. The PWV is a predictor of cardiovascular mortality in a variety of populations including CKD patients. ${ }^{6}$ In this thesis, next to PWV, we also measured the carotid-femoral transit time (CFTT), the time a pressure wave needs to travel from the carotid artery to the femoral artery, and an approximation of the PWV. In general, both a decline in GFR and an increase in albuminuria were associated with a greater arterial stiffness. A decline in GFR was characterized by a loss of the distensibility of the carotid, femoral and brachial arteries. The compliance however, remained largely unchanged due to a greater arterial diameter, which can be interpreted as a defense mechanism to prevent the loss of buffering capacity caused by a decrease in distensibility. A remarkable difference between the associations of GFR and albuminuria with arterial stiffness was the absence of a relation between GFR and CFTT. CFTT is an approximation of the aortic PWV, and 
several authors have shown an association between a decline in renal function and a higher PWV.7,8 Albuminuria is often regarded as a representative of endothelial dysfunction. However, also after adjustment for brachial artery endothelial flow mediated dilatation, a measure of endothelial dysfunction, the relation between albuminuria and PWV remained largely unchanged. It is not clear why this relation was not seen between GFR and PWV. The fact that the data partly derived from a follow-up study contains the possibility that the association was biased due to selective mortality of patients with a lower GFR.

From a clinical standpoint of view our epidemiological data are not directly linked with cardiovascular morbidity and mortality. A general accepted mechanistic view is that arterial stiffness causes increased central pulse pressure and systolic blood pressure. This increases the left vetricular load, resulting in a greater myocardial oxygen demand and subendocardial ischemia. Furthermore arterial stiffness is associated with $\mathrm{LVH}$, a known risk factor for coronary events in normo and hypertensive subjects.9,10 However, the above does not answer the question what the potential clinical impact of the observed increase in arterial stiffness could be. Therefore we used circumstantial evidence to put our data in a clinical context and extrapolated data from two population based studies investigating the impact of arterial stiffness on CV morbidity and mortality. ${ }^{11,12}$ The observed change of CFTT (\%), an approximation of the PWV, per quartile of UACR would be associated with an increase of CVD risk of $18 \%$ and an increase of all-cause mortality of $3 \%$. The potential clinical impact of an increase in femoral artery stiffness comes from data in DM-2 patients, in which femoral artery stiffness is a predictor of peripheral vascular disease. ${ }^{13,14}$ Thus, although femoral artery stiffness is not related to CV mortality, the observed increase in femoral artery stiffness with a decline in GFR may be a predictor of peripheral arterial disease. However, hitherto no studies have been done on this issue.

At last two remarkable findings need to be addressed. Firstly, the found associations between albuminuria and arterial stiffness persisted far below the current cut-off point for microalbuminuria. This is in line with previous findings and questions the current used cardiovascular risk calculations. ${ }^{15}$ Secondly, the associations of albuminuria and GFR with arterial stiffness were mutually independent. Although they might share the same determinants, such as diabetes or hypertension, at least our data suggest that albuminuria and a decline in renal function should be interpreted and consequently treated as independent cardiovascular risk factors.

\section{Chapter 3: IMT-inhomogeneity; a new surrogate marker of atherosclerosis?}

In the introduction the poor predictive value of the carotid IMT for CV events in patients with ESRD was mentioned. We used a novel ultrasound measurement 
technique to study the CCA-IMT and IMT-inhomogeneity, which is a parameter of spatial variance of the IMT. Application of this technique might increase the sensitivity of the IMT measurements and enable the detection of focal atherosclerotic lesions at an earlier stage in development. IMT was measured at 14 adjacent points simultaneously of an artery segment of $16.4 \mathrm{~mm}$. which results in a higher accuracy and sensitivity of the measurements. Using this technique, IMT values in ESRD patients were higher compared to controls. Also IMT-inhomogeneity was significantly higher in dialysis patients compared to controls. Both IMT and IMT-inhomogeneity were greater in patients with CVD compared to those without CVD.

The observation of higher IMT values in dialysis patients is in line with the accelerated atherosclerosis hypothesis introduced by Lindner. ${ }^{16}$ The intima media is exposed to several hemodynamic and toxic loads. Firstly, fluid overload and hypertension often encountered in ESRD patients result in outward arterial remodeling and increase the wall pressure with, according to Laplace's law compensatory wall thickening. Secondly, uremia is a highly "wall" toxic milieu in which lipid disturbances, oxidative stress, hyperhomocysteinemia, accumulation of asymmetric dimethylarginine (ADMA), advanced glycosylation end products (AGE's) and disturbances of the mineral metabolism may all result in arterial wall alteration. Due to inhomogeneity of the IMT, insensitivity of the commonly used single-point assessment or averaging ultrasound technique may be an explanation for the conflicting results between former studies 17,18 and the present study.

Although IMT and IMT-inhomogeneity strongly correlate, they should not be interpreted interchangeably. A regression analysis showed a different pattern of potential determinants for IMT and IMT-inhomogeneity. The non-traditional risk factors fetuin-A, a systemic calcification inhibitor, and IgG anti-oxLDL antibodies, a marker of oxidative stress associated with atherosclerosis, correlated with IMTinhomogeneities inversely and positively respectively. No correlation was seen between fetuin-A and anti-oxLDL antibodies with IMT. Although we do not have tissue samples of IMT-inhomogeneities, the observed correlations might point to a role for calcification and accelerated atherosclerosis in the development of IMTinhomogeneities. IMT-inhomogeneities may represent early changes in the structural properties of the arterial wall, which is in line with the increased frequency of plaques among these patients as compared to controls. ${ }^{18,19}$ The higher IMT values in dialysis patients may reflect thickness of the medial rather than the intima layer which could result from adaptations to the high hemodynamic burden in dialysis patients.

At last, both IMT and IMT-inhomogeneity were higher in dialysis patients with prevalent CVD. Whether this means that IMT-inhomogeneity is a potential risk marker for CVD remains to be proven in future prospective studies. 


\section{Chapter 4 and 6: Calcification inhibitors; determinants of arterial stiffness?}

Recently it has become clear that in patients with ESRD vascular calcification of both the intimal and medial layer are common phenomenona, related with cardiovascular and all-cause mortality. ${ }^{20}$ Intimal calcification is in combination with atherosclerosis a well known cause of occlusive arterial disease, whereas medial calcification is strongly associated with arterial stiffness. ${ }^{21}$ In humans, physiological serum concentrations of phosphate and calcium are above their solubility product and calcification inhibitors are needed to prevent precipitation. Fetuin-A, a powerful systemic calcification inhibitor, and MGP, a vitamin-K dependent locally acting calcification inhibitor were the calcification inhibitory factors studied in this thesis. Low levels of Fetuin-A correlate with increased vascular calcifications in dialysis patients. ${ }^{22}$ In non-uremic patients with coronary artery disease, MGP levels were lower compared to controls. Scarce data exist on the relation between MGP and calcification in dialysis patients. The calcification inhibitory effect of MGP not only depends on the quantity but also on the carboxylation status of MGP. Inhibition of MGP $\gamma$-carboxylation by the vitamin K-antagonist warfarin resulted in extensive calcification of arteries in vitro. ${ }^{23}$ Very recently an ELISA-based assay was developed for the specific and accurate quantification of undercarboxylated MGP (ucMGP) in serum.

The studies in chapter 4 and 6 investigated whether fetuin-A and ucMGP levels correlated with arterial stiffness in a dialysis population. Hitherto no data exist on ucMGP levels in dialysis patients. Therefore ucMGP levels in dialysis patients and controls were compared as well as the relation between ucMGP levels and parameters of the calcium-phosphate metabolism, including fetuin-A.

In chapter 4 we showed in a univariate analysis an inverse correlation between fetuin-A and PWV and Alx. In a multivariate analysis this correlation disappeared, which means that fetuin-A is not an independent predictor of functional arterial parameters. These findings have been confirmed in a recent study in peritoneal dialysis patients. ${ }^{24}$ In our study, serum fetuin-A did not correlate with other parameters of the mineral metabolism such as calcium, phosphate and intact parathyroid hormone (iPTH). Fetuin-A levels were comparable in dialysis patients and controls. In contrast to fetuin-A, ucMGP levels were lower in dialysis patients (chapter 6). UcMGP levels inversely correlated with serum phosphate levels and positively correlated with fetuin-A levels. In a multivariate analysis, ucMGP levels were inversely related to Alx, but not to PWV.

Both fetuin-A and MGP are involved in the calcification process which is an active process in which stimulants, such as calcium and phosphate, and inhibitors, compete. Schurgers et al. recently showed a strong association between vascular calcification and local deposition of ucMGP in arteries of non-uremic patients with atherosclerosis and Mönckeberg's sclerosis. ${ }^{25}$ The low levels of ucMGP observed in our dialysis population could be due to deposition of ucMGP in calcified arteries 
resulting in systemic depletion of ucMGP. Fetuin-A levels did not differ between patient and controls, which is in contrast with a previous study showing decreased levels of fetuin-A in dialysis patients. ${ }^{26}$ This could be due to the fact that fetuin-A acts as a negative acute-phase reactant whereas the level of inflammation in our cohort compared to the previous study cohorts were low.

In multiregression analysis ucMGP, but not fetuin-A, was positively related with iPTH and negatively with phosphate levels respectively. Because hyperphosphatemia is a driving force in vascular calcification 27,28 and also low PTH levels are related to vascular calcification ${ }^{29}$ these data suggest that ucMGP may be more closely related to active calcification than fetuin-A. The direct association between fetuin-A and ucMGP is in line with the recent finding that fetuin-A together with MGP is able to make up a complex with calcium and phosphate. ${ }^{30}$

The relation between fetuin-A and ucMGP serum levels with arterial stiffness are not uniform. Fetuin-A was not an independent predictor of arterial stiffness. ucMGP levels were inversely related to Alx, but not to PWV. In general, it is important to realize that UCMGP and fetuin-A levels were assessed at a single-point and related to markers of arterial stiffness which develop over many years. Furthermore, the main determinants of arterial stiffness are blood pressure and age, which may override the associations between calcification inhibitors and arterial stiffness.

The finding of a relation between ucMGP levels and Alx in the absence of a relation of UcMGP with PWV could be explained by the following. PWV represents the distensibility of the aorta and is the "gold standard" of arterial stiffness. Alx depends on many factors such as age, height, PWV and peripheral reflectance. Therefore, the association between ucMGP levels and Alx may be based on the relation between ucMGP and peripheral reflectance which is influenced by physical properties, vasomotor tone and the number of smaller (calcified) resistive arteries and branch points.

A major drawback of our study is the lack of tissue samples or calcification scores. No direct information is available to relate serum levels of calcification inhibitors with vascular calcification on one hand and vascular calcification with arterial stiffness on the other.

Nonetheless, although our data do not uniformly show a direct relation between serum levels of calcification inhibitors and functional arterial parameters, a prospective study combining time averaged serum levels of the calcification inhibitors, a measure of calcifcation score and arterial stiffness would certainly be of interest. Moreover, ucMGP levels may be influenced by vitamin $\mathrm{K}$, and substitution of vitamin $\mathrm{K}$ could potentially lower vascular calcification and consequently attenuate arterial stiffness. 


\section{Chapter 5: Fetuin-A; predictor of cardiovascular mortality in a dialysis population?}

The markedly increased cardiovascular mortality in patients with ESRD is related to both accelerated calcifying atherosclerosis, ${ }^{16,31}$ and disturbances of the calciumphosphate metabolism. ${ }^{32,33}$ It seems therefore reasonable to hypothesize on a relation between fetuin-A, the most powerful circulating calcification inhibitor of hydroxyapatite formation, and cardiovascular mortality in a dialysis population. Four studies have been published on the relationship between serum fetuin-A concentrations with all-cause and cardiovascular mortality in dialysis patients. All studies showed that a lower serum fetuin-A concentration was associated with increased mortality. ${ }^{34-37}$ However, no study thus far assessed the association between fetuin-A and non-cardiovascular mortality, although fetuin-A is a negative acute-phase protein and therefore may be related to infections and other inflammatory states. Furthermore no study enabled a direct comparison of the association between fetuin-A and mortality in HD and PD patients. This is of particular interest, since we previously observed a significant higher serum fetuin-A level in PD patients compared to HD patients.

In the Netherlands Cooperative Study on the Adequacy of Dialysis (NECOSAD) cohort, a well-defined Dutch cohort of incident dialysis patients we showed that fetuin-A was inversely related to all-cause mortality, even after adjustment for inflammation or malnutrition. The survival benefit for a higher fetuin-A level was equal to cardiovascular and non-cardiovascular survival. Although we confirmed the higher serum fetuin-A levels in PD patients compared to HD patients, no difference was found in the associations between fetuin-A levels and mortality in both groups.

The finding that fetuin-A is a general risk factor for mortality rather than a marker for CV mortality is a remarkable finding. Fetuin-A, being a systemic calcification inhibitor, is clearly linked to arterial calcification. Fetuin-A may also be a link between atherosclerosis, a chronic inflammatory process 38,39 and vascular calcification. Next to its role as a calcification inhibitor, fetuin-A appears to contribute to the resolution of inflammation by enhancing deactivation of activated macrophages and phagocytosis of apoptotic cells. ${ }^{40,41}$ Fetuin-A also inhibits apoptosis of vascular smooth muscle cells, a process known to contribute to the destabilization of atherosclerotic plaques. ${ }^{42}$ Thus lower fetuin-A levels would theoretically also contribute to accelerated atherosclerosis. Nonetheless, in dialysis patients the predictive value of fetuin-A levels for mortality is not restricted to CV mortality. However, in general, it is even more remarkable that a single-point measurement of a marker predicts outcome over several years. The same holds true for CRP values, and at least in epidemiological studies both markers may represent a marker of general health rather than being specifically related to cardiovascular or non-cardiovascular fitness. 


\section{Epicrisis and perspectives}

The research in this thesis research was inspired by the large burden of cardiovascular morbidity and mortality in CKD patients. The research of this thesis did not have an interventional character and therefore does not give a direct tool to diminish the high mortality in CKD patients. However, some results elucidate potential harmful mechanisms that contribute to the high mortality figures in CKD patients.

We have shown, that in a population with CKD 2-3, a lower GFR and an increase in urinary albumin excretion are inversely and positively respectively, related to arterial stiffness. These associations underscore the importance of a greater awareness on GFR and albuminuria as being potential cardiovascular risk factors in so-called mild renal insufficiency. The data also showed that less than $50 \%$ of subjects with a systolic blood pressure $>145 \mathrm{mmHg}$ were treated with antihypertensive medication. There is ample evidence that adequate blood pressure control improves albuminuria and prevents a decline in renal function. Adequate treatment is therefore of great importance. It may be hypothesized that subjects with increased arterial stiffness should be treated even more aggressively because they have already shown a functional impairment of their vascular system. Compared to controls, the CCA-IMT in ESRD patients seems not only to be thicker, but also more inhomogeneous. The inhomogeneity of the CCA-IMT may be a reason why conventional ultrasound techniques resulted in conflictuous results on the CCA-IMT in different ESRD populations. In contrast to CCA-IMT, IMTinhomogeneities were related with IgG anti-oxLDL antibodies and fetuin-A concentrations. This suggests that the inhomogeneities may represent early calcified-atherosclerotic lesions where the IMT increase represents a reaction to a hemodynamic load. In future studies this phenomenon needs to be studied in different cardiovascular risk populations and related to the presence of plaques and measurements of vascular calcifications. The role of IMT-inhomogeneity as a predictor of cardiovascular events is not yet known and therefore prospective data are urgently needed.

Single-point measurements of the calcification inhibitors fetuin-A and ucMGP were not conclusively correlated with aortic arterial stiffness, although ucMGP, also after adjustment for several confounders, inversely correlated with Alx. Although media calcification certainly is a major mechanism underlying arterial stiffness in ESRD patients, other factors such as endothelial dysfunction, chronic fluid overload, sympathetic nervous system over activation, accumulation of AGE's and activation of the renin-angiotensin-aldosteron-system may also play an important role. Our observations do not definitively rule out an association between ucMGP and fetuinA levels and arterial stiffness. Only a prospective study including time averaged measurements of calcification inhibitors, arterial stiffness measurement and a calcification assessment could determine the exact role of calcification inhibitors in the pathogenesis of arterial stiffness. At least in case of (uc)MGP this is of interest, 
because unlike other calcification inhibitors, ucMGP levels may provide a direct target for intervention studies, e.g. with vitamin $\mathrm{K}$.

We confirmed the role of fetuin-A as a predictor for mortality in both PD and HD patients. In contrast to the expected, we showed that the serum fetuin-A level was both a predictor of cardiovascular as well as non-cardiovascular mortality. Until recently it was suspected that the major link between low fetuin-A levels and mortality was caused by accelerated cardiovascular calcification with consecutively increased cardiovascular mortality. Fetuin-A should thus be regarded as a general risk factor for mortality in dialysis patients. Whether fetuin-A should be added to mortality risk assessment scores is not clear yet. However, it may make sense to measure fetuin-A (or ucMGP) levels in all dialysis patients to create a calcification risk assessment score. Patients with low levels of the calcification inhibitors may be more prone to arterial calcification, even if their calcium and phosphate levels are within the limits of the KDOQI guidelines. This gives the opportunity to individualize treatment of calcium and phosphate levels.

In conclusion, the high burden of mortality in CKD and especially ESRD patients resulted in a search for factors supposed to be responsible for the pessimistic outcome. Next to the so called traditional cardiovascular risk factors an ongoing flow of non-traditional risk factors has been discovered and related with cardiovascular mortality in CKD patients. Treatment of traditional risk factors often did not result in the expected outcome and diagnostic procedures sometimes yielded incompatible results. The foregoing stresses the complexity of the pathogenesis of cardiovascular disease in CKD. Because of the multicausal origin of the cardiovascular mortality in CKD, it is not to be expected that one simple intervention will lead to a substantial decrease in mortality. In general, ESRD needs to be prevented by adequately treating patients with hypertension and albuminuria. The multifactorial treatment of dialysis patients should at least include an aggressive management of the bone mineral metabolism and perhaps a reserved prescription of oral anticoagulants or substitution of vitamin K. All measures should be taken to protect or, if possible, to restore the integrity of the arterial wall, the key player in cardiovascular health. In spite of all recent developments this was already known more than a century ago according to a statement of the famous German pathologist Rudolf Virchow (1821-1902) "A man is as old as his arteries". 


\section{References}

1. Stam F, van Guldener C, Becker A, Dekker JM, Heine RJ, Bouter LM, Stehouwer CD. Endothelial dysfunction contributes to renal function-associated cardiovascular mortality in a population with mild renal insufficiency: the Hoorn study. J Am Soc Nephrol. 2006;17:537-545.

2. Henry RM, Kostense PJ, Bos G, Dekker JM, Nijpels G, Heine RJ, Bouter LM, Stehouwer CD. Mild renal insufficiency is associated with increased cardiovascular mortality: The Hoorn Study. Kidney Int. 2002;62:1402-1407.

3. Guerin AP, Blacher J, Pannier B, Marchais SJ, Safar ME, London GM. Impact of aortic stiffness attenuation on survival of patients in end-stage renal failure. Circulation. 2001;103:987-992.

4. London GM, Blacher J, Pannier B, Guerin AP, Marchais SJ, Safar ME. Arterial wave reflections and survival in end-stage renal failure. Hypertension. 2001;38:434-438.

5. Blacher J, Pannier B, Guerin AP, Marchais SJ, Safar ME, London GM. Carotid arterial stiffness as a predictor of cardiovascular and all-cause mortality in end-stage renal disease. Hypertension. 1998;32:570-574.

6. Laurent S, Cockcroft J, Van Bortel L, Boutouyrie P, Giannattasio C, Hayoz D, Pannier B, Vlachopoulos C, Wilkinson I, Struijker-Boudier H. Expert consensus document on arterial stiffness: methodological issues and clinical applications. Eur Heart J. 2006;27:2588-2605.

7. Mourad JJ, Girerd X, Boutouyrie P, Laurent S, Safar M, London G. Increased stiffness of radial artery wall material in end-stage renal disease. Hypertension. 1997;30:1425-1430.

8. Wang MC, Tsai WC, Chen JY, Huang JJ. Stepwise increase in arterial stiffness corresponding with the stages of chronic kidney disease. Am J Kidney Dis. 2005;45:494-501.

9. Roman MJ, Saba PS, Pini R, Spitzer M, Pickering TG, Rosen S, Alderman MH, Devereux RB. Parallel cardiac and vascular adaptation in hypertension. Circulation. 1992;86:1909-1918.

10. Boutouyrie P, Laurent S, Girerd X, Benetos A, Lacolley P, Abergel E, Safar M. Common carotid artery stiffness and patterns of left ventricular hypertrophy in hypertensive patients. Hypertension. 1995;25:651-659.

11. Willum-Hansen T, Staessen JA, Torp-Pedersen C, Rasmussen S, Thijs L, Ibsen H, Jeppesen J. Prognostic value of aortic pulse wave velocity as index of arterial stiffness in the general population. Circulation. 2006;113:664-670.

12. Mattace-Raso FU, van der Cammen TJ, Hofman A, van Popele NM, Bos ML, Schalekamp MA, Asmar R, Reneman RS, Hoeks AP, Breteler MM, Witteman JC. Arterial stiffness and risk of coronary heart disease and stroke: the Rotterdam Study. Circulation. 2006;113:657-663.

13. Kizu A, Koyama H, Tanaka S, Maeno T, Komatsu M, Fukumoto S, Emoto M, Shoji T, Inaba M, Shioi A, Miki T, Nishizawa Y. Arterial wall stiffness is associated with peripheral circulation in patients with type 2 diabetes. Atherosclerosis. 2003;170:87-91.

14. Taniwaki H, Shoji T, Emoto M, Kawagishi T, Ishimura E, Inaba M, Okuno Y, Nishizawa Y. Femoral artery wall thickness and stiffness in evaluation of peripheral vascular disease in type 2 diabetes mellitus. Atherosclerosis. 2001;158:207-214.

15. Gerstein HC, Mann JF, Yi Q, Zinman B, Dinneen SF, Hoogwerf B, Halle JP, Young J, Rashkow A, Joyce C, Nawaz S, Yusuf S. Albuminuria and risk of cardiovascular events, death, and heart failure in diabetic and nondiabetic individuals. JAMA. 2001;286:421-426.

16. Lindner A, Charra B, Sherrard DJ, Scribner BH. Accelerated atherosclerosis in prolonged maintenance hemodialysis. N Engl J Med. 1974;290:697-701.

17. Konings CJ, Dammers R, Rensma PL, Kooman JP, Hoeks AP, Kornet L, Gladziwa U, van der Sande FM, Leunissen KM. Arterial wall properties in patients with renal failure. Am J Kidney Dis. 2002;39:1206-1212.

18. Leskinen Y, Lehtimaki T, Loimaala A, Lautamatti V, Kallio T, Huhtala H, Salenius JP, Saha H. Carotid atherosclerosis in chronic renal failure-the central role of increased plaque burden. Atherosclerosis. 2003;171:295-302.

19. Savage T, Clarke AL, Giles M, Tomson CR, Raine AE. Calcified plaque is common in the carotid and femoral arteries of dialysis patients without clinical vascular disease. Nephrol Dial Transplant. 1998;13:2004-2012. 
20. London GM, Guerin AP, Marchais SJ, Metivier F, Pannier B, Adda H. Arterial media calcification in end-stage renal disease: impact on all-cause and cardiovascular mortality. Nephrol Dial Transplant. 2003;18:1731-1740.

21. Guerin AP, London GM, Marchais SJ, Metivier F. Arterial stiffening and vascular calcifications in end-stage renal disease. Nephrol Dial Transplant. 2000;15:1014-1021.

22. Moe SM, Chen NX. Inflammation and vascular calcification. Blood Purif. 2005;23:64-71.

23. Price PA, Chan WS, Jolson DM, Williamson MK. The elastic lamellae of devitalized arteries calcify when incubated in serum: evidence for a serum calcification factor. Arterioscler Thromb Vasc Biol. 2006;26:1079-1085.

24. Stompor T, Krzanonowski, M., Kusnierz-Cabala, B., Dubiel, M., Stompor, M., Grodzicki, T., Suluwicz, W. Pulse wave velocity and proteins regulating vascaulr calcification and bone mineralization in patients treated with peritoneal dialysis. Nephrol Dial Transplant. 2006;21 3605-3606.

25. Schurgers $\sqcup$, Teunissen KJ, Knapen MH, Kwaijtaal M, van Diest R, Appels A, Reutelingsperger CP, Cleutjens JP, Vermeer C. Novel conformation-specific antibodies against matrix gammacarboxyglutamic acid (Gla) protein: undercarboxylated matrix Gla protein as marker for vascular calcification. Arterioscler Thromb Vasc Biol. 2005;25:1629-1633.

26. Ketteler M, Bongartz P, Westenfeld R, Wildberger JE, Mahnken AH, Bohm R, Metzger T, Wanner C, Jahnen-Dechent W, Floege J. Association of low fetuin-A (AHSG) concentrations in serum with cardiovascular mortality in patients on dialysis: a cross-sectional study. Lancet. 2003;361: 827-833.

27. Jono S, McKee MD, Murry CE, Shioi A, Nishizawa Y, Mori K, Morii H, Giachelli CM. Phosphate regulation of vascular smooth muscle cell calcification. Circ Res. 2000;87:E10-17.

28. Giachelli CM, Jono S, Shioi A, Nishizawa Y, Mori K, Morii H. Vascular calcification and inorganic phosphate. Am J Kidney Dis. 2001;38:S34-37.

29. Chertow GM, Raggi P, Chasan-Taber S, Bommer J, Holzer H, Burke SK. Determinants of progressive vascular calcification in haemodialysis patients. Nephrol Dial Transplant. 2004;19: 1489-1496.

30. Coen G, Ballanti P, Balducci A, Grandi F, Manni M, Mantella D, Pierantozzi A, Ruggeri M, Sardella D, Sorbo G, Bonucci E. Renal osteodystrophy: alpha-Heremans Schmid glycoprotein/fetuin-A, matrix GLA protein serum levels, and bone histomorphometry. Am J Kidney Dis. 2006;48: 106-113.

31. Foley RN, Parfrey PS, Sarnak MJ. Epidemiology of cardiovascular disease in chronic renal disease. J Am Soc Nephrol. 1998;9:S16-23.

32. Block GA, Hulbert-Shearon TE, Levin NW, Port FK. Association of serum phosphorus and calcium $\mathrm{x}$ phosphate product with mortality risk in chronic hemodialysis patients: a national study. Am J Kidney Dis. 1998;31:607-617.

33. Noordzij M, Korevaar JC, Boeschoten EW, Dekker FW, Bos WJ, Krediet RT. The Kidney Disease Outcomes Quality Initiative (K/DOQI) guideline for bone metabolism and disease in CKD: association with mortality in dialysis patients. Am J Kidney Dis. 2005;46:925-932.

34. Honda H, Qureshi AR, Heimburger O, Barany P, Wang K, Pecoits-Filho R, Stenvinkel P, Lindholm B. Serum albumin, C-reactive protein, interleukin 6, and fetuin a as predictors of malnutrition, cardiovascular disease, and mortality in patients with ESRD. Am J Kidney Dis. 2006;47:139-148.

35. Ketteler M, Wanner C, Metzger T, Bongartz P, Westenfeld R, Gladziwa U, Schurgers L, Vermeer C, Jahnen-Dechent W, Floege J. Deficiencies of calcium-regulatory proteins in dialysis patients: a novel concept of cardiovascular calcification in uremia. Kidney Int Suppl. 2003:S84-87.

36. Stenvinkel P, Wang K, Qureshi AR, Axelsson J, Pecoits-Filho R, Gao P, Barany P, Lindholm B, Jogestrand T, Heimburger O, Holmes C, Schalling M, Nordfors L. Low fetuin-A levels are associated with cardiovascular death: Impact of variations in the gene encoding fetuin. Kidney Int. 2005; 67:2383-2392.

37. Wang AY, Woo J, Lam CW, Wang M, Chan IH, Gao P, Lui SF, Li PK, Sanderson JE. Associations of serum fetuin-A with malnutrition, inflammation, atherosclerosis and valvular calcification syndrome and outcome in peritoneal dialysis patients. Nephrol Dial Transplant. 2005;20: 1676-1685.

38. Glass CK, Witztum JL. Atherosclerosis. the road ahead. Cell. 2001;104:503-516.

39. Ross R. Atherosclerosis--an inflammatory disease. N Engl J Med. 1999;340:115-126. 
40. Wang H, Zhang M, Bianchi M, Sherry B, Sama A, Tracey KJ. Fetuin (alpha2-HS-glycoprotein) opsonizes cationic macrophagedeactivating molecules. Proc Natl Acad Sci USA. 1998;95: 14429-14434.

41. Jersmann HP, Dransfield I, Hart SP. Fetuin/alpha2-HS glycoprotein enhances phagocytosis of apoptotic cells and macropinocytosis by human macrophages. Clin Sci (Lond). 2003;105: 273-278.

42. Tsirpanlis G. Is Inflammation the Link between Atherosclerosis and Vascular Calcification in Chronic Kidney Disease? Blood Purif. 2007;25:179-182. 
Chapter 9

Summary 
130 Chapter 9 


\section{Summary}

Life does not end if renal function quits, but the overall prognosis is not rosy at all. Though the therapeutic armamentarium for renal failure has been broadened over the years, modern treatment still has not been able to optimize prognosis. Science still searches explanatory causes of the high burden of cardiovascular morbidity and mortality in patients with chronic kidney disease. This thesis is the resultant of such search in which the vessel wall plays a central role.

\section{Chronic kidney disease and cardiovascular risk}

Renal insufficiency is defined as a lowering in glomerular filtration rate, and/or the presence of proteinuria and classified into 5 stages (Table 9.1.). The increased prevalence of cardiovascular disease in dialysis patients is known for years. More recently, it has become clear that even patients with mild to moderate chronic kidney disease (CKD) have an increased cardiovascular risk. In the Hoorn-study, starting from a normal eGFR (>90 ml/min/1.73m²), a linear association was found between eGFR decrease and cardiovascular mortality. In case of albuminuria, the PREVEND-study, performed in the Dutch city of Groningen, has shown that a doubling of the albuminuria was associated with a $29 \%$ increase of in cardiovascular mortality.

A decline in renal function is mostly accompanied with traditional cardiovascular risk factors such as hypertension, hyperlipidemia, obesity and diabetes mellitus (DM). However, these traditional risk factors do not completely account for the association between CKD and the increased cardiovascular risk. Therefore, in the past years, investigators intensively searched for additional non-traditional risk factors that could explain the association between CKD and cardiovascular risk.

Table 9.1 Stages of chronic kidney disease.

\begin{tabular}{llc}
\hline Stage & Description of kidney damage with: & GFR $\left(\mathrm{ml} / \mathrm{min} / 1.73 \mathrm{~m}^{2}\right)$ \\
\hline 1 & Normal or $\uparrow$ GFR, but evidence of kidney damage e.g., albuminuria & $\geq 90$ \\
2 & Mild chronic kidney failure with evidence of kidney damage e.g., & $60-89$ \\
& albuminuria and $\downarrow$ GFR & $30-59$ \\
3 & Moderate chronic kidney failure, $\downarrow$ GFR & $15-29$ \\
4 & Severe chronic kidney failure, $\downarrow$ GFR & $<15$ \\
5 & End-stage renal failure & \\
\hline
\end{tabular}

Classification of chronic kidney disease according to the K/DOQI clinical practice guidelines for chronic kidney disease; GFR: glomerular filtration rate. 


\section{Vascular alterations in chronic kidney disease}

Arteries have two functions. First, arteries fulfill the nutritive needs of the tissues. Both in the general population and in patients with chronic kidney disease, atherosclerosis is the most important threat for this "transport" function. Atherosclerotic changes are mostly localized at the intima layer of elastic arteries. This process will cause a reduction of the lumen size of the artery, which eventually causes ischemia. Apart from the traditional risk factors such as age, male gender, smoking, hypertension and diabetes mellitus, several non-traditional risk factors have been associated with atherosclerosis in subjects with chronic CKD. These factors incorporate anemia due to a decline in erythropoietin production, uremic toxins due to a decrease in renal clearance and increase in oxidative stress. Last but not least, atherosclerosis is an inflammatory process. CKD results in a decrease in the renal clearance of pro-inflammatory cytokines which causes a rise of inflammatory markers such as C-reactive protein, which contribute to an atherogenic milieu.

The second important arterial function is the transformation of the pulsatile blood flow which comes from the left ventricle, into a continuous flow. This cushioning function depends on the flexibility of the vessel wall. Renal dysfunction is associated with mediasclerosis (hardening of the media-layer of the vessel wall) which causes an increase in arterial stiffness and impedes the cushioning function. Aging is a major cause of an increase in arterial stiffness. However, CKD involves factors that may also additionally influence arterial stiffness. The arterial wall is exposed to hemodynamic and atherogenic factors. Two proteins, collagen and elastin are major contributors to arterial stiffness that normally are balanced. CKD often combines with hypertension and the resulting increase in luminal pressure causes an excessive collagen production and an increase in arterial stiffness. Also non-traditional risk factors influence arterial stiffness. The frequently encountered volume overload in CKD results in an activation of the systemic and local renin angiotensin aldosteron system. This causes a rise in the collagen part of the extracellular matrix and a proliferation of the vascular smooth muscles. From stage 3-4 CKD onwards, the derangement of the calcium-phosphate metabolism is a contributor to mediasclerosis of the large vessels which results in an increase in arterial stiffness and cardiovascular mortality.

In this thesis the results of several studies of the association between renal insufficiency and arterial alterations in patients with mild to moderate chronic kidney disease and end-stage renal disease are presented. In addition, the associations of traditional and non-traditional risk factors such as markers of oxidative stress and derangements of the calcium-phosphate metabolism with such arterial alterations are shown. At last, the association of serum fetuin-A, a systemic calcification inhibitor, with mortality in a large dialysis cohort is included in this thesis. 


\section{Chronic kidney disease and arterial stiffness}

In chapter 2 we studied whether mild to moderate CKD was associated with a greater arterial stiffness. This study uses data from the Hoorn-study. Briefly, the Hoorn Study is a cohort study of glucose tolerance and cardiovascular disease in the general population. In 806 subjects with a mean age of 68 years, peripheral and central arterial stiffness was measured and eGFR and urinary albumin creatinine ratio (UACR) were used as renal function parameters. The most important findings of this study were that both a decrease of the eGFR and an increase of the UACR were mutually independently associated with a greater peripheral arterial stiffness. Furthermore a greater UACR, in contrast to eGFR, was associated with a greater central arterial stiffness. In addition, the found associations were not influenced by the presence of diabetes.

These findings may explain, in part, why a lower eGFR and an increased microalbuminuria are associated with greater risk of CVD and suggest that amelioration of arterial stiffness could be a target of intervention.

\section{Intima media inhomogeneity; a new surrogate parameter for atherosclerosis?}

The arterial wall consists of an intimal, medial and adventitial layer. The thickness of the intima-media complex of the common carotid artery (CCA) is generally used as a marker for generalized atherosclerosis. However, it has become clear that the intima media thickness (IMT) is not just determined by atherogenic factors, but also increases due to hemodynamic factors. In addition, several previous studies have shown unexpectedly "normal" values of the IMT of dialysis patients compared to controls. This remarkable finding could be caused by an insufficient method of IMT measurement. On the other hand, although the IMT value is comparable the IMT could still differ in homogeneity.

In chapter 3, a novel ultrasound technique was used. Instead of a single-point assessment or averaging of the IMT over a longer segment, we measured IMT at 14 adjacent points simultaneously of an artery segment of $16.4 \mathrm{~mm}$. This results in a higher accuracy and sensitivity of the measurements and gives the opportunity to be informed of the inhomogeneity of the IMT. Using this novel ultrasound scanner we studied whether the IMT, both in absolute value and inhomogeneity, of dialysis patients differed from controls. In addition, the associations between several traditional and non-traditional risk factors and IMT and IMT-inhomogeneity were studied. The most important finding was that both the IMT and the IMTinhomogeneity of the CCA was greater in dialysis patients compared to controls. IMT and IMT-inhomogeneity strongly correlated. However, serum fetuin-A, a calcification inhibitor and antibodies against oxidized low density lipids independently correlated with IMT-inhomogeneity, but not with IMT. Although CCA- 
IMT and IMT-inhomogeneity are related, the different associations between both measurements and non-traditional risk factors show that they are distinct entities.

\section{The association between calcification inhibitors and arterial stiffness}

The calcium * phosphate product in the human body is higher than the solubility product, without doing harm to the body. The fact that we do not look like stalagmites and stalactites is partly due to the presence of ions counteracting the precipitation of calcium and phosphate. Moreover, the presence of systemically and locally acting calcification inhibitors is also of major importance. Previous studies have shown a large increase in intima and mediacalcifications in dialysis patients. Both types of calcification are associated with a greater cardiovascular risk. An increase in arterial stiffness is the possible link between arterial calcifications and cardiovascular risk. Arterial stiffness is independently associated with a greater cardiovascular mortality.

In chapter 4 we studied whether serum fetuin-A, a systemic calcification inhibitor is a predictor of the pulse wave velocity (PWV) and the augmentation index (Alx). The PWV between the carotid and femoral artery is a widely used stiffness parameter which has been associated with cardiovascular morbidity and mortality in a wide variety of populations. The aortic augmentation index (Alx) represents the additional load to which the left ventricle is subjected as a result of the timing of wave reflection. The major finding was that serum fetuin-A was not an independent predictor of arterial stiffness. In chapter 6 we used a novel assay to measure the non-carboxylated part of matrix gla protein (ucMGP). MGP is a calcification inhibitor that can only be activated after a vitamin $\mathrm{K}$ dependent carboxylation process. This study was the first one to compare ucMGP levels between dialysis patients and matched healthy controls. Furthermore, the association between ucMGP levels and arterial stiffness, measured as PWV and Alx was studied. Serum ucMGP was significantly lower in dialysis patients. We also found a negative association between ucMGP levels and serum phosphate levels. In contrast to the Alx, ucMGP levels were not independently associated with PWV. However, it should be noticed that Alx is not merely a parameter of arterial stiffness, but a combination of arterial stiffness and peripheral reflection. Both studies have shown that serum levels of the calcification inhibitors fetuin-A and ucMGP are no independent predictors of arterial stiffness.

\section{Fetuin-A, a prognostic marker for mortality in dialysis patients?}

Vascular calcification is associated with increased cardiovascular mortality. In addition, a derangement of the calcium-phosphate metabolism and especially an increase in phosphate level has been associated with cardiovascular mortality. Previous studies therefore studied the association between serum fetuin- $A$ and cardiovascular mortality. In dialysis patients a lower serum fetuin-A level was 
associated with a greater cardiovascular mortality. However, fetuin-A not only is a calcification inhibitor, but also reacts as a negative acute phase protein and has several other functions besides calcification inhibition. Fetuin-A could potentially also be related to non-cardiovascular mortality. In chapter 5 we studied whether fetuin-A is also a predictor of non-cardiovascular mortality. We used data from the Netherlands Cooperative Study on the Adequacy of Dialysis (NECOSAD), a large, prospective, multicenter cohort study. The association between serum fetuin-A and all-cause, cardiovascular and non-cardiovascular mortality was studied in a total of 987 dialysis patients (664 hemodialysis (HD) and 323 peritoneal (PD) patients). Fetuin-A turned out to be not only a predictor of all-cause and cardiovascular, but also of non-cardiovascular mortality in both the HD and PD patients. This study deemphasizes fetuin-A as a specific cardiovascular risk marker. Serum fetuin-A seems to be a marker of the general health of dialysis patients.

\section{A real-life case}

In chapter 7 we present a case showing that arterial calcification makes part of the extra-osseous calcification process. A male patient with a long-standing history of diabetes mellitus type 2 complicated by micro- and macrovascular complications and end-stage renal disease caused by diabetic nephropathy treated with peritoneal dialysis, had both mediasclerosis and circumferential calcified vasa deferentia.

\section{Epicrisis}

Chapter 8 is an integration of the studies in the foregoing chapters. The studies will be put in perspective of the current literature. This thesis underlines the complexity and diversity of the potential causative mechanisms that are responsible for the high cardiovascular burden in CKD patients. The arterial wall plays a central role. The arterial wall not only changes in structure but also in function. Even mild renal insufficiency is associated with a change in arterial stiffness. Although this thesis certainly added some novel aspects to the search for the explanation of the association between CKD and cardiovascular risk, the very old adage by the German pathologist Rudolf Virchow (1821-1902) still holds true "a man is as old as his arteries". 
136 


\section{chapter 10}

Samenvatting 
138 Chapter 10 


\section{Samenvatting}

Hoewel het leven niet ophoudt als de nieren "er mee stoppen", is de prognose allerminst gunstig te noemen. Ondanks het feit dat het therapeutisch arsenaal heel wat nierfunctievervangende en andere ondersteunende mogelijkheden biedt, is ook de meest moderne behandeling niet in staat gebleken de prognose te optimaliseren. Nog steeds bestaat er een grote behoefte aan additionele verklaringen voor de sterk toegenomen frequentie van hart- en vaatziekten bij patiënten met een afgenomen nierfunctie. Met deze wetenschap in het achterhoofd is dit proefschrift tot stand gekomen waarbij vaatwandveranderingen een centrale rol spelen.

\section{Nierfunctieverlies en cardiovasculair risico}

Nierfunctieverlies wordt gedefinieerd als een verminderde glomerulaire filtratiesnelheid (GFR) en/of de aanwezigheid van proteïnurie. Chronische nierinsufficiëntie wordt geclassificeerd in 5 stadia (Tabel 10.1). Het is reeds enkele decennia bekend dat dialysepatiënten een sterk toegenomen prevalentie van harten vaatziekten hebben. Meer recent is uit divers epidemiologisch onderzoek duidelijk geworden dat reeds bij een milde tot matige nierinsufficiëntie het cardiovasculaire risico stijgt. In de Hoorn-studie werd uitgaande van een normale GFR (>90 $\mathrm{ml} / \mathrm{min} / 1.73 \mathrm{~m}^{2}$ ) een lineair verband gevonden tussen eGFR daling en cardiovasculaire sterfte. Dit suggereert dat het cardiovasculaire risico reeds toeneemt bij een eGFR $<90 \mathrm{ml} / \mathrm{min} / 1.73 \mathrm{~m}^{2}$. Wat betreft albuminurie heeft de Groningse PREVEND-studie aangetoond dat verdubbeling van de albuminurie in de normale populatie leidt tot $29 \%$ stijging van de kans op cardiovasculaire sterfte. Het is overigens juister om in geval van albuminurie te spreken over een cardiovasculaire risicomarker en niet zozeer over een risicofactor omdat er geen bewijs is dat albuminurie direct betrokken is bij het atherosclerotisch proces.

Tabel 10.1 Indeling chronische nierinsufficiëntie in stadia.

\begin{tabular}{lll}
\hline Stadium & Beschrijving & GFR $\left(\mathrm{ml} / \mathrm{min} / 1.73 \mathrm{~m}^{2}\right)$ \\
\hline 1 & Nierschade met normale of $\uparrow$ GFR & $\geq 90$ \\
2 & Nierschade met lichte $\downarrow$ GFR & $60-89$ \\
3 & Matige $\downarrow$ GFR & $30-59$ \\
4 & Ernstige $\downarrow$ GFR & $15-29$ \\
5 & Eind stadium nierfalen & $<15$ (of dialyse) \\
\hline
\end{tabular}

Chronische nierinsufficiëntie wordt gedefinieerd als nierschade (proteïnurie of erytrocyturie) of een GFR $<60 \mathrm{ml} / \mathrm{min} / 1.73 \mathrm{~m}^{2}$ die langer dan 3 maanden bestaat. (naar; K/DOQI clinical practice guidelines for chronic kidney disease). 
Hoewel nierfunctieverlies veelal samengaat met de bekende vasculaire risicofactoren zoals hypertensie, hypercholesterolemie, overgewicht en diabetes (DM) blijken deze "traditionele" risicofactoren de associatie tussen nierfunctieverlies en het gestegen cardiovasculair risico slechts gedeeltelijk te verklaren. Dit gegeven heeft de laatste jaren geleid tot een intensieve zoektocht naar aanvullende verklaringen van het verband tussen nierfunctieverlies en cardiovasculair risico.

\section{Nierfunctieverlies en vasculaire veranderingen}

De functie van arteriën is tweeledig. Ten eerste voorzien bloedvaten weefsels van zuurstof en nutriënten. Zowel in de algemene populatie als bij patiënten met nierinsufficiëntie is atherosclerose de voornaamste oorzaak van een teloorgang van deze "vervoersfunctie" van de bloedvaten. De atherosclerotische veranderingen treden met name op in de intima-laag van elastische arteriën. Uiteindelijk leidt de vorming van plaques tot lumenreductie waarbij distaal infarcering op kan treden door ischemie. Naast de bekende traditionele risicofactoren zoals leeftijd, mannelijk geslacht, roken, hypertensie en diabetes mellitus worden bij chronische nierinsufficiëntie tal van niet-traditionele risicofactoren geassocieerd met het atherosclerotisch proces. Als additionele factoren gelden onder andere anemie ten gevolge van een dalende erytropoëtine productie, uremische toxines door een afname van de renale klaring en dyslipidemie met de vorming van vasculotoxisch geoxideerd LDL. Tenslotte wordt atherosclerose beschouwd als een inflammatoire ziekte. Chronische nierinsufficiëntie gaat onder andere gepaard met een verminderde klaring van proinflammatoire cytokines waardoor een verhoging van inflammatoire markers zoals C-reactieve proteïne optreedt, die een bijdrage leveren aan een atherogeen milieu. Een tweede belangrijke arteriële functie is het omvormen van de bloedstroom van een uit de linker ventrikel komende pulsatiele, naar een continue bloedstroom. Deze dempende functie is afhankelijk van de soepelheid van de vaatwand. In geval van nierfunctieverlies treedt een verstijving van de vaatwand op.

Een toename van arteriële stijfheid ten gevolge van mediasclerose (verharding van de mediale laag van de arteriewand) is vooral een verouderingsproces. Er zijn echter bij chronische nierinsufficiëntie additionele factoren die de vaatwandstijfheid ongunstig kunnen beïnvloeden. De arteriële vaatwand staat bloot aan hemodynamische en atherogene factoren. Collageen en elastine zijn twee eiwitten die een belangrijke contributie leveren aan de vaatwandstijfheid en die onder normale omstandigheden in een gelijkblijvende verhouding aanwezig zijn. Chronische nierinsufficiëntie gaat vaak gepaard met hypertensie waarbij een toename van de lumendruk leidt tot een excessieve collageenproductie en een toename van de vaatwandstijfheid. Ook niet-traditionele risicofactoren spelen hierbij een rol. Zo leidt de bij chronische nierinsufficiëntie frequent voorkomende 
volume-overbelasting tot activatie van het systemische en het lokale renineangiotensine-aldosteron-systeem hetgeen een toename van het collageen aandeel in de extracellulaire matrix en een proliferatie van de gladde spieren in de vaatwand veroorzaakt. Deze activatie van het renine-angiotensine-aldosteronsysteem is geassocieerd met een toename van de vaatstijfheid.

Tenslotte treedt vanaf stadium 3-4 chronische nierinsufficiëntie een verstoord calcium-fosfaat metabolisme op hetgeen geassocieerd is met mediasclerose van de grote vaten en gepaard gaat met een toename van arteriële stijfheid en cardiovasculaire sterfte.

Dit proefschrift bevat de resultaten van studies naar de relatie tussen nierfunctieverlies en vaatwandveranderingen in patiënten met een milde tot matige nierinsufficiëntie en in dialysepatiënten. Hierbij wordt gekeken naar de invloed van zowel traditionele als niet-traditionele risicofactoren zoals markers van oxidatieve stress en een verstoord calcium-fosfaat metabolisme op deze vaatwandveranderingen. Tenslotte is onderzoek naar de rol van fetuïne-A, een in het serum voorkomende calcificatieremmer, als voorspeller van mortaliteit in dialysepatiënten in dit proefschrift opgenomen.

\section{Nierfunctieverlies en vaatwandstijfheid}

In hoofdstuk 2 werd onderzocht of licht tot matig nierfunctieverlies gepaard gaat met een toename van de arteriële vaatwandstijfheid. In deze studie werd gebruik gemaakt van data van de Hoorn-studie. De Hoorn-studie is een cohort studie in de algemene bevolking naar het voorkomen van een verstoord glucose metabolisme, DM en hart- en vaatziekten. In totaal werden bij 806 personen met een gemiddelde leeftijd van 68 jaar de perifere en centrale arteriële vaatwandstijfheid gemeten. De eGFR en de verhouding albumine/kreatinine in de urine (UACR) werden als nierfunctieparameters gebruikt. In tegenstelling tot voorafgaande studies kon hierdoor enerzijds bestudeerd worden of deze parameters beide geassocieerd waren met vaatwandstijfheid. Anderzijds kon worden bestudeerd of de associaties onafhankelijk van elkaar waren. De belangrijkste bevindingen van deze studie waren dat zowel een afname van de eGFR als een toename van de albumine uitscheiding in de urine gepaard gingen met een toename van de perifere arteriële stijfheid en dat deze relatie onafhankelijk van elkaar bleek te zijn. Daarnaast was een grotere mate van albuminurie, in tegenstelling tot een afname van de eGFR geassocieerd met een grotere centrale arteriële stijfheid. Daarenboven bleken de bevindingen te gelden voor zowel personen met als zonder DM. De resultaten vormen een verklaring waarom afname van de GFR en toename van albuminurie zijn geassocieerd met een grotere cardiovasculaire sterfte. 


\section{Intima media inhomogeniteit; een nieuwe surrogaatmarker voor atherosclerose?}

In een dwarsdoorsnede van een arterie kan men vanaf de luminale zijde bekeken achtereenvolgens 3 lagen onderscheiden de intima, de media en de adventitia. Het intima-media complex van de halsslagader (a. carotis) wordt algemeen als een goede afspiegeling van de mate van gegeneraliseerde atherosclerose gezien. Inmiddels is echter gebleken dat de intima-media dikte (IMT) niet alleen wordt beïnvloed door atherogene factoren, maar dat deze ook verdikt onder invloed van hemodynamische factoren. Verder bleek in het verleden uit divers onderzoek dat tegen verwachting in dialyse patiënten niet afwijkende IMT waardes hadden ten opzichte van gezonde leeftijdsgenoten. Deze opmerkelijke bevinding zou kunnen berusten op een ontoereikende meetmethode. Anderzijds zou bij gelijke dikte mogelijk wel een verschil kunnen bestaan in opbouw van de IMT. In hoofdstuk 3 werd gebruik gemaakt van een nieuwe echografische techniek waarbij de IMT van de a. carotis over een gebied van $1.6 \mathrm{~cm}$ op 14 punten werd gemeten. Hierdoor ontstaat enerzijds mogelijk een betere meting van de ware IMT terwijl anderzijds een indruk kan worden verkregen van de onregelmatigheid, de zogenaamde inhomogeniteit van de IMT. In het verleden werd dikwijls gebruik gemaakt van een enkel meetpunt van de IMT. Deze methode kan leiden tot een hogere kans op meetfouten. Met behulp van de zojuist beschreven nieuwe echografische meetmethode werd de vraag onderzocht of de IMT van de a. carotis van dialyse patiënten afwijkt qua grootte en opbouw (inhomogeniteit) ten opzichte van gezonde proefpersonen. Tevens werden de associaties tussen diverse traditionele en niet-traditionele risicofactoren en de IMT en de IMT-inhomogenteit onderzocht. De belangrijkste uitkomst was dat de IMT van dialyse patiënten, gemeten met de nieuwe echo techniek, zowel dikker als inhomogener was dan de IMT van de gezonde proefpersonen. De IMT en IMT-inhomogeniteit waren sterk met elkaar geassocieerd. Serum fetuïne-A, een calcifciatie remmende factor en antistoffen tegen geoxideerd LDL waren wel geassocieerd met IMT-inhomogeniteit maar niet met de IMT. Dit is een aanwijzing dat IMT en IMT-inhomogeniteit mogelijk 2 verschillende entiteiten zijn.

\section{De relatie van calcificatieremmers met arteriële stijfheid}

Het calcium-fosfaat product in het menselijk lichaam overstijgt het oplosbaarheidproduct zonder dat wij daar negatieve consequenties van ervaren. Het feit dat wij niet als stalagmieten en stalactieten door het leven gaan komt enerzijds door de aanwezigheid van een veelheid van andere ionen, die het neerslaan van calcium en fosfaat bemoeilijken, anderzijds zijn er zowel in het serum als lokaal in de vaten en andere weefsels calcificatieremmers aanwezig die de neerslag van calcium en fosfaat tegengaan. Uit in het verleden verricht onderzoek is gebleken dat dialyse patiënten een sterke toename van intima- en 
mediaverkalkingen hebben. Verder zijn beide verkalkinglocaties geassocieerd met een toegenomen cardiovasculair risico. Een mogelijke verklaring voor de associatie tussen verkalkingen van de media en het cardiovasculaire risico vormt de toegenomen arteriële stijfheid die, zoals reeds beschreven, onafhankelijk is geassocieerd met een hogere cardiovasculaire sterfte. In hoofdstuk 4 werd bestudeerd of fetuïne-A, een calcificatie remmer, een voorspeller was van de polsgolfsnelheid (PWV) en de aortale augmentatie-index (Alx) bij dialyse patiënten. De PWV is een directe maat van arteriële stijfheid, de Alx is een meer afgeleide stijfheidmaat. Fetuïne-A bleek geen onafhankelijke voorspeller van arteriële stijfheid te zijn. In hoofdstuk 6 werd een nieuwe analysetechniek toegepast, waarmee het mogelijk is, in serum, het niet gecarboxyleerde deel van het matrix gla-eiwit (ucMGP) te meten. MGP is een calcificatieremmer die slechts werkt indien het carboxylatieproces, dat onder invloed staat van vitamine $\mathrm{K}$, goed verloopt. In deze studie werd ucMGP voor de eerste keer vergeleken tussen dialyse patiënten en gezonde proefpersonen. Tevens werd de relatie tussen ucMGP en de vaatwandstijfheid gemeten middels de PWV en de Alx bestudeerd. UcMGP bleek beduidend lager te zijn bij dialyse patiënten. Verder was er een omgekeerd evenredige relatie tussen de ucMGP serumwaarde en de fosfaatwaarde. De relatie tussen ucMGP en de vaatwandstijfheid is minder eenduidig. UcMGP is geen onafhankelijke voorspeller van de PWV maar wel van de Alx. De Alx is echter niet zozeer een maat van arteriële stijfheid maar een combinatie van arteriële stijfheid en perifere reflectie. Uit beide onderzoeken komen serumspiegels van de calcificatieremmers fetuïne-A en ucMGP dus niet naar voren als onafhankelijke voorspellers van arteriële stijfheid.

\section{Fetuïne-A, voorspeller van mortaliteit in dialyse patiënten?}

Zoals boven beschreven, is de mate van vaatwandcalcificatie gerelateerd aan cardiovasculaire sterfte. Tevens is een verstoord calcium-fosfaat metabolisme, en met name een verhoogde fosfaatwaarde gerelateerd aan een grotere cardiovasculaire sterfte. In recent onderzoek heeft men daarom gekeken naar de relatie tussen de calcificatieremmer fetuïne-A en cardiovasculaire sterfte. Het is gebleken dat in dialyse patiënten een lagere fetuïne-A spiegel gepaard gaat met een grotere cardiovasculaire sterfte. Fetuïne-A is echter ook een negatief acuut fase eiwit en heeft naast de calcificatieremmende werking andere functies waardoor fetuïne-A mogelijk ook een relatie met niet-cardiovasculaire sterfte kan hebben. In hoofdstuk 5 onderzochten we de hypothese dat fetuïne-A ook een voorspeller is van niet-cardiovasculaire sterfte. Er werd gebruik gemaakt van data van de NECOSAD-studie een studie naar de adequaatheid van de dialysebehandeling in Nederland. Hierdoor kon in 987 dialyse patiënten (664 hemodialyse (HD), 323 peritoneaal dialyse (PD)) de relatie tussen fetuïne-A en cardiovasculaire, niet-cardiovasculaire en totale sterfte worden bestudeerd. 
Fetuïne-A bleek zowel een voorspeller van cardiovasculaire als nietcardiovasculaire sterfte te zijn. Dit gold zowel in de HD als de PD populatie. Deze studie ontkrachtte de gedachte dat fetuïne-A moet worden gezien als een specifieke cardiovasculaire risicofactor. Serum fetuïne-A lijkt meer een marker van de algemene conditie van een dialyse patiënt en is een voorspeller van de totale sterfte.

\section{Uit de praktijk}

Dat de problemen van de vaatwandverkalkingen een manifestatie zijn van de zogenaamde extra-ossale calcificatie blijkt in hoofdstuk 7. In deze casus wordt een patiënt met DM, die in verband met diabetische nefropathie peritoneaal dialyse verricht, beschreven, waarbij naast een duidelijke mediasclerose ook verkalkingen van de zaadleiders is opgetreden.

\section{Epicrise}

Tenslotte wordt in hoofdstuk 8 de in de voorafgaande hoofdstukken vergaarde kennis geïntegreerd en bezien in het licht van de recente literatuur. Dit proefschrift onderstreept de complexiteit en diversiteit van de mechanismen die verantwoordelijk worden geacht voor de hoge cardiovasculaire sterfte bij patiënten met een chronische nierinsufficiëntie. Een centrale rol is weggelegd voor de vaatwand. De vaatwand veranderd niet alleen van vorm maar ook de functie is onderhevig aan veranderingen. Zo blijkt uit dit proefschrift dat een toename van de arteriële stijfheid al vanaf een milde nierinsufficiëntie gezien. Hoewel dit proefschrift zeker nieuwe aspecten aan de zoektocht naar de verklaringen van het verband tussen nierfunctieverlies en cardiovasculair risico heeft toegevoegd, geldt nog steeds het aloude adagium van de Duitse patholoog Rudolf Virchow (18211902) "de mens is zo oud als zijn vaten". 


\section{Curriculum vitae}

De auteur werd op 6 april 1972 geboren te Brunssum. In 1990 behaalde hij het Gymnasium $\beta$ diploma aan het Sint-Janscollege te Hoensbroek waarna gestart werd met de studie geneeskunde aan de Rijksuniversiteit Limburg te Maastricht. In november 1996 werd het artsexamen Cum Laude behaald. In datzelfde jaar startte hij als arts-assistent interne geneeskunde zijn loopbaan in het Catharina Ziekenhuis te Eindhoven waar hij van april 1998 tot april 2002 de opleiding tot internist gevolgd heeft (opleider dr. S.J. Hoorntje). De opleiding tot internist werd in het academisch ziekenhuis Maastricht voortgezet onder leiding van Prof. dr. K.M.L. Leunissen (waarnemend opleider interne geneeskunde, opleider nefrologie) en gecombineerd met de subspecialisatie tot nefroloog. In april 2004 werd gestart met onderzoek naar vaatwandafwijkingen bij patiënten met een chronische nierziekte. In 2005 volgde de registratie tot internist-nefroloog. Nadat hij in 2006 als internist werkzaam was in zowel het academisch ziekenhuis Maastricht als in het Kuratorium für Dialyse und Nierentransplantation te Würselen (Duitsland) is hij vanaf december 2006 als internist-nefroloog werkzaam in het azM en combineert klinische taken met onderzoek.

Hij is getrouwd met Jozet Frijns. Samen hebben ze drie zonen; Maurits (2001), Reinout (2003) en Lennard (2004). 
